\title{
WEIGHT-BASED STIGMA/DISCRIMINATION AND DISORDERED EATING: \\ EXPLORING THE MECHANISMS IN OBESE ADULTS AND NORMAL-WEIGHT \\ UNDERGRADUATES
}

by

\begin{abstract}
Aliza Friedman
BSc. (Hons), Queen's University, 2013
\end{abstract}

\author{
A thesis \\ presented to Ryerson University \\ in partial fulfillment of the \\ requirements for the degree of \\ Master of Arts \\ in the Program of \\ Psychology \\ Toronto, Ontario, Canada, 2015 \\ C(Aliza Friedman) 2015
}




\section{AUTHOR'S DECLARATION FOR ELECTRONIC SUBMISSION OF A THESIS}

I hereby declare that I am the sole author of this thesis. This is a true copy of the thesis, including any required final revisions, as accepted by my examiners.

I authorize Ryerson University to lend this thesis to other institutions or individuals for the purpose of scholarly research.

I further authorize Ryerson University to reproduce this thesis by photocopying or by other means, in total or in part, at the request of other institutions or individuals for the purpose of scholarly research.

I understand that my thesis may be made electronically available to the public. 
Weight-Based Stigma/Discrimination and Disordered Eating: Exploring the Mechanisms in Obese Adults and Normal-Weight Undergraduates

Master of Arts, 2015

\author{
Aliza Friedman \\ Psychology, Ryerson University
}

\begin{abstract}
Individuals who experience stigma/discrimination on the basis of their weight are at an elevated risk for disordered eating; however, the specific associations between various facets of weightbased stigma/discrimination with disordered eating and the mechanisms underlying this association remain unclear. To address this conundrum, the current study examined the relations between three components of weight-based stigma/discrimination with binge/emotional eating, as well as potential psychological distress mechanisms of these relations, in obese female bariatric surgery-seeking patients and predominately normal-weight female undergraduate students. Results revealed that individuals who reported concerns regarding experiencing weightbased stigma, perceived that they have been discriminated against on the basis of their weight, and/or internalized anti-fat attitudes were at an elevated risk for binge eating across both samples. Body shape concerns emerged as the most relevant explanatory mechanism in the relation between weight-based stigma/discrimination and disordered eating across both samples.
\end{abstract}




\section{Acknowledgements}

I would first like to thank my supervisor, Dr. Stephanie Cassin, for her continued support over the past two years and invaluable feedback on this thesis. I would also like to express my appreciation to Dr. Becky Choma, for her endless support with my data analysis, as well as to Dr. Michelle Dionne for agreeing to be my external reviewer.

I would also like to thank my fellow members of the Healthy Eating and Lifestyle laboratory. Molly and Lauren, I really appreciate all of the encouragement and insightful feedback both of you have provided me over the past two years. Laura, thank you for your patience spending many hours running participants for this study. To my cohort in the psychology department, thank you all for your friendship, encouragement, and support. This thesis would not have been possible without all of you.

Lastly, I would like to thank my family and friends for helping me to reach this milestone. 


\section{Table Of Contents}

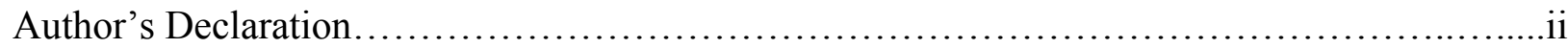

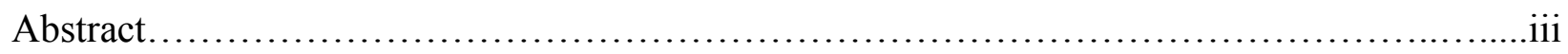

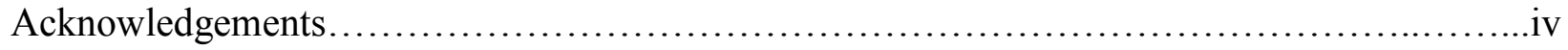

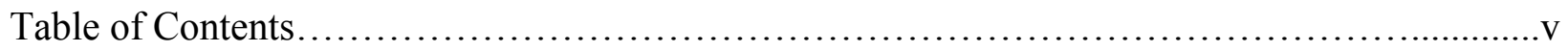

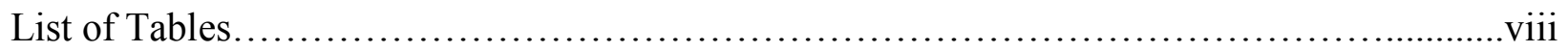

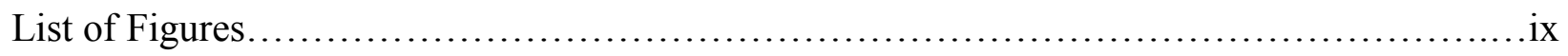

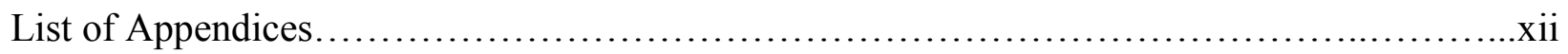

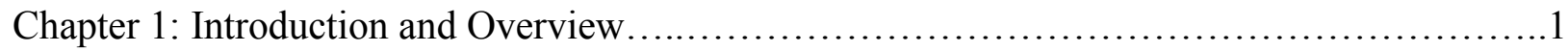

Stigma, Perceived Discrimination, and Internalized Weight Bias.......................... 2

Stigma.....................................................................

Perceived Discrimination......................................................

Internalized Weight Bias.................................................... 5

Weight-Based Stigma, Perceived Discrimination, and Internalized Weight Bias..........6

The Cyclic Obesity/Weight-Based Stigma (COBWEBS) Model..........................8

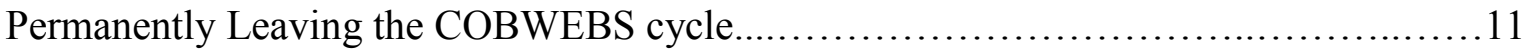

Weight-Based Stigma and Disordered Eating...................................... 12

Potential Mechanisms Underlying The Relation Between Weight-Based Stigma and

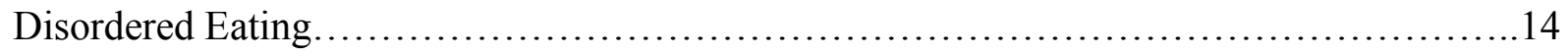

Weight-Based Stigma Across the Weight Spectrum................................ 15

The Present Study....................................................... 17

Chapter 2: Bariatric Sample.................................................... 20

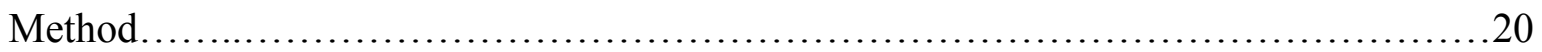




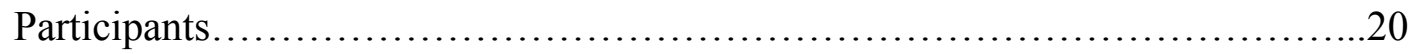

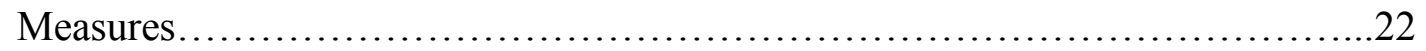

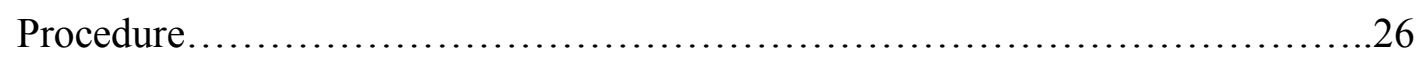

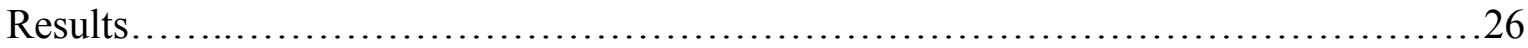

Preliminary Analyses..................................................... 26

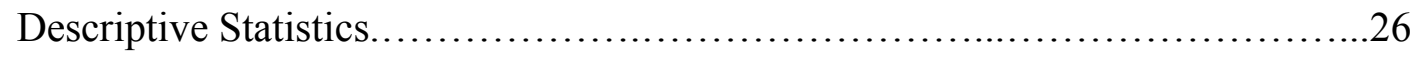

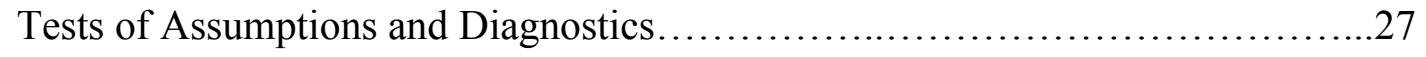

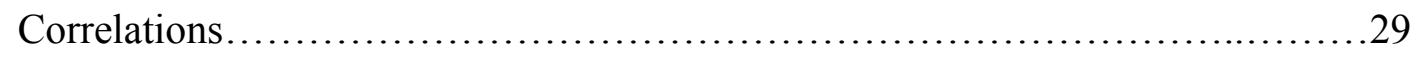

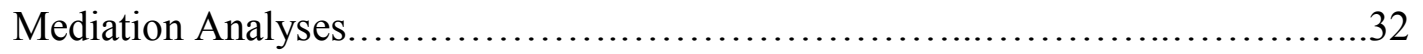

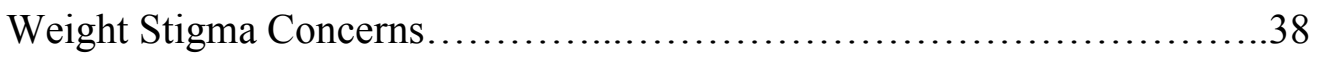

Experiences/Perceptions of Discrimination...............................41

Weight Bias Internalization............................................44

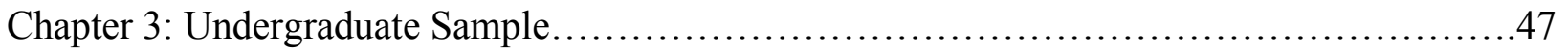

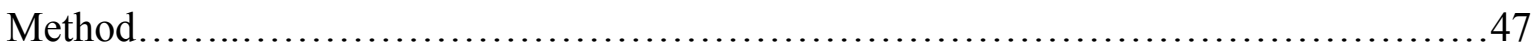

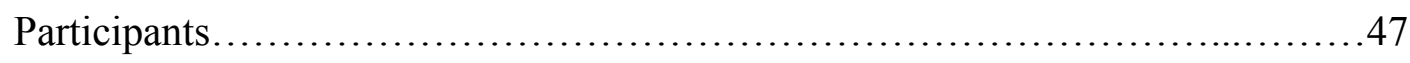

Measures.......................................................................

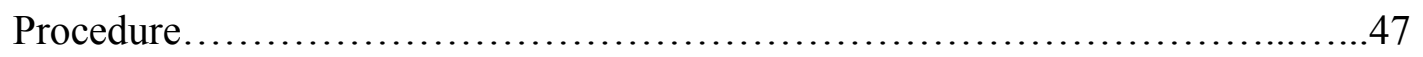

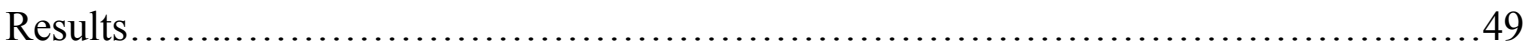

Preliminary Analyses......................................................49

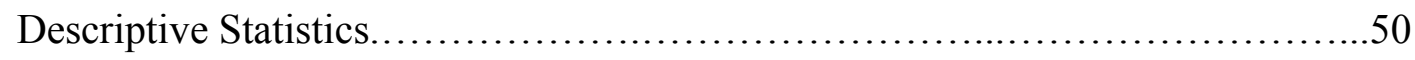

Tests of Assumptions and Diagnostics......................................50

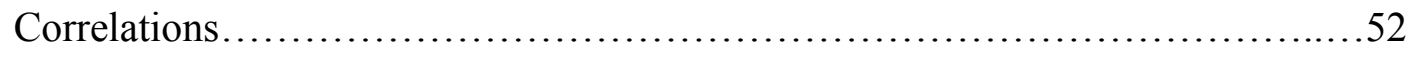

Mediation Analyses.........................................................53 
Weight Stigma Concerns .............................................59

Experiences/Perceptions of Discrimination............................62

Weight Bias Internalization.........................................66

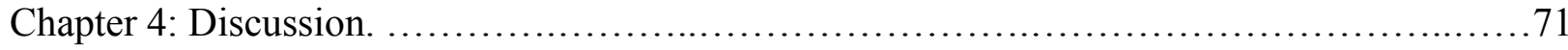

Summary of Descriptive and Correlational Results....................................71

Summary of Mediation Results........................................................ 75

Weight Stigma Concerns............................................................ 76

Experiences/Perceptions of Discrimination........................................ 78

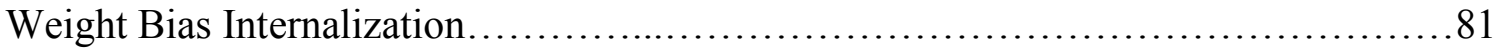

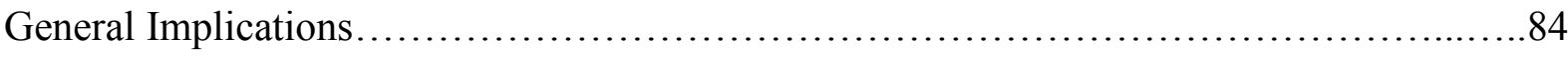

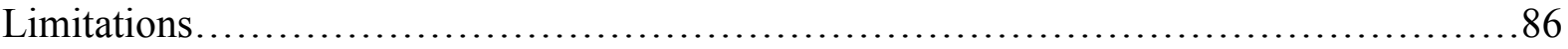

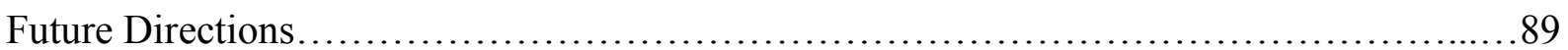

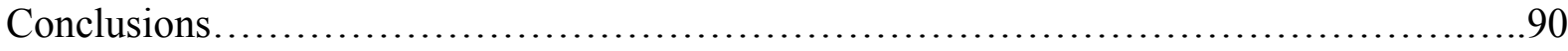

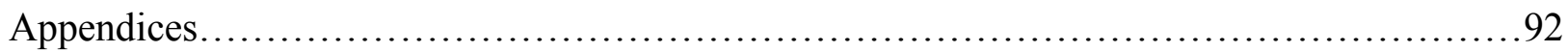

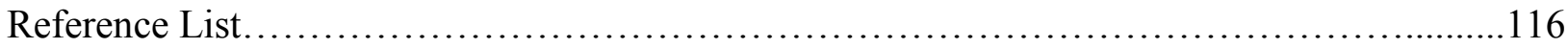




\section{List of Tables}

Table 1: Sociodemographic Characteristics of the Bariatric Sample........................21

Table 2: Scale Intercorrelations and Coefficient Alpha Reliabilities for the Bariatric Sample....31

Table 3: Specific and Total Indirect Effects of Weight Stigma Concerns on Disordered Eating Variables through Mediators Controlling for BMI and Age, Bariatric Sample..................35

Table 4: Specific and Total Indirect Effects of Experiences/Perceptions of Discrimination on Disordered Eating Variables through Mediators Controlling for BMI and Age, Bariatric Sample

Table 5: Specific and Total Indirect Effects of Weight Bias Internalization on Disordered Eating Variables through Mediators Controlling for BMI and Age, Bariatric Sample..................37

Table 6: Sociodemographic Characteristics of the Undergraduate Sample....................48

Table 7: Differences in Scale Means and Medians as a Function of Sample...................51

Table 8: Scale Intercorrelations and Coefficient Alpha Reliabilities for the Undergraduate

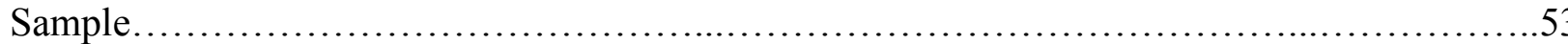

Table 9: Specific and Total Indirect Effects of Weight Stigma Concerns on Disordered Eating Variables through Mediators Controlling for Age and BMI, Undergraduate Sample.............56

Table 10: Specific and Total Indirect Effects of Experiences/Perceptions of Discrimination on Disordered Eating Variables through Mediators Controlling for Age and BMI, Undergraduate Sample

Table 11: Specific and Total Indirect Effects of Weight Bias Internalization on Disordered Eating Variables through Mediators Controlling for Age and BMI, Undergraduate Sample

Table 12: Mean Item Scores on Scale Variables in the Bariatric and Undergraduate Samples 


\section{List of Figures}

Figure 1: The Cyclical Obesity/Weight-Based Stigma (COBWEBS) model ...................9

Figure 2: A statistical model of mediation........................................... 33

Figure 3: Unstandardized regression coefficients between weight stigma concerns, potential mediators, and binge eating controlling for age and BMI in the bariatric sample.

Figure 4: Unstandardized regression coefficients between weight stigma concerns, potential mediators, and emotional eating (anger/frustration subscale) controlling for age and BMI in the bariatric sample.

Figure 5: Unstandardized regression coefficients between weight stigma concerns, potential mediators, and emotional eating (anxiety subscale) controlling for age and BMI in the bariatric sample.

Figure 6: Unstandardized regression coefficients between weight stigma concerns, potential mediators, and emotional eating (depression subscale) controlling for age and BMI in the bariatric sample.

Figure 7: Unstandardized regression coefficients between experiences/perceptions of discrimination, potential mediators, and binge eating controlling for age and BMI in the bariatric sample.

Figure 8: Unstandardized regression coefficients between experiences/perceptions of discrimination, potential mediators, and emotional eating (anger/frustration subscale) controlling for age and BMI in the bariatric sample.

Figure 9: Unstandardized regression coefficients between experiences/perceptions of discrimination, potential mediators, and emotional eating (anxiety subscale) controlling for age and BMI in the bariatric sample.

Figure 10: Unstandardized regression coefficients between experiences/perceptions of discrimination, potential mediators, and emotional eating (depression subscale) controlling for age and BMI in the bariatric sample................................................... 4

Figure 11: Unstandardized regression coefficients between weight bias internalization, potential mediators, and binge eating controlling for age and BMI in the bariatric sample

Figure 12: Unstandardized regression coefficients between weight bias internalization, potential mediators, and emotional eating (anger/frustration subscale) controlling for age and BMI in the

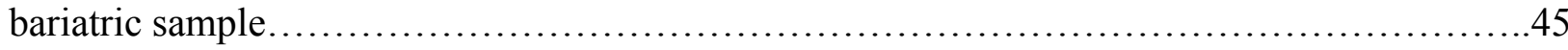


Figure 13: Unstandardized regression coefficients between weight bias internalization, potential mediators, and emotional eating (anxiety subscale) controlling for age and BMI in the bariatric

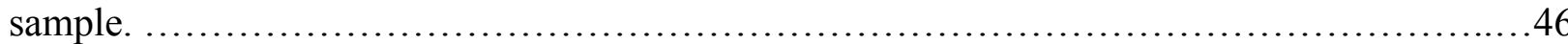

Figure 14: Unstandardized regression coefficients between weight bias internalization, potential mediators, and emotional eating (depression subscale) controlling for age and BMI in the bariatric sample

Figure 15: Unstandardized regression coefficients between weight stigma concerns, potential mediators, and binge eating controlling for age and BMI in the undergraduate sample.....

Figure 16: Unstandardized regression coefficients between weight stigma concerns, potential mediators, and emotional eating (anger/frustration subscale) controlling for age and BMI in the undergraduate sample.

Figure 17: Unstandardized regression coefficients between weight stigma concerns, potential mediators, and emotional eating (anxiety subscale) controlling for age and BMI in the undergraduate sample.

Figure 18: Unstandardized regression coefficients between weight stigma concerns, potential mediators, and emotional eating (depression subscale) controlling for age and BMI in the undergraduate sample.

Figure 19: Unstandardized regression coefficients between experiences/perceptions of discrimination, potential mediators, and binge eating controlling for age and BMI in the undergraduate sample.

Figure 20: Unstandardized regression coefficients between experiences/perceptions of discrimination, potential mediators, and emotional eating (anger/frustration subscale) controlling for age and BMI in the undergraduate sample.

Figure 21. Unstandardized regression coefficients between experiences/perceptions of discrimination, potential mediators, and emotional eating (anxiety subscale) controlling for age and BMI in the undergraduate sample.

Figure 22. Unstandardized regression coefficients between experiences/perceptions of discrimination, potential mediators, and emotional eating (depression subscale) controlling for age and BMI in the undergraduate sample

Figure 23. Unstandardized regression coefficients between weight bias internalization, potential mediators, and binge eating controlling for age and BMI in the undergraduate sample.

Figure 24. Unstandardized regression coefficients between weight bias internalization, potential mediators, and emotional eating (anger/frustration subscale) controlling for age and BMI in the undergraduate sample 
Figure 25. Unstandardized regression coefficients between weight bias internalization, potential mediators, and emotional eating (anxiety subscale) controlling for age and BMI in the undergraduate sample.

Figure 26. Unstandardized regression coefficients between weight bias internalization, potential mediators, and emotional eating (depression subscale) controlling for age and BMI in the undergraduate sample... .70 


\section{List of Appendices}

Appendix A: Weight Stigma Concerns (Hunger \& Major, 2015).........................99

Appendix B: Experiences/Perceptions of Discrimination (Hunger \& Major, 2015)............93

Appendix C: Weight Bias Internalization Scale (modified WBIS; Durso \& Latner, 2008).......94

Appendix D: Patient Health Questionnaire-4 (PHQ-4; Kroenke, Spitzer, Williams, \& Lowe,

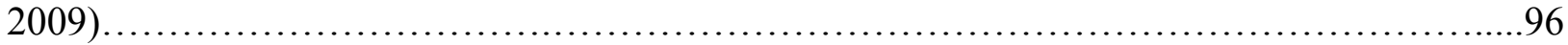

Appendix E: Body Shape Questionnaire (BSQ; Cooper, Taylor, Cooper, \& Fairburn, 1987).....97

Appendix F: Binge Eating Scale (BES; Gormally, Black, Daston, \& Rardin, 1982)...........101

Appendix G: Emotional Eating Scale (EES; Arnow, Kenardy, \& Agras, 1995)...............104

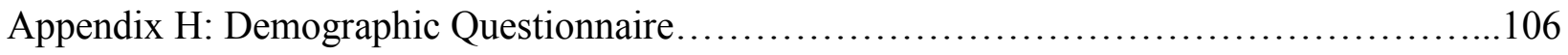

Appendix I: Mean Item Scores on Scale Variables in the Bariatric and Undergraduate

Samples................................................................... 107

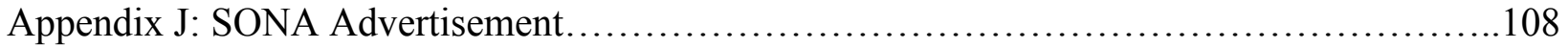

Appendix K: Informed Consent Agreement............................................. 111

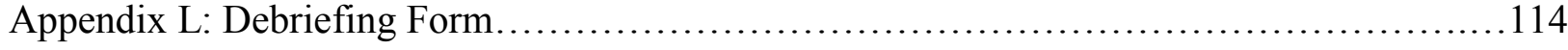




\section{Chapter 1}

\section{Introduction and Overview}

Weight-based stigma, defined as negative attitudes towards individuals on the basis of their weight and shape, is often considered to be the last socially acceptable form of bias (Latner, O’Brien, Durso, Brinkman, \& MacDonald, 2008; Puhl \& Brownell, 2001). Commonly endorsed stereotypes about overweight and obese individuals include beliefs that they are lazy, overemotional, sexually inexperienced, and lacking self-control (Puhl \& Brownwell, 2001). These biases are pervasive, and have been reported in numerous populations, including children (Davison \& Birch, 2004), high school teachers (Neumark-Sztainer, Story, \& Harris, 1999), and college students (Regan, 1996). Weight-based stigma even extends to health care professionals, including dietetics students (Berryman, Dubale, Manchester, \& Mittelstaedt, 2006), registered nurses (Poon \& Tarrant, 2009), psychologists (Davis-Coelho, Waltz, \& Davis-Coelho, 2000), primary care physicians (Hebl \& Xu, 2001) and health care professionals specializing in obesity (Schwartz, Chambliss, Brownell, Blair, \& Billington, 2003). When compared to stigma against two other stigmatized groups (i.e., gay individuals, Muslim individuals) using a universal measure of bias (Universal Measure of Bias; UMB; Latner et al., 2008), university students reported significantly greater levels of weight bias, further evidencing the pervasiveness and social acceptability of weight-based stigma.

Although some researchers have proposed that stigma could be harnessed as an effective strategy for targeting public health concerns such as obesity (Bayer, 2008; Stuber, Myer, \& Link, 2008), there is little evidence to suggest that being a target of weight-based stigma improves weight loss outcomes. Experiencing weight-based stigma instead produces a paradoxical effect (Major, Hunger, Bunyan, \& Miller, 2014), such that targeted individuals have been found to 
demonstrate poorer weight-loss outcomes in a behavioural weight-loss treatment program (Wott \& Carels, 2010), as well as avoidance of exercise (Varatanian \& Novak, 2011). Experimental studies highlight the same phenomenon: exposure to weight-based stigmatizing news articles actually increases caloric consumption among women who self-identify as overweight or obese (Major, et al., 2014). In addition to poorer weight-loss outcomes, experiencing weight-based stigma is also associated with numerous adverse psychological and physical health outcomes, including increased rates of psychological distress (Ashmore, Friedman, Reichmann, \& Musante, 2008), suicide ideation (Chen, Fettich, \& McCloskey, 2012), and disordered eating (Ashmore et al., 2008).

\section{Stigma, Perceived Discrimination, and Internalized Weight Bias}

Stigma. According to sociologist Erving Goffman (1963), stigma is defined as an "attribute that is deeply discrediting" for the individual (p. 3). Goffman states that there are three different types of stigma: "abominations of the body" (i.e., stigmas associated with physical disfigurement), "blemishes of individual character" (i.e., characterological stigmas such as sexual orientation or mental illness), and "tribal stigmas" (i.e., stigmas such as race that are passed on from one generation to the next; p. 4). Given that obesity is associated with physical unattractiveness (Harris, Harris, \& Bochner, 1982; Wigton \& McGaghie, 2001) and a host of negative personality characteristics (Puhl \& Brownhell, 2001), obesity can be conceptualized as a physical and a characterological stigma (DeJong, 1980). Additionally, unlike many purely physical stigmas (e.g., race, physical disabilities), individuals who are overweight or obese are typically considered to be personally responsible for their condition (e.g., Hilbert, Rief, \& Braehler, 2008), which in turn may make them more likely to experience discrimination (DeJong, 1980). Although the majority of research studies thus far have focused on individuals' 
(both obese and non-obese) attitudes towards the overweight and obese (e.g., Davison \& Birch, 2004), more recent studies have begun to focus on the experiences of individuals who are overweight and obese. With respect to stigma specifically, researchers have begun exploring individuals' concerns over experiencing weight stigma (Hunger \& Major, 2015; Major et al., 2014), suggesting that even suspecting or anticipating weight stigma may lead to deleterious outcomes (Hunger, Major, Blodorn, \& Miller, in press).

Perceived Discrimination. Weight-based stigma often leads to discriminatory treatment against the overweight and obese, which can be defined as "the inappropriate and potentially unfair treatment of individuals due to group membership" (Dovidio, Hewstone, Glick, \& Esses, 2010, p. 8). Paradies (2006) notes that discrimination can be operationalized as either objective or subjective (i.e., perceived), and that the two constructs are conceptually distinct. Perceived discrimination is defined as the subjective interpretation of discrimination, which may or may not coincide with actual discrimination. Given that objective discrimination is difficult to operationalize, most studies focus instead on perceived discrimination (Paradies, 2006). It is also plausible that individuals may not perceive discrimination in settings when it has in fact occurred; for example, they may attribute a discriminatory act to internal causes (e.g., their personality or appearance) as opposed to discrimination (e.g., Schmitt \& Branscombe, 2002). Furthermore, perceived discrimination has been found to predict poorer mental and physical health (Pascoe \& Smart Richman, 2009), suggesting that perceived discrimination is a relevant psychological construct.

Overweight and obese individuals report perceiving discriminatory treatment in a number of situations, including health care, employment, and educational settings, as well as within interpersonal relationships (Puhl \& Heuer, 2009). Andreyeva, Puhl, and Brownell (2008) 
measured the prevalence of perceived discrimination in the United States related to individuals' weight or height, and found that the prevalence of perceived weight/height discrimination has increased by an alarming $66 \%$ in recent years, from $7.3 \%$ in $1995-1996$ to $12.2 \%$ in $2004-2006$. Although the effects of weight discrimination in particular cannot be directly isolated from this study, individuals who reported experiencing weight/height discrimination demonstrated significantly higher body mass index (BMI) and body weight, whereas there were no significant differences related to height. Thus, these findings suggest that rates of perceived weight/height discrimination likely reflect weight discrimination to a greater extent (Andreyeva et al., 2008). Similarly, by dividing individuals into different categories based on their BMI (e.g., BMI of 27$29 \mathrm{~kg} / \mathrm{m}^{2}$ ), Andreyeva and colleagues demonstrated that this rapid increase in perceived weight/height discrimination was not attributed to the increasing prevalence of obesity over the same time period. Although average BMI remained relatively stable across weight categories over the 10-year period (aside from the category of BMI $\geq 45 \mathrm{~kg} / \mathrm{m}^{2}$ ), the prevalence of weight/height discrimination nevertheless increased for each BMI category for people with a BMI of $27-29 \mathrm{~kg} / \mathrm{m}^{2}$ (overweight) and $31-40 \mathrm{~kg} / \mathrm{m}^{2}$ (obese).

Prevalence ratings of perceived discrimination increase substantially when considering individuals who are severely obese. Using the same 1995-1996 database of US adults, Puhl, Andreyeva and Brownell (2008) found that $40 \%$ of individuals with a BMI $\geq 35 \mathrm{~kg} / \mathrm{m}^{2}$ reported experiencing either some major form of lifetime weight/height discrimination (e.g., being denied a bank loan) or perceived daily interpersonal discrimination (e.g., being called names or insulted), with discrimination in employment-based settings occurring most frequently. When comparing the prevalence of weight/height discrimination to other types of discrimination, weight/height discrimination was the third most prevalent form of perceived discrimination for 
women (following gender and age) and the fourth most prevalent form of discrimination among men and women combined (following gender, age, and race; Puhl et al., 2008). Taken together, these findings demonstrate that perceived weight discrimination is highly prevalent within society today, and is growing at a rate that exceeds the rising prevalence of obesity.

Internalized Weight Bias. In addition to measuring overweight and obese individuals' concerns regarding weight-based stigma and perceived discrimination, researchers have also begun to examine whether overweight and obese individuals internalize negative attitudes regarding weight. Unlike other minority groups (e.g., Asians, gay/bisexual men and women), individuals who are overweight or obese do not demonstrate a favourable in-group bias (Crandall, 1994; Latner et al., 2008; Rudman, Feinberg, \& Fairchild, 2002), and instead actually internalize anti-fat stereotypes (e.g., Crandall, 1994; Durso \& Latner, 2008; Wang, Brownell, \& Wadden, 2004). For example, in the study discussed previously comparing bias across three stigmatized groups (gay individuals, Muslims, and "fat" individuals), university students who reported greater homosexual orientation (i.e., measured using a seven-point Kinsey scale) identified reported significantly lower bias towards gay individuals; however, greater BMI was not significantly associated with reduced weight bias (Latner et al., 2008).

There are a number of differences between overweight/obese individuals and other stigmatized groups (e.g., race, sexual orientation) that may account for the lack of favourable ingroup bias. First, Major, Eliezer, and Rieck (2012) highlight that individuals often become overweight or obese later in life, which allows them a substantial amount of time to internalize the negative stereotypes against the overweight and obese prior to joining those groups themselves. Second, individuals who are overweight or obese might perceive that they can disassociate from the stigmatized group at any time by losing weight, which may prevent them 
from connecting to the group and learning to dispel negative obesity stereotypes (Latner et al., 2008). Finally, although most diets do not lead to long-term positive health or weight-loss benefits (Mann, Tomiyama, Westling, Lew, Samuels, \& Chatman, 2007), obesity is often perceived to be within an individual's personal control (e.g., Hilbert et al., 2008). Given that stigmas associated with greater perceived controllability have been found to engender less pity, greater levels of anger, and less willingness to assist (e.g., Weiner, Perry, \& Magnusson, 1988), individuals who are overweight and obese must cope with this additional contributor to stigma not present in many other stigmatized groups (e.g., race, gender, age).

\section{Weight-Based Stigma, Perceived Discrimination, and Internalized Weight Bias.}

Although constructs such as weight stigma concerns, perceived discrimination, and internalized weight bias are related, these terms are often erroneously used interchangeably. For example, until the development of the Weight Bias Internalization Scale (WBIS; Durso \& Latner, 2008), a scale that measures the extent to which individuals who are overweight or obese endorse negative attributions about obesity as being true for themselves specifically, measures of anti-fat attitudes were understood as representing weight bias internalization. Durso and Latner (2008) posit that holding negative attributions towards individuals who are overweight or obese does not necessarily indicate that individuals hold these beliefs for themselves, necessitating the separation of holding anti-fat attitudes towards individuals who are overweight or obese, and weight bias internalization (i.e., holding these negative attributions about oneself).

Furthermore, measures assessing weight stigma experiences (i.e., experiencing others making negative weight-related assumptions) are often confounded with perceived discrimination (i.e., the behavioural manifestation of stigma). For example, the Stigmatizing Situations Inventory (SSI; Myers \& Rosen, 1999) is a self-report scale that measures frequency 
of stigmatizing experiences. Three of the items on the scale assess the experience of having others make negative weight-related assumptions (e.g., "having people assume you have emotional problems because you are overweight"), whereas the remaining items refer to experiencing a variety of stigmatizing situations such as interpersonal interactions (e.g., "nasty comments from children"), physical barriers (e.g., "e.g., not being able to fit into seats at restaurants, theaters, and other public places"), and job discrimination (e.g., "losing a job because of your size"). Perceived discrimination is typically assessed in a similar manner, using self-report inventories that measure experiences of discrimination in employment, health care and educational settings (e.g., "not given a job promotion"; Andreyeva et al., 2008), as well as in interpersonal interactions (e.g., "receive poorer service than other people at restaurants or stores"; Andreyeva et al., 2008). Thus, the experience of stigmatizing situations and perceived discrimination are both primarily measuring perceptions of interpersonal and institutional discrimination, suggesting that the experience of weight-based stigma (as is currently measured) and perceived discrimination may in fact represent the same phenomenon.

Moreover, constructs including weight stigma concerns, perceived discrimination, and internalized weight bias are not typically assessed simultaneously within one research study, which hinders the interpretation of findings within and across research studies. For example, in a sample of overweight and obese women, Pearl, Puhl, and Dovidio (2014) found that weight bias internalization was negatively correlated with motivation to exercise and self-efficacy to engage in exercise, whereas weight stigma experiences was positively correlated with current exercise frequency. These findings suggest that varied weight stigma constructs may be associated with differential health-related outcomes, and by including these constructs within the same research 
study, researchers can begin to understand how each construct uniquely contributes to psychological, physical and disordered eating-related outcomes.

Research conducted to date demonstrates that weight stigma concerns, perceiving weightbased discrimination, and weight bias internalization have each been found to be associated with a host of negative psychological, physical, and disordered eating-related outcomes among overweight and obese populations. Controlling for BMI, adverse outcomes include increased rates of depression and anxiety (Friedman, Reichmann, Costanzo, Zelli, Ashmore, \& Musante, 2005), poorer weight-loss treatment outcomes in a behavioural weight-loss treatment program (Wott \& Carels, 2010), as well as greater impairment in mental and physical health-related quality of life (Latner, Durso, \& Mond, 2013). Accordingly, Puhl and Heuer (2010) highlight that weight stigma is a serious public health concern that must be properly addressed in order to target the obesity epidemic. In order to elucidate the relations between weight-based stigma/discrimination and negative psychological and disordered eating-related outcomes, the Cyclical Obesity/Weight-Based Stigma (COBWEBS) model (Tomiyama, 2014) will be examined.

\section{The Cyclic Obesity/Weight-Based Stigma (COBWEBS) Model}

The COBWEBS model is a biopsychosocial approach that integrates a number of different research areas (e.g., health psychology, neuroendocrinology, and social psychology) to explain the link between weight-based stigma, eating behaviours, and subsequent weight gain (Tomiyama, 2014). This model proposes a positive feedback loop, in which obesity/weightbased stigma produces stress, which in turn increases eating and cortisol secretions, which subsequently predicts increased weight gain and further increases in weight-based stigma (See 
Figure 1). Accordingly, weight-based stigma is a dynamic construct within this model, such that it increases as a function of increased weight gain.

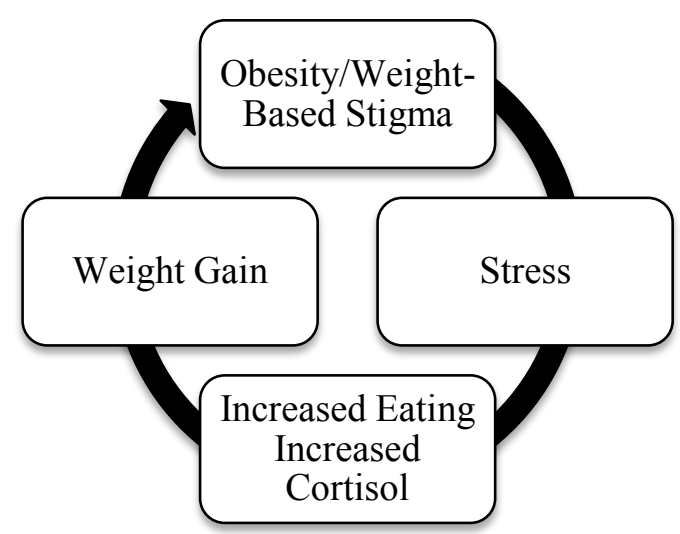

Figure 1. The Cyclical Obesity/Weight-Based Stigma (COBWEBS) model. Adapted from "Weight Stigma is Stressful. A Review of Evidence for the Cyclical Obesity/Weight-Based Stigma model," by A.J. Tomiyama, 2014, Appetite, 82, p. 9. Copyright 2014 by Elsevier Ltd.

Within this model, weight stigma is considered to be a psychological stressor, which is in line with previous research in other non-weight social stigmas (e.g., Major \& O’Brien, 2005). For example, in a meta-analysis conducted by Pascoe and Smart Richman (2009), perceived discrimination (in particular racial or ethnic discrimination) was found to increase stress, defined either by a physiological stress responses (e.g., cardiovascular reactivity) or psychological responses (e.g., feelings of depression or anxiety, changes in self-esteem). Similarly, in a sample of individuals with mental illness (e.g., schizophrenia, schizoaffective disorders, and other affective disorders), Rusch and colleagues (2009) found that higher levels of perceived societal stigma about mental illness was associated with higher stigma stress appraisals, which was defined as the perception that the harm associated with the stigma exceeded the individual's ability to cope.

With respect to mechanisms within this model, Tomiyama (2014) proposes a number of potential mediators (e.g., cortisol release, negative emotions such as shame) in the relation 
between obesity/weight-based stigma and weight gain; however, she identifies two primary mechanisms: cortisol secretions and eating behaviours. Although no published studies have specifically linked weight-based stigma to a cortisol response, Tomiyama (2014) notes that associations have been established between cortisol release and social-evaluative situations (social situations with potential for negative judgement; Dickerson \& Kemeny, 2004), abdominal obesity (Bjorntorp \& Rosmond, 2000), and increased food consumption in stressful situations (Epel, Lapidus, McEwen, \& Brownell, 2001). For eating behaviours specifically, Tomiyama (2014) refers to increased eating as a coping response to experiencing stress associated with obesity/weight-based stigma. For example, a recent experiment conducted by Major and colleagues (2014) found that exposure to weight-stigmatizing news messages (but not nonstigmatizing messages) led to increased caloric intake among those who self-identified as overweight. Accordingly, Puhl, Moss-Racusin and Schwartz (2007) found that adults who internalize weight bias reported that they coped with weight-based stigma by increasing their food intake and refusing to diet.

Binge eating and emotional eating can be conceptualized as maladaptive eating behaviours that are used by some individuals to cope with stress and negative affect (e.g., Arnow et al., 1995; Heatherton \& Baumeister, 1991; Henderson \& Huon, 2002). According to DSM-5, a binge-eating episode is characterized by two key criteria (APA, 2013): An individual must consume "an amount of food that is definitely larger than what most people would eat in a similar period of time under similar circumstances", and must also experience a loss of control during this binge-eating episode (p. 350). Emotional eating can be defined as eating in response to negative emotions, such as depression, anxiety, or anger (Arnow et al., 1995). Although emotional eating (as assessed by the Emotional Eating Scale [EES] Arnow et al., 1995) is 
significantly positively correlated with binge eating (as assessed by the Binge Eating Scale [BES] Gormally et al., 1982), Fischer and colleagues (2007) found that there is only moderate overlap between high scorers on the EES and high scorers on the BES in an obese bariatric surgery-seeking sample. This finding suggests that emotional eating and binge eating are theoretically and operationally distinct constructs. Tomiyama (2014) does not explicitly include binge eating as a potential eating behaviour within her model; however, given that binge eating can be understood as being motivated by a desire to escape psychological distress (e.g., Heatherton \& Baumeister, 1991), there is a clear rationale for its inclusion within the model.

Permanently leaving the COBWEBS cycle. Tomiyama (2014) characterizes the COBWEBS model as a "vicious" cycle (p. 9), in particular because it is very challenging for individuals to permanently exit the cycle. Tomiyama (2014) asserts that not all individuals will respond to weight stigma by increasing their eating as a coping behaviour; instead, individuals may also engage in behaviours such as dieting, or psychological coping strategies in order to cope with the effects of weight stigma. While dieting may lead to short-term weight loss, most diets are unlikely to lead to long-term positive health or weight-loss benefits (Mann et al., 2007). Exposure to weight-stigmatizing news messages has also been found to decrease diet selfefficacy among women who self-identified as overweight, suggesting that coping with stigma may limit the amount of mental resources available for dietary control (Major et al., 2014). Thus, attempting to exit the COBWEBS cycle by dieting may not be feasible. Tomiyama (2014) notes a number of psychological coping strategies that may be used to regulate the emotional distress associated with other societal social stigmas. For example, individuals can attribute a negative outcome to discrimination, as opposed to their own personal shortcomings (Major \& O'Brien, 2005). If an obese individual attributes not being hired for a job to discrimination instead of his 
or her appearance or personal characteristics, self-esteem may be protected in the process (Crocker \& Major, 1989). However, Tomiyama (2014) asserts that attributing a negative outcome to discrimination may be more challenging in the weight stigma domain given its widespread social acceptability. Tomiyama (2014) states that it is possible that losing weight and maintaining weight loss through diet and/or exercise, or changing one's self-perception of the importance of weight may help individuals exit the cycle; however permanently leaving the COBWEBS cycle is incredibly challenging.

\section{Weight-Based Stigma and Disordered Eating}

Much of the research examining the relations between weight-based stigma and binge eating has focused specifically on weight bias internalization. Weight bias internalization has been found to be associated positively with objective binge eating episodes in a sample of severely obese adolescents seeking bariatric surgery (Roberto et al., 2012), and with increased binge eating in adult samples of overweight and obese men and women (Puhl, Moss-Racusin, \& Schwartz, 2007) as well as overweight and obese adults seeking weight-loss treatment (Carels, Wott, Young, Gumble, Koball \& Oehlof, 2010). Similarly, Durso and Latner (2008) demonstrated that weight bias internalization was associated positively with greater binge frequency over a six-month period in a group of overweight and obese adults. Consistent with Tomiyama's (2014) COBWEBS model, binge eating can be conceptualized as a coping mechanism for the stress associated with experiencing weight-based stigma.

The effects of experiencing weight-based stigma and perceiving weight-based discrimination have also been examined in relation to binge eating and emotional eating. For example, in a sample of obese adults seeking weight-loss surgery, Friedman and colleagues (2005) found that the frequency of stigmatizing situations experienced within the past month 
predicted greater emotional eating and a current diagnosis of Binge Eating Disorder (BED). Furthermore, increased frequency of stigmatizing situations has also been found to be associated with higher rates of binge eating and poorer weight loss treatment outcomes in a behavioural weight-loss treatment program for overweight and obese adults (Wott \& Carels, 2010). Finally, in a sample of obese adults, Ashmore and colleagues (2008) found that lifetime occurrence of weight stigmatization was associated with increased rates of binge eating. Regarding perceived discrimination, Farrow and Tarrant (2009) found that perceived weight-based discrimination among college students with varied BMIs was associated positively with greater emotional eating. Similarly, in a varied sample of normal-weight, overweight, and obese adults, Durso and colleagues (2012) found that perceived interpersonal (e.g., everyday encounters in interpersonal settings) and institutional discrimination (e.g., perceived job loss due to one's weight) predicted greater emotional eating and higher binge eating frequency at 3 months, with stronger relations for interpersonal discrimination.

Taken together, these findings demonstrate that there is a positive association between experiencing weight-based stigma, perceiving weight-based discrimination, and internalizing anti-fat attitudes with disordered eating across a variety of populations (i.e., obese adults, weight loss treatment-seeking obese adults, and bariatric surgery-seeking obese adolescents). Although the relation between experiencing weight-based stigma/discrimination and binge eating has garnered a lot of research attention, the relation between experiencing weight-based stigma/discrimination and emotional eating remains quite understudied. Given that emotional eating and binge eating are theoretically and operationally distinct constructs (Fischer et al., 2007), and emotional eating is prevalent among overweight adults (Geliebter \& Aversa, 2003), 
the relations between experiencing weight-based stigma/discrimination and emotional eating warrants empirical investigation.

\section{Potential Mechanisms Underlying The Relations Between Weight-Based Stigma and Disordered Eating}

The association between experiencing stigmatizing situations, perceiving weight-based discrimination and subsequent weight bias internalization with disordered eating is wellestablished; however, the specific mechanisms underlying this association remain unclear. Consistent with Tomiyama's (2014) model, general psychological distress (e.g., depression and anxiety) could potentially mediate the relation between experiencing weight-based stigma, perceiving weight-based discrimination, and internalizing a negative weight bias with disordered eating. For example, Roberto and colleagues (2012) found that weight bias internalization was associated with psychological distress and increased binge eating episodes, but not with dietary restraint, suggesting that the link between weight-bias internalization and binge eating might be accounted for by psychological distress rather than dietary restraint. Furthermore, in a sample of obese adults, Ashmore and colleagues (2008) found that weight-based stigma experiences predicted increased binge eating episodes and psychological distress, whereby $20 \%$ of the variance in binge eating was accounted for by psychological distress. Similarly, in a sample of

adult bariatric surgery patients, pre-surgery weight bias internalization was associated positively with pre-surgery depressive symptoms (Lent et al., 2014). Finally, in a sample of treatmentseeking adults with BED, Pearl, White, and Grilo (2014a) found a reciprocal relation between depression, weight-bias internalization, and poor mental and physical health. Depression mediated the relation between weight-bias internalization and poorer mental and physical health; however, weight-bias internalization was also found to mediate the relation between depression 
and poorer mental and physical health. In other words, individuals who internalize anti-fat attitudes, may be more likely to experience depression, and this in turn should predict binge eating; however, this relation was also found when including weight bias internalization as a mediator and depression as an independent variable. Taken together, these results suggest that psychological distress variables may act as explanatory mechanisms in the relation between experiencing weight-based stigma/discrimination and disordered eating among overweight and obese populations.

Body shape concerns may also act as a mediator in the relation between experiencing weight-based stigma, perceiving weight-based discrimination, and weight bias internalization with disordered eating. In a sample of obese, treatment-seeking adults, Friedman and colleagues (2005) found that experiencing stigmatizing situations significantly predicted greater body image concerns after statistically controlling for BMI. Furthermore, the researchers found that the effect of experiencing stigmatizing situations on body image concerns was moderated by obese individuals' anti-fat beliefs, such that only those with high levels of anti-fat beliefs experienced body image distress. Among obese adolescents seeking bariatric surgery, Roberto and colleagues (2012) found that weight bias internalization was associated positively with greater eating, shape, and weight concerns. These findings provide preliminarily evidence for the role of body shape concerns as a potential mechanism underlying the relation between experiencing weight-based stigma/discrimination and disordered eating.

\section{Weight-Based Stigma Across the Weight Spectrum}

The effects of experiencing weight-based stigma/discrimination have typically been studied among overweight and obese populations (i.e., those who have likely been the target of objective weight-based stigma and discrimination); however, these effects may actually 
generalize to individuals across the weight spectrum. Preliminary research conducted to date suggests that self-identification as overweight or obese (irrespective of objective weight status) may be a more relevant predictor of experiencing the negative effects associated with weight stigma/discrimination compared to BMI (Major et al., 2014). For example, Major and colleagues (2014) found that exposure to weight-stigmatizing news messages led to increased caloric intake and decreased diet self-efficacy among those who self-identified as overweight; however, objective weight (BMI) did not yield significant effects.

Self-identification as being overweight or obese, however, is not a necessary requirement to enter the COBWEBS cycle (Tomiyama, 2014). Tomiyama (2014) asserts all individuals, irrespective of their objective weight status, could enter the COBWEBS cycle as long they perceive themselves as having been stigmatized for their weight. For example, normal-weight individuals may perceive that they are being stigmatized for their weight if they believe that they do not meet the societal expectation of the ultrathin ideal. In a study examining individuals' ratings of ideal heights and weights (BMI), the average weight at which women considered themselves to be overweight was a mean of $23.7 \mathrm{~kg} / \mathrm{m}^{2}$, which is well below the limit of 25.0 $\mathrm{kg} / \mathrm{m}^{2}$ (Crawford \& Campbell, 1999). Similarly, although overweight or obese individuals report increased rates of weight stigma experiences compared to normal-weight individuals (Carr \& Friedman, 2005), some researchers have illustrated that the relation between experiencing weight-based stigma and eating pathology is not moderated by BMI (Varatanian \& Novak, 2011). Regarding weight-bias internalization, Pearl and Puhl (2014) recently applied the concept to an adult population with varied BMIs. Although individuals who were overweight and obese reported greater weight-bias internalization, weight-bias internalization predicted lower selfesteem, greater depression, greater anxiety, and more binge eating behaviour across the sample. 
Consistent with these findings, normal-weight individuals demonstrate substantial concern over being stigmatized because of their weight, and these concerns are associated positively with poorer physical health (Hunger \& Major, 2015). Taken together, these findings demonstrate that although individuals who are overweight or obese may experience greater levels of weight-based stigma/discrimination, weight-based stigma/discrimination may affect individuals across the weight spectrum.

\section{The Present Study}

The primary goal of the present study was to examine the effects of weight stigma concerns, perceiving weight-based discrimination, and weight bias internalization on disordered eating in two distinct samples: a clinical sample of obese bariatric surgery-seeking patients (referred to as the bariatric sample within this thesis), and a non-clinical sample of predominately normal-weight undergraduate students (referred to as the undergraduate sample within this thesis). For the purpose of the present study, normal-weight, overweight, and obese were defined using BMI cut offs. According to Health Canada (2003), normal-weight is defined as a BMI of $18.5-24.9 \mathrm{~kg} / \mathrm{m}^{2}$, overweight is defined as a BMI of $25.0-29.9 \mathrm{~kg} / \mathrm{m}^{2}$, and obese is defined as a $\mathrm{BMI} \geq 30 \mathrm{~kg} / \mathrm{m}^{2}$.

Participation in this study was restricted to females for a number of reasons. First, women have significantly higher rates of disordered eating than men (Striegel-Moore et al., 2009), suggesting that gender is likely an important confound in the relation between weight-based stigma and disordered eating. Second, many measures of disordered eating were developed for females and are not as applicable to male populations (e.g., Body Shape Questionnaire; Cooper et al., 1987). Third, women appear to be at greater risk for weight-based discrimination, with one study finding that obese women (BMI of $30-35 \mathrm{~kg} / \mathrm{m}^{2}$ ) were more than three times more likely 
to report weight/height discrimination as compared to their male counterparts in the same BMI category (Puhl et al., 2008). Lastly, bariatric surgery samples are typically comprised of approximately $80 \%$ female patients (Sockalingam et al., 2013).

This study examined three components of weight-based stigma and discrimination: concerns that others' judgments are weight-based (weight stigma concerns), perceived experiences of weight-based discrimination (experiences/perceptions of discrimination), and the degree to which an individual internalizes negative weight-based stereotypes (weight bias internalization). Thus, the present study examined both a behavioural manifestation of stigma (experiences/perceptions of discrimination), as well as two stigma-related individual difference factors (weight stigma concerns and weight bias internalization). Together, these three variables are collectively referred to as the weight stigma/discrimination variables. By including three different components of weight-based stigma and discrimination, it is possible to determine whether a single component is most detrimental for disordered eating.

Disordered eating was operationalized using two different self-report scales measuring binge eating and emotional eating. Three different components of emotional eating were assessed: eating in response to anger/frustration, anxiety, and depression. Collectively, these variables are referred to as the disordered eating variables.

The secondary goal of the present study was to explore the mechanisms that underlie the relations between weight-based stigma/discrimination and disordered eating in normal-weight undergraduates and obese adults. Measures of body shape concerns and general psychological distress were examined as potential mediators. These mediators are collectively referred to as the distress variables. Accordingly, this study represents a partial test of Tomiyama's (2014) 
COBWEBS model, such that weight-based stigma/discrimination predicts distress, which in turn predicts disordered eating.

It was hypothesized that:

1. Weight stigma concerns would be associated positively with binge eating and all three components of emotional eating (anxiety, anger/frustration, and depression) in both samples.

2. Experiences/perceptions of discrimination would be associated positively with binge eating and all three components of emotional eating (anxiety, anger/frustration, and depression) in both samples.

3. Weight bias internalization would be associated positively with binge eating and all three components of emotional eating (anxiety, anger/frustration, and depression) in both samples.

4. General psychological distress and body shape concerns would mediate the relations between each of the weight stigma/discrimination and disordered eating variables in both samples. The relative strength of each potential mediator in these relations was exploratory in nature. Given that weight-based stigma/discrimination appears to be prevalent across the weight spectrum, it was further hypothesized that the identical mediational model (aside from potential mean differences) would emerge in both samples. 


\section{Chapter 2: Bariatric Sample}

\section{Method}

\section{Participants}

Participants consisted of 103 females recruited from the Bariatric Surgery Program at Toronto Western Hospital (TWH). Participants ranged in age from 23 to $67(M=42.32, S D=$ 10.36), and ranged in BMI from 35.39 to $73.36 \mathrm{~kg} / \mathrm{m}^{2}(M=49.31, S D=8.09)$. The majority of participants were Caucasian (62.4\%), married (43.6\%), had a college diploma (40.6\%), and were employed full-time (58.4\%). Additional participant sociodemographic information, including ethnicity, occupational/educational status, and relationship status can be found in Table 1.

Eligibility criteria for bariatric surgery at TWH are determined during a multidisciplinary

health care team assessment. All patients must be over the age of 18 , and have a BMI $\geq 40 \mathrm{~kg} / \mathrm{m}^{2}$ or a $\mathrm{BMI} \geq 35 \mathrm{~kg} / \mathrm{m}^{2}$ with at least one obesity-related comorbidity (e.g., sleep apnea, diabetes, high blood pressure). Patients must also report having made previous attempts at weight-loss (UHN, 2015). Exclusion criteria for bariatric surgery at TWH include complex surgical histories that would increase the risk for surgical complications, presence of poorly controlled medical or psychiatric conditions, hospitalization for psychiatric reasons or a suicide attempt within the past 12 months, as well as current substance abuse or dependence (including nicotine). 
Table 1

Sociodemographic Characteristics of the Bariatric Sample

\begin{tabular}{lr}
\hline Characteristic & $n(\%)$ \\
\hline Relationship Status & $44(43.6)$ \\
Married & $34(33.7)$ \\
Single, never married & $9(8.9)$ \\
Common-law & $13(12.8)$ \\
Separated or divorced & $1(1.0)$ \\
Other & \\
Race/Ethnicity & $63(62.4)$ \\
White (Caucasian) & $14(13.9)$ \\
Black (African American) & $9(8.9)$ \\
South Asian & $7(6.9)$ \\
Latin/South American & $4(4.0)$ \\
Arab/West Asian & $3(3.0)$ \\
Other & $0(0.0)$ \\
Southeast Asian & $0(0.0)$ \\
East Asian & \\
Highest Level of Education & \\
College diploma & $41(40.6)$ \\
High school diploma & $26(25.7)$ \\
Bachelor's degree & $20(19.8)$ \\
Some university & $6(5.9)$ \\
Some college & $4(4.0)$ \\
Some high school & $2(2.0)$ \\
Graduate degree & $2(2.0)$ \\
Employment Status & \\
Full-time & $59(58.4)$ \\
Unemployed & $12(11.9)$ \\
Disability Insurance & $11(10.9)$ \\
Part-time & $11(10.9)$ \\
Social Assistance & $4(4.0)$ \\
Retired & $3(3.0)$ \\
Leave of Absence & $1(1.0)$ \\
\hline Note. Due to missing data, $n$ ) &
\end{tabular}

Note. Due to missing data, $n$ 's range from 100 to 101 . 


\section{Measures}

\section{Independent Variables.}

Weight Stigma Concerns (Hunger \& Major, 2015; Appendix A). The Weight Stigma Concerns scale is a 5-item self-report inventory that was developed from previously validated measures of race-, gender-, and sexual orientation-based stigma concerns (e.g., Pinel, 1999). All items are rated on a 7-point Likert -type scale from 1 (strongly disagree) to 7 (strongly agree), with higher scores indicating higher levels of weight stigma concerns (e.g., "I am concerned that other people's opinion of me will be based on my weight"). Hunger and Major (2015) found excellent internal consistency $(\alpha=.94)$ and good convergent and discriminant validity in a nonclinical population ${ }^{1}$.

Experiences/Perceptions of Discrimination (Hunger \& Major, 2015; Appendix B). The Experiences/Perceptions of Discrimination scale is a 5-item self-report inventory of perceived weight discrimination that was adapted from a previously validated measure of perceptions of racial discrimination (Williams, Yan, \& Jackson, 1997). All items refer to experiences/perceptions of discrimination within the past 12-month period (e.g., "In the past 12 months, how often have you been treated with less respect than other people because of your weight?”). In the scale developed by Hunger and Major (2015), items are rated on a 4-point Likert-type scale from 0 (never) to 4 (all the time); however, in the present study, the inventory was rated on a 6-point scale from 1 (never) to 6 (always) to increase variability in responses. Hunger and Major (2015) found excellent internal consistency $(\alpha=.92)$ in a non-clinical population.

\footnotetext{
${ }^{1}$ Coefficient alpha reliabilities for the bariatric and undergraduate samples can be found in Tables 2 and 8, respectively.
} 
Weight-Bias Internalization Scale (WBIS; Durso \& Latner, 2008; Appendix C). The

WBIS is an 11-item self-report measure of the degree to which obese and overweight individuals internalize weight-based stereotypes. All items are rated on a Likert-type scale from 1 (strongly disagree) to 7 (strongly agree), with higher scores representing a higher degree of weight bias internalization (e.g., "I hate myself for being overweight"). For the present study, the scale was modified for use in individuals across body weight categories (e.g., "I hate myself for being overweight" was modified to "I hate myself for my weight"). The WBIS has a high internal consistency $(\alpha$ 's $>.87)$ and demonstrates good convergent validity with measures of anti-fat attitudes and drive for thinness (Durso \& Latner, 2008; Hilbert et al., 2014; Pearl \& Puhl, 2014).

\section{Mediators.}

\section{Patient Health Questionnaire for Anxiety and Depression-4 (PHQ-4; Kroenke et al.,}

2009; Appendix D) ${ }^{2}$. The PHQ-4 is a 4-item self-report measure of anxiety and depression based on DSM-IV criteria. It was developed as an ultra-brief version of its predecessors, the Patient Health Questionnaire-8 (PHQ-8; Kroenke \& Spitzer, 2002) and the Generalized Anxiety Disorder-7 (GAD-7; Spitzer, Kroenke, Williams, \& Lowe, 2006). Individuals are asked to report how often they have been bothered by a series of symptoms (e.g., "feeling down, depressed, or hopeless", "feeling nervous, anxious or on edge") over the past two weeks from 0 (not at all) to 3 (nearly every day). Kroenke and colleagues (2009) found that the PHQ-4 had high internal consistency $(\alpha=.85)$ in primary- care patients and demonstrated similar construct validity with variables including physician visits and self-reported disability days when compared to the

\footnotetext{
2 The present study initially included depression and anxiety (as measured by the PHQ-8 and GAD-7, respectively) as separate mediators. Due to issues with multicollinearity between mediators (additional information to follow), a single measure of psychological distress (as measured by the PHQ-4) was found to be more appropriate.
} 
longer measures of depression and anxiety. Within the context of the present study, the PHQ-4 was used to assess general psychological distress.

Body Shape Questionnaire (BSQ; Cooper et al., 1987; Appendix E). The BSQ is a 34item self-report measure that assesses individuals' concerns about their body shape, with a particular focus on "feeling fat" (e.g., "has feeling full [e.g., after a large meal] made you feel fat?"). Items are rated on a 6-point scale ranging from 1 (never) to 6 (always), with higher scores indicating greater body shape dissatisfaction. The BSQ demonstrates high internal consistency in both clinical populations of women with eating disorders and non-clinical populations ( $\alpha$ 's $>$ .94), and is significantly positively correlated with weight-related and non-weight-related measures of body dissatisfaction (Cooper et al., 1987; Evans \& Dolan, 1993; Ghaderi \& Scott, 2004; Rosen, Jones, Ramirez, \& Waxman, 1996; Pook, Tuschen-Caffier, \& Brahler, 2008). BSQ scores are also significantly correlated with non-appearance-related measures of psychopathology, including anxiety and depression (Evans \& Dolan, 1993).

\section{Dependent Variables.}

Binge Eating Scale (BES; Gormally et al., 1982; Appendix F). The BES is a 16-item inventory that was initially designed for assessment of binge eating in obese individuals. The scale measures the emotional/cognitive (e.g., "Almost all the time I experience strong guilt or self-hate after I overeat") and behavioural (e.g., "At times, I tend to eat quickly and then, I feel uncomfortably full afterwards") symptoms associated with binge eating. Each item on the scale is comprised of 3 or 4 response options, and individuals are asked to circle the item that best describes how they feel about their eating behaviour. Each of these items is assigned a value from 0 (no binge eating problem) to 3 (severe binge eating problem), with total scores ranging from 0 to 32. The BES has demonstrated strong internal consistency in non-clinical populations 
of university undergraduate students $(\alpha=.93$; Napolitano \& Himes, 2011) and clinical populations of binge eaters $(\alpha=.85$; Gormally et al., 1982). The BES also has good test-retest reliability $(r=.87)$, and good sensitivity in identifying individuals with BED in a sample of female binge eaters (Timmerman, 1999). The BES is moderately correlated with binge episodes derived from food records, and can discriminate between a binge episode and high caloric intake. The BES has been found to be an effective screening measure for BED in obese individuals seeking bariatric surgery, but should not be used as a sole diagnostic tool because it produces a high false positive rate (Grupski et al., 2013).

Emotional Eating Scale (EES; Arnow et al., 1995; Appendix G). The EES is a 25-item self-report measure that assesses individuals' desire to eat in response to experiencing certain emotions (e.g., "jealous", "worried"). Responses are rated on a 5-point scale from 0 (no desire to eat) to 4 (an overwhelming urge to eat). Factor analysis of the EES conducted by Arnow and colleagues (1995) identified three factors: anger/frustration, anxiety, and depression, each of which make up a separate subscale on the EES. Arnow and colleagues found good internal consistency $(\alpha=.81)$ and adequate test-retest reliability $(r=.79, p<.001)$ in a sample of obese women seeking treatment for weight loss and binge eating. Waller and Osman (1998) validated the EES in a sample of undergraduate female students, finding comparable levels of internal consistency and strong convergent validity with other measures of eating psychopathology. The EES anxiety subscale has also been found to predict objective measures of emotional eating, such that those who score higher on the EES anxiety subscale consume significantly more calories following experimentally-induced anxiety (Schneider et al., 2012). Arnow and colleagues (1995) indicate that the EES should be analyzed by subscale only, and therefore, only EES subscale scores were used in the present study. 


\section{Procedure}

Participants from the TWH Bariatric Surgery Program completed a questionnaire package consisting of the following questionnaires in the specified order as part of their presurgical assessment: Weight Stigma Concerns (Hunger \& Major, 2015; Appendix A), Experiences/Perceptions of Discrimination (Hunger \& Major, 2015; Appendix B), a modified version of the WBIS (Durso \& Latner, 2008; Appendix C), PHQ-4 (Kroenke et al., 2009; Appendix D), BSQ (Cooper et al., 1987; Appendix E), BES (Gormally et al., 1982; Appendix F), and the EES (Arnow et al., 1995; Appendix G). Paper-and-pencil measures were completed (as opposed to electronic questionnaires), as is the practice in the TWH Bariatric Surgery Program. Data for the present study was extracted from the clinic database. Demographic information (age, ethnicity, current relationship status, current employment status, highest level of education attained, and BMI) was collected through a chart review.

\section{Results}

\section{Preliminary Analyses}

Data were initially assessed for missing values before scoring all of the scales. Scale scores were excluded from analyses if participants were missing more than $10 \%$ of the items on any given scale. Scale scores were pro-rated if participants reported $90 \%$ or more of the data on a given scale (Schlomer, Bauman, \& Card, 2010).

\section{Descriptive Statistics}

Means, standard deviations, and medians of all independent variables, mediators, dependent variables, and potential covariates (age and BMI) for the bariatric and undergraduate samples can be found in Chapter 3 (Table 7). Mean item scores for each scale variable can be found in Appendix I (Table 12). 


\section{Tests of Assumptions and Diagnostics}

Prior to conducting correlational and mediational analyses, assumptions regarding normality, homoscedasticity, and multicollinearity were examined for each mediation model. Skew values indicated that the following variables were significantly positively skewed when applying a 95\% criterion: BMI; experiences/perceptions of discrimination; general psychological distress; and emotional eating — anger/frustration and anxiety subscales. Weight stigma concerns was significantly negatively skewed. Standardized residuals for all variables were examined to determine whether any specific cases were influencing normality. Two cases with standardized residuals of 3.28 and 3.12 were removed from the sample given that their removal substantially improved the distribution for BMI, with skew and kurtosis values decreasing from 0.98 to 0.66 and 1.03 to 0.98 , respectively. Following removal of these outliers, all aforementioned variables except for the emotional eating — anxiety subscale were still significantly skewed at the 95\% criterion with skew and kurtosis values ranging from -0.68 to 1.03 and kurtosis values ranging from -0.72 to 0.2 . West, Finch, and Curran (1996) note that cut-off values of 2 and 7 (absolute values) for skew and kurtosis, respectively should be used as representing substantial departures in normality, suggesting that even the skewed data did not violate this criterion. Skew and kurtosis values for the remaining variables ranged from -0.38 to 0.46 and from -0.92 to 0.18 , respectively, indicating that these variables were normally distributed. Given that data can be non-normal when assessing for mediation using bootstrapping procedures (Sufahani \& Ahmad, 2012), transformations of non-normal variables were not required to proceed with analyses. ${ }^{3}$ Homoscedasticity, the assumption stating that the variance of the dependent variable is

\footnotetext{
${ }^{3}$ Logarithmic and square root transformations of skewed variables were conducted to determine whether data transformations would impact multicollinearity between predictor and mediator variables. These transformations did not reduce multicollinearity, and thus the original nonnormal data were used in all analyses.
} 
consistent across the independent variable, was determined by examining the scatterplots of the standardized residuals plotted against the predicted outcome values according to each specific model (Field, 2013). Examination of these plots revealed that homoscedasticity was violated when examining the relations between weight bias internalization, the mediator variables, and binge eating; as well as when examining the relations between each weight stigma/discrimination variable, the mediator variables, and the anger/frustration subscale of emotional eating. Accordingly, a heteroscedasticity- consistent standard error estimator (HC3) was applied when conducting mediation analyses in these specific models to produce heteroscedasticity-consistent standard error estimators for all regression coefficients (Hayes \& Cai, 2007).

Multicollinearity between predictor and mediator variables was examined according to bivariate correlation coefficients, as well as by examining tolerance and variance inflation factor (VIF) statistics. Values were considered to be problematic if bivariate correlations were above 0.80 (Field, 2009), tolerance values were less than 0.1 (Menard, 1995), and VIF values were greater than 10 (Myers, 1990). The correlation between body shape concerns and weight bias internalization was $r_{\mathrm{s}}=0.83$, suggesting potential for multicollinearity. Both scales were first examined for potential conceptual overlap, and specific potential overlapping items were not identified. Despite this high correlation, tolerance and VIF values were not violated. Tolerance values for the independent variables and the mediators ranged from 0.24 to 0.61 and VIF values from 1.60 to 4.18 , respectively for all models. It is important to note that although these values do not violate the aforementioned cut-off values, high correlations between mediator variables can nevertheless be especially problematic within a multiple mediator model, given that the paths from each mediator to the outcome are estimated controlling for all other mediators (Hayes, 2013). High correlations between mediator variables increases the sampling variance in the 
estimates of each of the mediators' relation with the dependent variables, which in turn will increase the width of the confidence intervals, making it harder to detect a significant effect ${ }^{4}$.

To test whether the mediation model was unduly influenced by a small number of cases, data were examined for outliers and influential cases within the context of a multiple linear regression. Examination of standardized residuals of the variables indicated that there were no cases with a standardized residual above an absolute value of 3.29. Examination of the residual statistics (Cook's distance, standardized DFBeta values) indicated that there were no influential cases having an effect on the model. All 101 cases had a Cook's distance less than 1 and DFBetas less than the absolute value of 1 (Cook \& Weisberg, 1982; Field, 2013).

\section{Correlations}

Scale intercorrelations between independent variables, dependent variables and proposed mediators can be found in Table 2. Due to violations of normality, Spearman's rho correlations are reported. The Spearman's correlation coefficient is a nonparametric statistic that first ranks the data, and then applies the Pearson's equation to the ranked scores (Field, 2009). The relations of age and BMI to all variables were also calculated to identify potential covariates (see Table 2).

In partial support of the first and second hypotheses, there were significant, positive correlations between weight stigma concerns and experiences/perceptions of discrimination (independent variables) with the dependent variables of binge eating and two facets of emotional eating (anger/frustration and anxiety) with small effect sizes (Cohen, 1992). Weight stigma concerns and experiences/perceptions of discrimination were not significantly associated with the depression subscale of emotional eating.

\footnotetext{
${ }^{4}$ Given strong correlations between mediators within the initial proposed model (analyzing depression and anxiety separately), the decision was made to combine depression and anxiety into one variable called psychological distress, as measured by the PHQ-4.
} 
In support of the third hypothesis, there were significant, positive correlations between weight bias internalization (independent variable) and the dependent variables, binge eating as well as with all three facets of emotional eating (anger/frustration, anxiety, and depression). This relation had a moderate effect size for binge eating, and small effect sizes for all three facets of emotional eating (Cohen, 1992). 
Table 2

Scale Intercorrelations and Coefficient Alpha Reliabilities for the Bariatric Sample

\begin{tabular}{|c|c|c|c|c|c|c|c|c|c|c|c|}
\hline Measure & 1 & 2 & 3 & 4 & 5 & 6 & 7 & 8 & 9 & 10 & 11 \\
\hline 1. Weight Stigma Concerns & .96 & $.77 * *$ & $.70 * *$ & $.34 * *$ & $.58 * *$ & $.39 * *$ & $.26^{*}$ & $.24 *$ & .14 & -.04 & .01 \\
\hline $\begin{array}{l}\text { 2. Experiences/Perceptions of } \\
\text { Discrimination }\end{array}$ & & .95 & $.55^{* *}$ & $.35^{* *}$ & $.51 * *$ & $.35 * *$ & $.31 * *$ & $.25^{*}$ & .19 & -.08 & .05 \\
\hline 3. Weight Bias Internalization & & & .91 & $.62 * *$ & $.83 * *$ & $.59 * *$ & $.42 * *$ & $.40 * *$ & $.27 * *$ & .05 & .01 \\
\hline $\begin{array}{l}\text { 4. Patient Health } \\
\text { Questionnaire-4 }\end{array}$ & & & & .87 & $.64 * *$ & $.51 * *$ & $.42 * *$ & $.34 * *$ & $.29 * *$ & .06 & .06 \\
\hline 5. Body Shape Concerns & & & & & .98 & $.60 * *$ & $.45 * *$ & $.42 * *$ & $.31 * *$ & .19 & -.08 \\
\hline 6. Binge Eating Scale & & & & & & .97 & $.68 * *$ & $.61 * *$ & $.60 * *$ & .15 & .08 \\
\hline $\begin{array}{l}\text { 7. Emotional Eating Scale } \\
\text { (Anger/Frustration) }\end{array}$ & & & & & & & .93 & $.85^{* *}$ & $.82 * *$ & $.21 *$ & .07 \\
\hline $\begin{array}{l}\text { 8. Emotional Eating Scale } \\
\text { (Anxiety) }\end{array}$ & & & & & & & & .89 & $.78 * *$ & $.21 *$ & -.01 \\
\hline $\begin{array}{l}\text { 9. Emotional Eating Scale } \\
\text { (Depression) }\end{array}$ & & & & & & & & & .86 & .16 & .11 \\
\hline 10. Age & & & & & & & & & & & -.10 \\
\hline 11. BMI & & & & & & & & & & & \\
\hline
\end{tabular}

Note. Coefficient alpha reliabilities are boldface in the diagonal. Due to missing data, $n$ 's range from 97 to 101.

$* p<.05, * * p<.01$. 


\section{Mediation Analyses}

To examine the fourth and final hypothesis that the distress variables (i.e., general psychological distress and body shape concerns) would mediate the relation between the weight stigma/discrimination and disordered eating variables, multiple mediational analyses were conducted using non-parametric bootstrapping. Twelve mediational analyses were conducted with the bariatric sample, such that each of the three weight stigma/discrimination independent variables were analyzed separately with binge eating and the three emotional eating subscales.

According to Hayes (2013), a mediational model "is any casual system in which at least one causal antecedent $X$ variable is proposed as influencing an outcome $Y$ through a single intervening variable $M$ ' (p. 86; see Figure 2). The simple relation between $\mathrm{X}$ and $\mathrm{Y}$ is often referred to as the total effect (Figure 2, Panel A). In Figure 2 (Panel B), the regression coefficient $a$ represents the effect of the independent variable on the proposed mediator, whereas regression coefficient $b$ represents the effect of the mediator on the dependent variable after statistically controlling for the effect of the independent variable (Preacher \& Hayes, 2008). The indirect effect can then be defined as the product of paths $a$ and $b$ (i.e., $a b)$. The direct effect ( $\left.c^{\prime}\right)$ is defined as the difference between the total effect $(c)$ and the indirect effect $(a b)\left(\right.$ i.e., $\left.c^{\prime}=c-a b\right)$. Given that modern mediational approaches do not require a significant total effect to proceed with mediation analyses (e.g., Rucker, Preacher, Tormala \& Petty, 2011), analyses were conducted irrespective of significant total effects. 
A

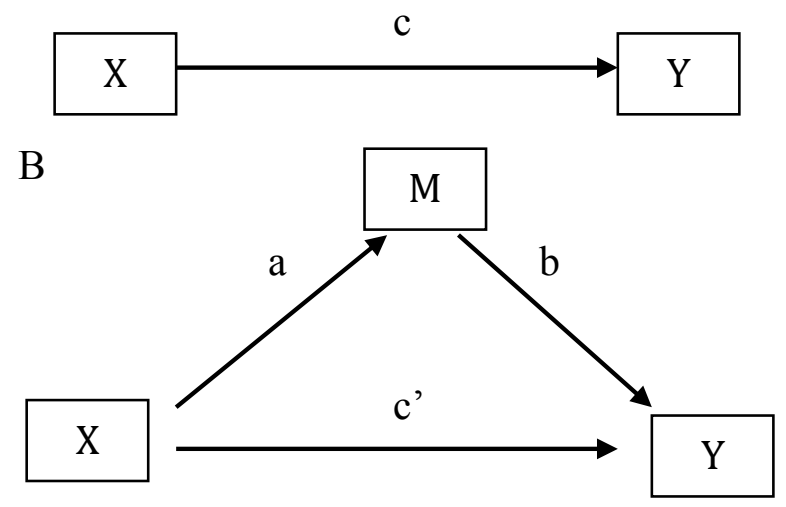

Figure 2. A statistical model of mediation. (A) A depiction of the total effect of variable X on $\mathrm{Y}$. (B) An illustration of a mediation design, where the relation between $\mathrm{X}$ and $\mathrm{Y}$ is predicted to be accounted for by the indirect effects of $\mathrm{M}$. Adapted from "Asymptotic and resampling strategies for assessing and comparing indirect effects in multiple mediator models," by K.J. Preacher and A.F. Hayes, 2008, Behaviour Research Methods, 40, p. 880. Copyright 2008 by Psychonomic Society, Inc.

Ten thousand resamples of the sampling distribution were used to derive bootstrap confidence intervals and determine significance of the indirect effects at the .05 level. Both mediators (general psychological distress and body shape concerns) were examined simultaneously (i.e., in parallel) within each of the twelve models using the SPSS PROCESS Macro (Hayes, 2013). Given that age was associated positively with the emotional eatinganger/frustration and anxiety subscales, it was included as a covariate in each model for consistency. Although BMI was not significantly associated with any of the variables, it was included as a covariate in each analysis to remain consistent with this area of literature. Results were considered significant if a zero value was not present in the $95 \%$ confidence intervals.

The completely standardized effect $\left(a b_{c s}\right)$ is reported as a measure of effect size for the indirect (mediated) effects. Controlling for the effects of covariates, the completely standardized effect represents the indirect effect in terms of the difference in SDs of the dependent variable by one SD of the independent variable (Hayes, 2013; 2015). For example, consider $\mathrm{ab}_{\mathrm{cs}}=0.33$ for 
the first mediation analysis (see Table 3). If participant A is one SD higher in weight stigma concerns than participant B, participant A would be estimated to be 0.33 SDs higher in binge eating as a result of the combined distress variables which in turn influence binge eating. This effect is interpreted relative to 0 , such that larger effects are further from 0 .

Tables 3 to 6 depict information regarding the indirect (mediated) effects and their confidence intervals. Figures 3 through 14 show a visual representation of the independent, mediator, and dependent variables in each mediational model with the unstandardized regression coefficients. 
Table 3

Specific and Total Indirect Effects of Weight Stigma Concerns on Disordered Eating Variables through Mediators Controlling for BMI and Age, Bariatric Sample

\begin{tabular}{|c|c|c|c|c|c|c|}
\hline \multirow{2}{*}{$\begin{array}{l}\text { Disordered } \\
\text { Eating } \\
\text { Variable }\end{array}$} & \multirow[t]{2}{*}{$\begin{array}{l}\text { Mediator } \\
\text { Variables }\end{array}$} & \multirow[t]{2}{*}{$\begin{array}{c}\text { Point } \\
\text { Estimate }\end{array}$} & \multirow[t]{2}{*}{$S E$} & \multicolumn{2}{|c|}{$\begin{array}{c}\text { Bootstrapped } 95 \% \\
\text { BC Confidence } \\
\text { Intervals }\end{array}$} & \multirow[t]{2}{*}{$a b_{c s}$} \\
\hline & & & & Lower & Upper & \\
\hline \multirow[t]{4}{*}{ BES } & $\mathrm{BSQ}^{*}$ & .2720 & .0939 & .1023 & .4757 & .2818 \\
\hline & PHQ-4 & .0469 & .0402 & -.0319 & .1295 & .0485 \\
\hline & Total* & .3189 & .0789 & .1790 & .4952 & .3304 \\
\hline & $(\mathrm{C} 1)^{*}$ & .2252 & .1210 & .0010 & .4840 & \\
\hline \multirow[t]{4}{*}{$\mathrm{EES}-\mathrm{Ang}^{\mathrm{a}}$} & $\mathrm{BSQ}^{*}$ & .2190 & .1171 & .0157 & .4772 & .1596 \\
\hline & PHQ-4 & .0739 & .0799 & -.0681 & .2554 & .0539 \\
\hline & Total* & .2928 & .0947 & .1275 & .5015 & .2135 \\
\hline & (C1) & .1451 & .1767 & -.1911 & .5194 & \\
\hline \multirow[t]{4}{*}{ EES-Anx } & BSQ & .1662 & .0978 & -.0042 & .3841 & .1595 \\
\hline & PHQ-4 & .0433 & .0593 & -.0640 & .1731 & .0416 \\
\hline & Total* & .2096 & .0790 & .0735 & .3926 & .2010 \\
\hline & (C1) & .1229 & .1412 & -.1393 & .4172 & \\
\hline \multirow[t]{4}{*}{ EES-Dep } & BSQ & .0934 & .0689 & -.0283 & .2433 & .1394 \\
\hline & PHQ-4 & .0135 & .0373 & -.0613 & .0902 & .0201 \\
\hline & Total* & .1069 & .0545 & .0102 & .2262 & .1595 \\
\hline & $(\mathrm{C} 1)$ & .0799 & .0965 & -.0968 & .2836 & \\
\hline
\end{tabular}

Note. BES = Binge Eating Scale; EES-Ang = Emotional Eating Scale-Anger /Frustration subscale; EES-Anx = Emotional Eating Scale-Anxiety subscale; EES-Dep = Emotional Eating Scale-Depression subscale; $\mathrm{SE}=$ standard error; $\mathrm{BC}=$ bias corrected; 10,000 bootstrap samples; $\mathrm{ab}_{\mathrm{cs}}=$ completely standardized indirect effect; Total $=$ total combined indirect effects of BSQ and PHQ-4; C1 = Contrast of BSQ vs. PHQ-4. This value is significant if the difference between the two mediators' indirect effects is significant. If the point estimate value for the contrast is positive, this indicates that the indirect effect of BSQ- PHQ-4 is positive, such that BSQ is a significantly greater mediator than PHQ-4 (assuming the point estimates for the indirect effects of both mediators are positive).

${ }^{\mathrm{a}} \mathrm{HC} 3$ correction factor applied.

$* p<.05$. 
Table 4

Specific and Total Indirect Effects of Experiences/Perceptions of Discrimination on Disordered Eating Variables through Mediators Controlling for BMI and Age, Bariatric Sample

\begin{tabular}{|c|c|c|c|c|c|c|}
\hline \multirow[t]{2}{*}{$\begin{array}{l}\text { Disordered } \\
\text { Eating } \\
\text { Variable }\end{array}$} & \multirow[t]{2}{*}{$\begin{array}{l}\text { Mediator } \\
\text { Variables }\end{array}$} & \multirow[t]{2}{*}{$\begin{array}{c}\text { Point } \\
\text { Estimate }\end{array}$} & \multirow[t]{2}{*}{$S E$} & \multicolumn{2}{|c|}{$\begin{array}{c}\text { Bootstrapped } 95 \% \\
\text { BC Confidence } \\
\text { Intervals }\end{array}$} & \multirow[t]{2}{*}{$a b_{c s}$} \\
\hline & & & & Lower & Upper & \\
\hline \multirow[t]{4}{*}{ BES } & BSQ* & .3671 & .1035 & .1880 & .6002 & .3045 \\
\hline & PHQ-4 & .0481 & .0443 & -.0324 & .1471 & .0399 \\
\hline & Total* & .4153 & .0952 & .2498 & .6300 & .3445 \\
\hline & $(\mathrm{C} 1)^{*}$ & .3190 & .1275 & .0983 & .6064 & \\
\hline \multirow[t]{4}{*}{ EES- Ang ${ }^{a}$} & $\mathrm{BSQ}^{*}$ & .2777 & .1354 & .0494 & .5966 & .1623 \\
\hline & PHQ-4 & .0777 & .0924 & -.0728 & .2990 & .0454 \\
\hline & Total* & .3555 & .1223 & .1479 & .6312 & .2077 \\
\hline & (C1) & .2000 & .1970 & -.1652 & .6268 & \\
\hline \multirow[t]{4}{*}{ EES- Anx } & $\mathrm{BSQ}^{*}$ & .2273 & .1150 & .0345 & .4906 & .1746 \\
\hline & PHQ-4 & .0431 & .0684 & -.0789 & .1983 & .0331 \\
\hline & Total* & .2704 & .0989 & .1084 & .5035 & .2077 \\
\hline & $(\mathrm{C} 1)$ & .1843 & .1613 & -.0963 & .5455 & \\
\hline \multirow[t]{4}{*}{ EES- Dep } & $\mathrm{BSQ}^{*}$ & .1422 & .0752 & .0106 & .3105 & .1700 \\
\hline & PHQ-4 & .0137 & .0415 & -.0679 & .1020 & .0164 \\
\hline & Total* & .1559 & .0635 & .0463 & .2977 & .1864 \\
\hline & $(\mathrm{C} 1)$ & .1285 & .1036 & -.0553 & .3579 & \\
\hline
\end{tabular}

Note. BES = Binge Eating Scale; EES- Ang = Emotional Eating Scale- Anger/Frustration subscale; EES- Anx = Emotional Eating Scale- Anxiety subscale; EES- Dep = Emotional Eating Scale- Depression subscale; $\mathrm{SE}=$ standard error; $\mathrm{BC}=$ bias corrected; 10,000 bootstrap samples; $\mathrm{ab}_{\mathrm{cs}}=$ completely standardized indirect effect; Total= total combined indirect effects of BSQ and PHQ-4; C1 = Contrast of BSQ vs. PHQ-4. This value is significant if the difference between the two mediators' indirect effects is significant. If the point estimate value for the contrast is positive, this indicates that the indirect effect of BSQ- PHQ-4 is positive, such that BSQ is a significantly greater mediator than PHQ-4 (assuming the point estimates for the indirect effects of both mediators are positive). ${ }^{\mathrm{a}} \mathrm{HC} 3$ correction factor applied. $* p<.05$. 
Table 5

Specific and Total Indirect Effects of Weight Bias Internalization on Disordered Eating Variables through Mediators Controlling for BMI and Age, Bariatric Sample

\begin{tabular}{|c|c|c|c|c|c|c|}
\hline \multirow{2}{*}{$\begin{array}{l}\text { Disordered } \\
\text { Eating } \\
\text { Variable }\end{array}$} & \multirow[t]{2}{*}{$\begin{array}{l}\text { Mediator } \\
\text { Variables }\end{array}$} & \multirow[t]{2}{*}{$\begin{array}{c}\text { Point } \\
\text { Estimate }\end{array}$} & \multirow[t]{2}{*}{$S E$} & \multicolumn{2}{|c|}{$\begin{array}{l}\text { Bootstrapped } 95 \% \\
\text { BC Confidence } \\
\text { Intervals }\end{array}$} & \multirow[t]{2}{*}{$a b_{c s}$} \\
\hline & & & & Lower & Upper & \\
\hline \multirow[t]{4}{*}{$\mathrm{BES}^{\mathrm{a}}$} & BSQ & .1144 & .0773 & -.0195 & .2868 & .2249 \\
\hline & PHQ-4 & .0270 & .0300 & -.0354 & .0826 & .0530 \\
\hline & Total* & .1414 & .0721 & .0126 & .2987 & .2779 \\
\hline & (C1) & .0875 & .0924 & -.0768 & .2882 & \\
\hline \multirow[t]{4}{*}{ EES- Ang ${ }^{a}$} & BSQ & .1453 & .1213 & -.0641 & .4143 & .1993 \\
\hline & PHQ-4 & .0556 & .0676 & -.0750 & .1906 & .0763 \\
\hline & Total* & .2009 & .1066 & .0144 & .4282 & .2756 \\
\hline & (C1) & .0897 & .1650 & -.2128 & .4360 & \\
\hline \multirow[t]{4}{*}{ EES- Anx } & BSQ & .0903 & .0946 & -.0745 & .3027 & .1635 \\
\hline & PHQ-4 & .0295 & .0507 & -.0647 & .1354 & .0535 \\
\hline & Total & .1199 & .0861 & -.0342 & .3064 & .2169 \\
\hline & (C1) & .0608 & .1250 & -.1712 & .3271 & \\
\hline \multirow[t]{4}{*}{ EES-Dep } & BSQ & .0722 & .0750 & -.0617 & .2280 & .2027 \\
\hline & PHQ-4 & .0095 & .0320 & -.0528 & .0737 & .0266 \\
\hline & Total & .0816 & .0695 & -.0472 & .2230 & .2293 \\
\hline & (C1) & .0627 & .0919 & -.1073 & .2523 & \\
\hline
\end{tabular}

Note. BES = Binge Eating Scale; EES- Ang = Emotional Eating Scale- Anger/Frustration subscale; EES- Anx = Emotional Eating Scale- Anxiety subscale; EES- Dep = Emotional Eating Scale- Depression subscale; $\mathrm{SE}=$ standard error; $\mathrm{BC}=$ bias corrected; 10,000 bootstrap samples; $\mathrm{ab}_{\mathrm{cs}}=$ completely standardized indirect effect; Total = total combined indirect effects of BSQ and PHQ-4; C1 = Contrast of BSQ vs. PHQ-4. This value is significant if the difference between the two mediators' indirect effects is significant. If the point estimate value for the contrast is positive, this indicates that the indirect effect of BSQ- PHQ-4 is positive, such that BSQ is a significantly greater mediator than PHQ-4 (assuming the point estimates for the indirect effects of both mediators are positive).

${ }^{\mathrm{a}} \mathrm{HC} 3$ correction factor applied. $* p<.05$. 
Weight Stigma Concerns. The first mediation analysis examined the indirect effects of weight stigma concerns on binge eating through body shape concerns and general psychological distress, controlling for age and BMI (see Figure 3). The total effect of weight stigma concerns on binge eating was significant, $b=.46, S E=.09, t(91)=5.19, p<.001$. Weight stigma concerns had a significant total indirect effect on binge eating through the combined distress variables and a significant specific indirect effect on binge eating through body shape concerns, but not through general psychological distress. The indirect effect of weight stigma concerns on binge eating through body shape concerns was significantly greater than the indirect effect of general psychological distress (See Table 3).

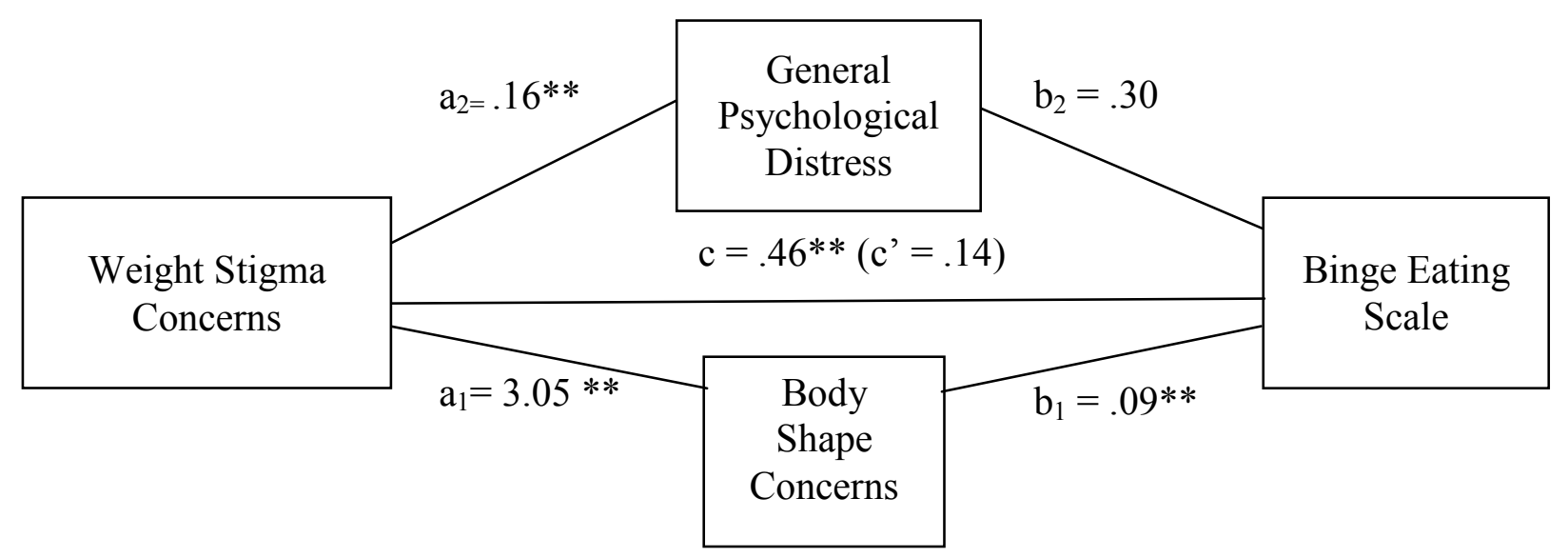

Figure 3. Unstandardized regression coefficients between weight stigma concerns, potential mediators, and binge eating controlling for age and BMI in the bariatric sample. $\mathrm{c}=$ total effect; $\mathrm{c}^{\prime}=$ direct effect. $N=95$. ${ }^{*} p<0.05,{ }^{* *} p<0.01$.

The second mediation analysis examined the indirect effects of weight stigma concerns on emotional eating — anger/frustration subscale through body shape concerns and general psychological distress, controlling for age and BMI (see Figure 4). The total effect of weight stigma concerns on emotional eating- anger/frustration subscale was significant, $b=.50, S E=$ $.14, t(91)=3.69, p<.001$. Weight stigma concerns had a significant total indirect effect on 
emotional eating- anger/frustration subscale through the combined distress variables, and a significant specific indirect effect on emotional eating- anger/frustration subscale through body shape concerns, but not through general psychological distress. The contrast between mediators was nonsignificant (See Table 3).

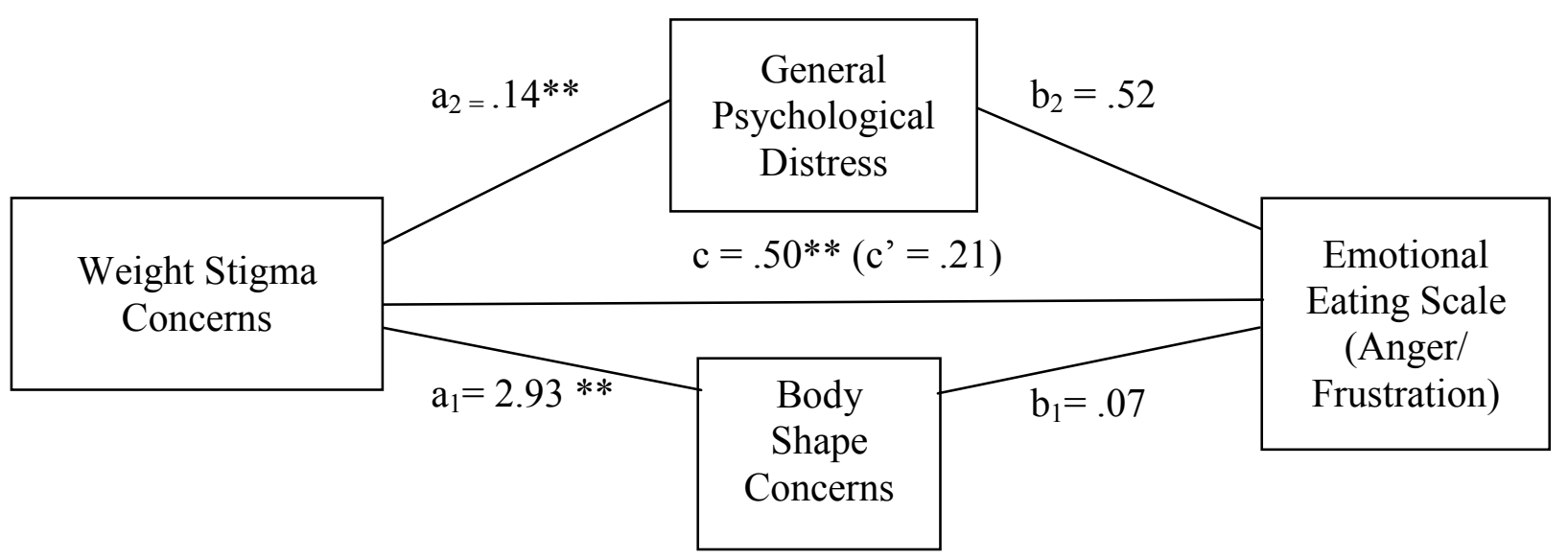

Figure 4. Unstandardized regression coefficients between weight stigma concerns, potential mediators, and emotional eating (anger/frustration subscale) controlling for age and BMI in the bariatric sample. c $=$ total effect; $\mathrm{c}^{\prime}=$ direct effect. $N=95$. ${ }^{*} p<0.05,{ }^{* *} p<0.01$.

The third mediation analysis examined the indirect effects of weight stigma concerns on emotional eating — anxiety subscale through body shape concerns and general psychological distress, controlling for age and BMI (see Figure 5). The total effect of weight stigma concerns on emotional eating- anxiety subscale was significant, $b=.36, S E=.10, t(90)=3.52, p<.0001$. Weight stigma concerns had a significant total indirect effect on emotional eating- anxiety subscale through the combined distress variables, but no significant specific indirect effects (see Table 3). 


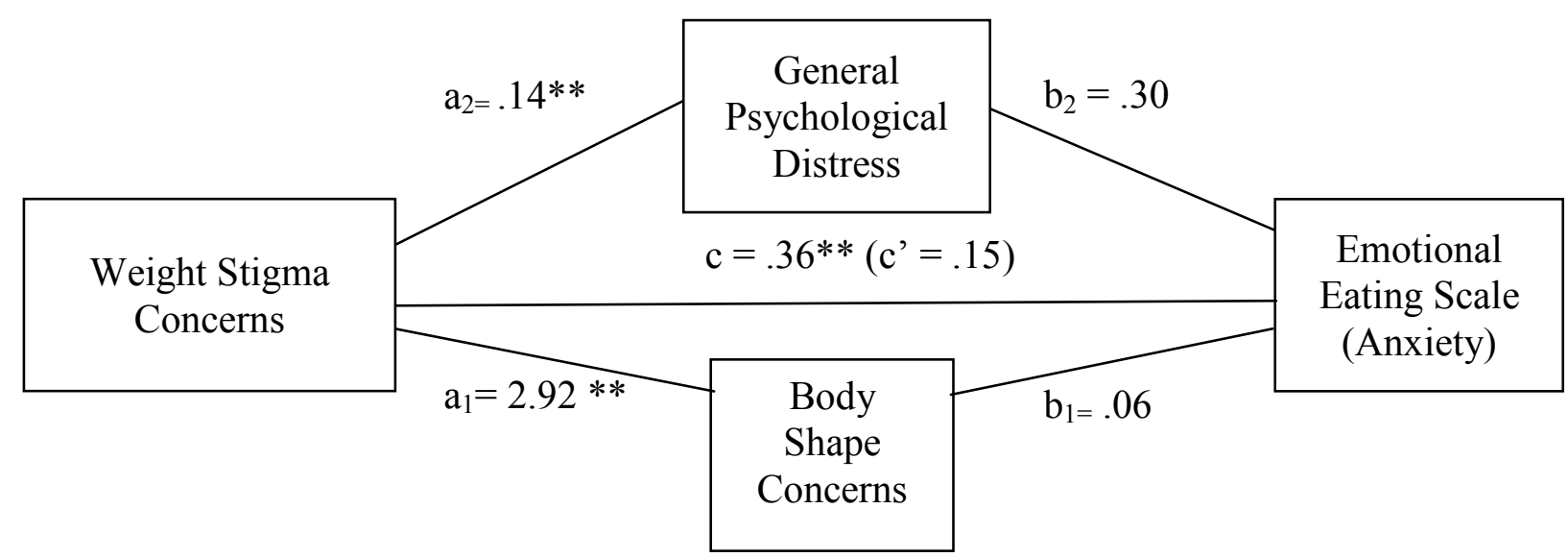

Figure 5. Unstandardized regression coefficients between weight stigma concerns, potential mediators, and emotional eating (anxiety subscale) controlling for age and BMI in the bariatric sample. c $=$ total effect; c' $=$ direct effect. $N=94$. ${ }^{*} p<0.05, * * p<0.01$.

The fourth mediation analysis examined the indirect effects of weight stigma concerns on emotional eating - depression subscale through body shape concerns and general psychological distress, controlling for age and BMI (see Figure 6). The total effect of weight stigma concerns on emotional eating- depression subscale was significant, $b=.17, S E=.07, t(91)=2.55, p<.05$. Weight stigma concerns had a significant total indirect effect on emotional eating- depression through the combined distress variables, but no significant specific indirect effects (See Table 3).

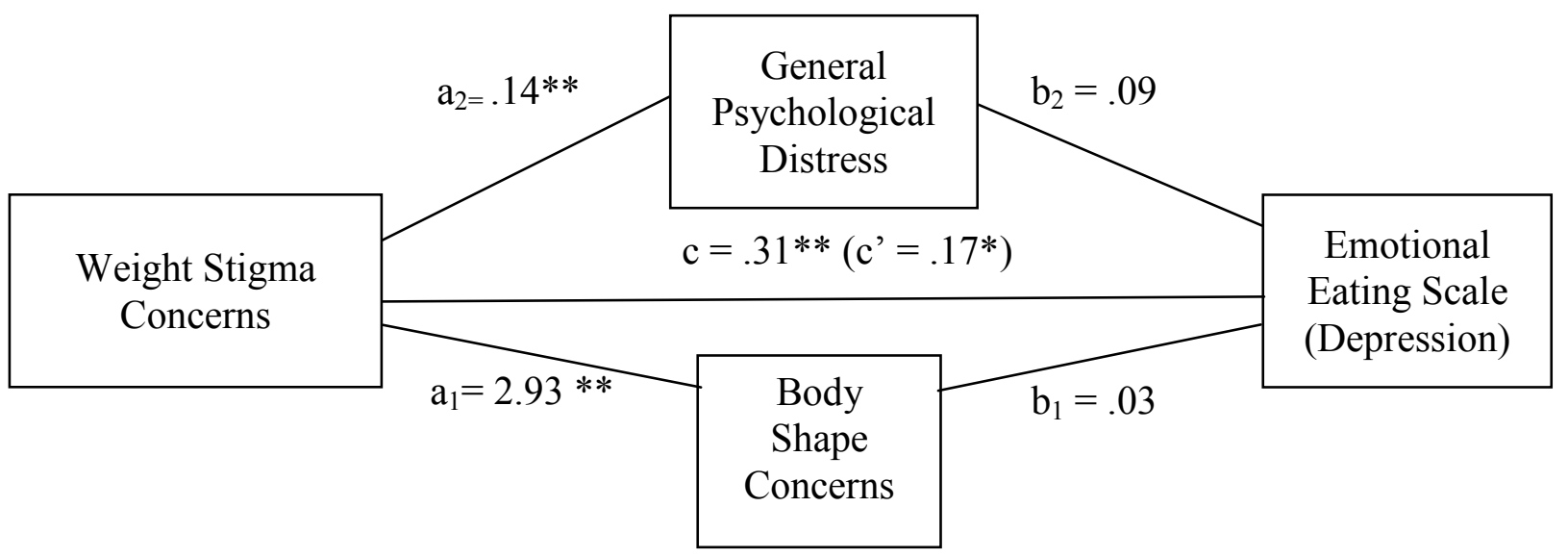

Figure 6. Unstandardized regression coefficients between weight stigma concerns, potential mediators, and emotional eating (depression subscale) controlling for age and BMI in the bariatric sample. c $=$ total effect; c' $=$ direct effect. $N=95$.

$* p<0.05, * * p<0.01$. 
Experiences/Perceptions of Discrimination. The fifth mediation analysis examined the indirect effects of experiences/perceptions of discrimination on binge eating through body shape concerns and general psychological distress, controlling for age and BMI (see Figure 7). The total effect was significant, $b=.37, S E=.12, t(92)=3.07, p<.01$. Experiences/perceptions of discrimination had a significant total indirect effect on binge eating through the combined distress variables, and a significant specific indirect effect on binge eating through body shape concerns, but not through general psychological distress. The indirect effect of experiences/perceptions of discrimination on binge eating through body shape concerns was significantly greater than the indirect effect of general psychological distress (See Table 5). This analysis can best be understood as demonstrating suppression effects for two reasons (MacKinnon, Krull, \& Lockwood, 2000). First, the magnitude of the indirect effects ( $a b=.4153$ for the total indirect effect) increases after inclusion of the mediator as compared to the total effect $(c=.37)$ (see Table 4). Second, the direct $\left(c^{\prime}\right)$ and indirect effect $(a b)$ have different signs, demonstrating inconsistent mediation (see Figure 7.)

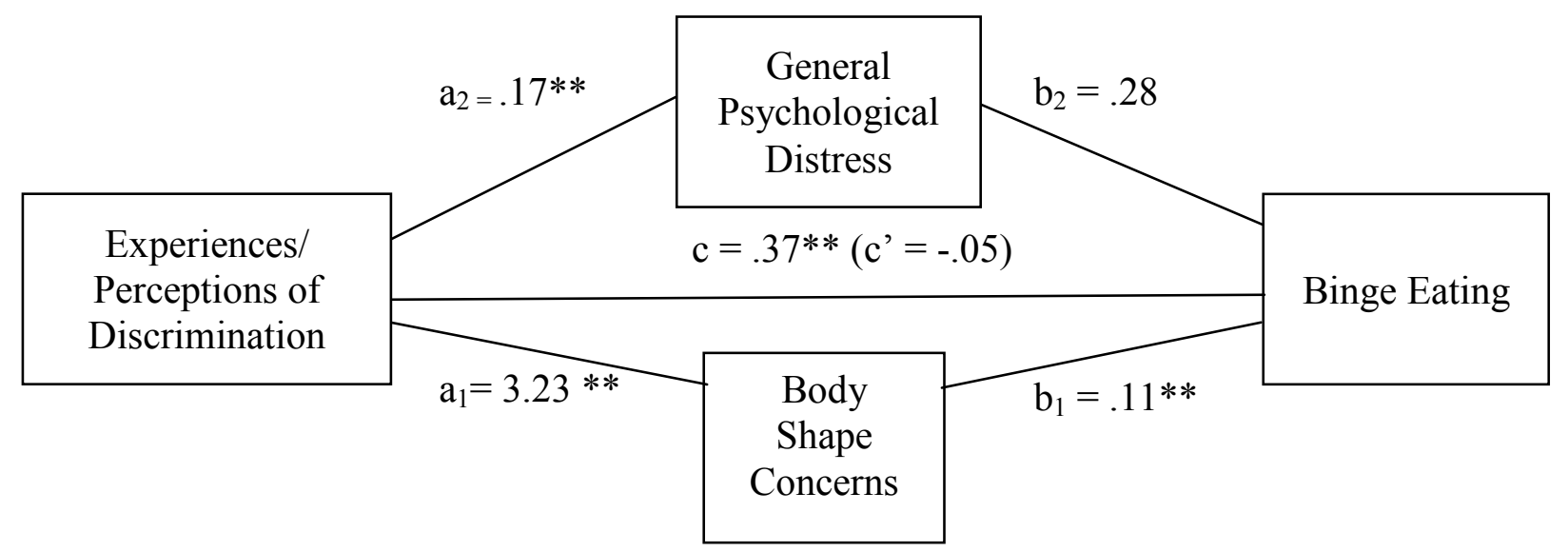

Figure 7. Unstandardized regression coefficients between experiences/perceptions of discrimination, potential mediators, and binge eating controlling for age and BMI in the bariatric Sample. c $=$ total effect; c' $=$ direct effect. $N=96$. ${ }^{*} p<0.05,{ }^{*} p<0.01$. 
The sixth mediation analysis examined the indirect effects of experiences/perceptions of discrimination on emotional eating — anger/frustration subscale through body shape concerns and general psychological distress, controlling for age and BMI (see Figure 8). The total effect was significant, $b=.51, S E=.19, t(92)=2.68, p<.01$. Experiences/perceptions of discrimination had a significant total indirect effect on emotional eating- anger/frustration subscale through the combined distress variables, and a significant specific indirect effect on emotional eatinganger/frustration subscale through body shape concerns, but not through general psychological distress. The contrast between mediators was nonsignificant (See Table 4).

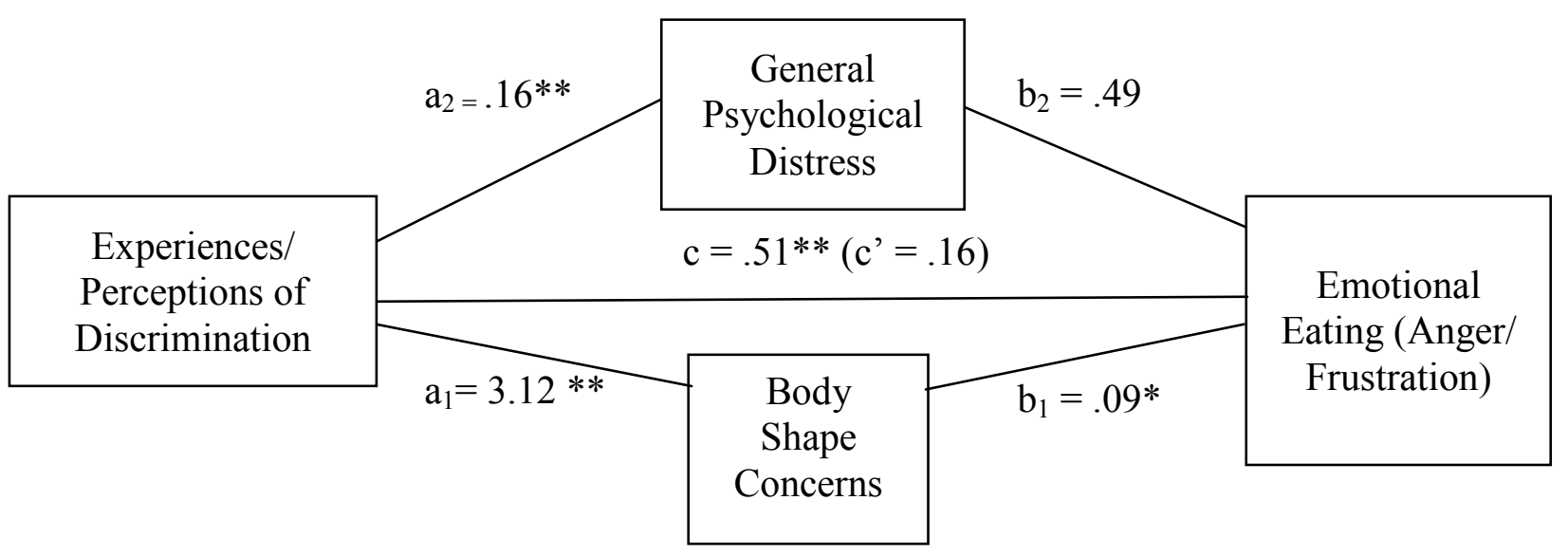

Figure 8. Unstandardized regression coefficients between experiences/perceptions of discrimination, potential mediators, and emotional eating (anger/frustration subscale) controlling for age and BMI in the bariatric Sample. c = total effect; c' $=$ direct effect. $N=96$. ${ }^{*} p<0.05,{ }^{* *} p<0.01$.

The seventh mediation analysis examined the indirect effects of experiences/perceptions of discrimination on emotional eating — anxiety subscale through body shape concerns and general psychological distress, controlling for age and BMI (see Figure 9). The total effect was significant, $b=.33, S E=.13, t(91)=2.51, p<.05$. Experiences/perceptions of discrimination had a significant total indirect effect on emotional eating- anxiety subscale through the combined distress variables, and a significant specific indirect effect on emotional eating- anxiety subscale 
through body shape concerns, but not through general psychological distress. The contrast between mediators was nonsignificant (See Table 4).

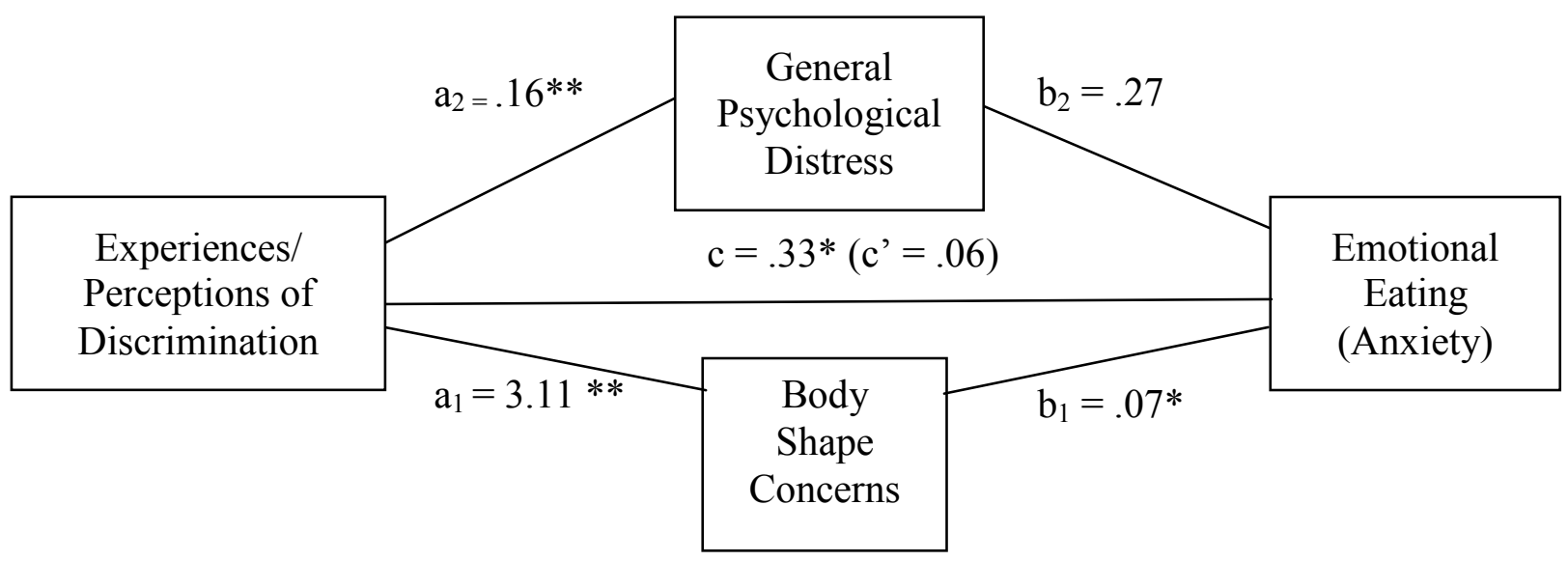

Figure 9. Unstandardized regression coefficients between experiences/perceptions of discrimination, potential mediators, and emotional eating (anxiety subscale) controlling for age and BMI in the bariatric sample. c = total effect; c' = direct effect. $N=95$. ${ }^{*} p<0.05,{ }^{*} p<0.01$.

The eighth mediation analysis examined the indirect effects of experiences/perceptions of discrimination on emotional eating-depression subscale through body shape concerns and general psychological distress, controlling for age and BMI (see Figure 10). The total effect was nonsignificant, $b=.11, S E=.09, t(92)=1.26, p>.05$. Experiences/perceptions of discrimination had a significant total indirect effect on emotional eating- depression subscale through the combined distress variables, and a significant specific indirect effect on emotional eating- depression subscale through body shape concerns but not through general psychological distress. The indirect effect of experiences/perceptions of discrimination on emotional eatingdepression subscale through body shape concerns was not significantly greater than the indirect effect of general psychological distress (See Table 4). This effect can best be interpreted as a suppression effect (See Figure 10). 


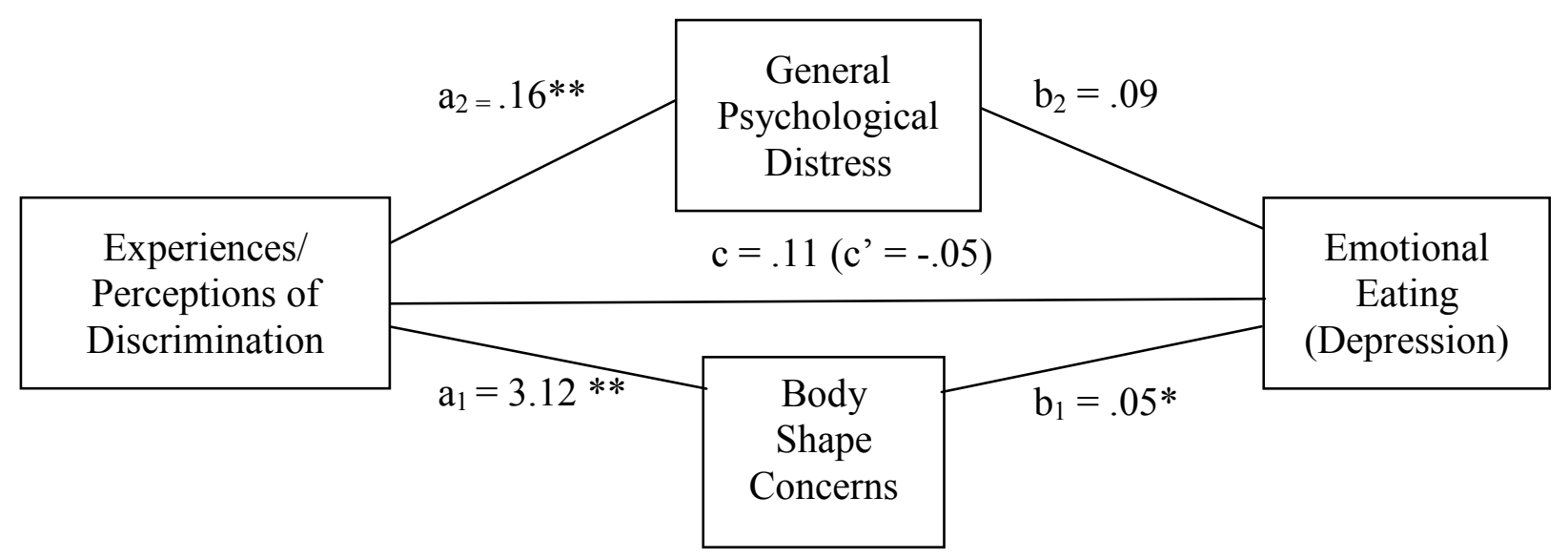

Figure 10. Unstandardized regression coefficients between experiences/perceptions of discrimination, potential mediators, and emotional eating (depression subscale) controlling for age and BMI in the bariatric sample. c $=$ total effect; c' $=$ direct effect. $N=96$. $* p<0.05, * * p<0.01$.

Weight Bias Internalization. The ninth mediation analysis examined the indirect effects of weight bias internalization on binge eating through body shape concerns and general psychological distress, controlling for age and BMI (see Figure 11). The total effect of weight bias internalization on binge eating was significant, $b=.31, S E=.04, t(91)=7.38, p<.0001$. Weight bias internalization had a significant total indirect effect on binge eating through the combined distress variables, but no significant specific indirect effects (see Table 5).

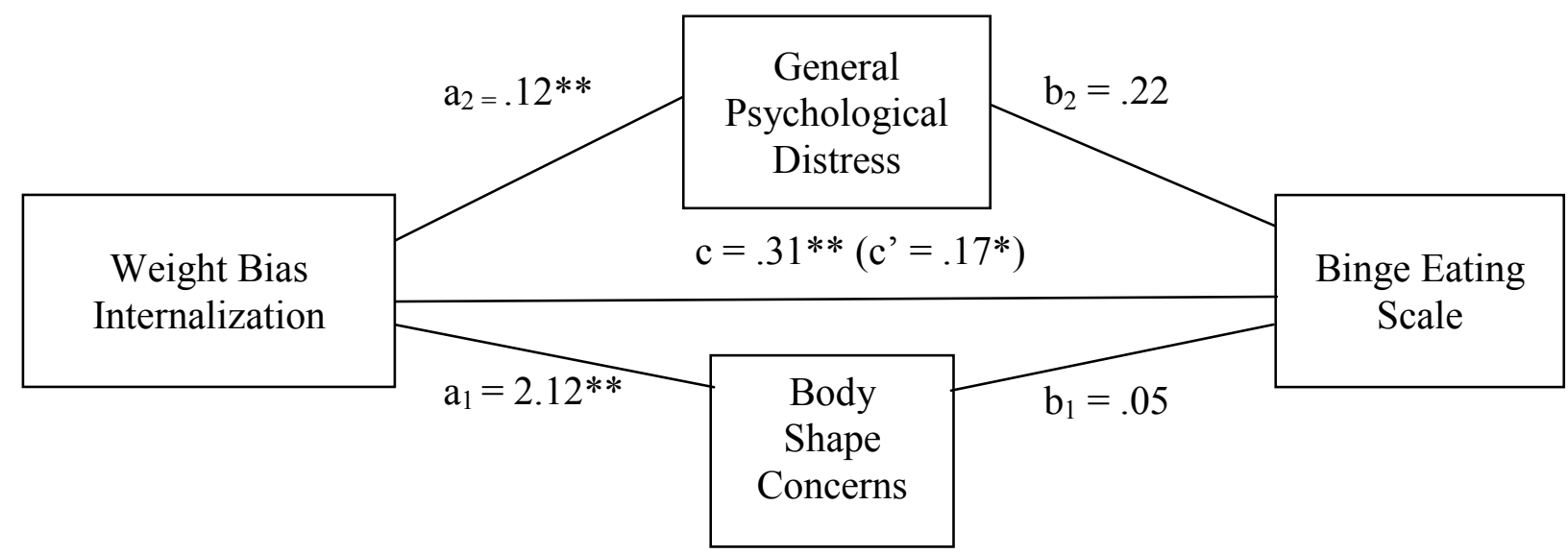

Figure 11. Unstandardized regression coefficients between weight bias internalization, potential mediators, and binge eating controlling for age and BMI in the bariatric sample. $\mathrm{c}=$ total effect; $\mathrm{c}^{\prime}=$ direct effect. $N=95$. ${ }^{*} p<0.05, * * p<0.01$. 
The tenth mediation analysis examined the indirect effects of weight bias internalization on emotional eating — anger/frustration subscale through body shape concerns and general psychological distress, controlling for age and BMI (see Figure 12). The total effect of weight bias internalization on emotional eating- anger/frustration subscale was significant, $b=.31, S E=$ $.07, t(91)=4.54, p<.0001$. Weight bias internalization had a significant total indirect effect on emotional eating- anger/frustration subscale through the combined distress variables, but no significant specific indirect effects (see Table 5).

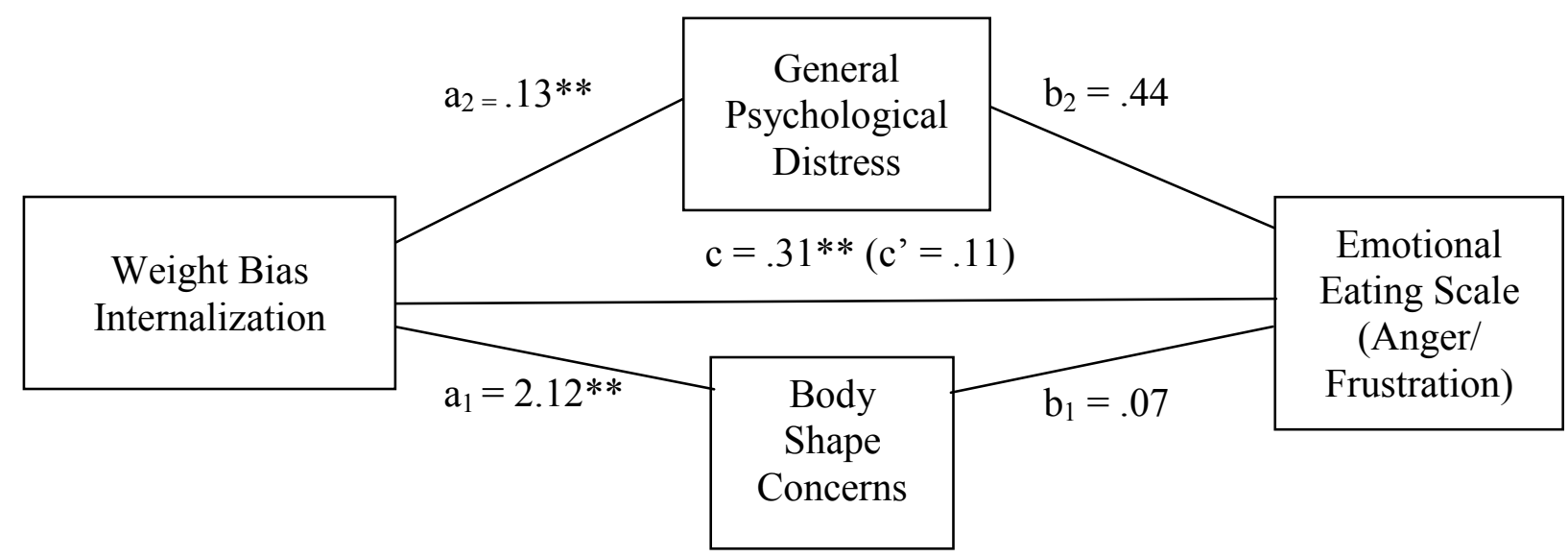

Figure 12. Unstandardized regression coefficients between weight bias internalization, potential mediators, and emotional eating (anger/frustration subscale) controlling for age and BMI in the bariatric sample. c $=$ total effect; $\mathrm{c}^{\prime}=$ direct effect. $N=95$. ${ }^{*} p<0.05,{ }^{*} p<0.01$.

The eleventh mediation analysis examined the indirect effects of weight bias internalization on emotional eating - anxiety subscale through body shape concerns and general psychological distress, controlling for age and BMI (see Figure 13). The total effect of weight bias internalization on emotional eating- anxiety subscale was significant, $b=.23, S E=.05, t(90)$ $=4.37, p<.0001$. There were no significant combined or specific indirect effects in this model (see Table 5). 


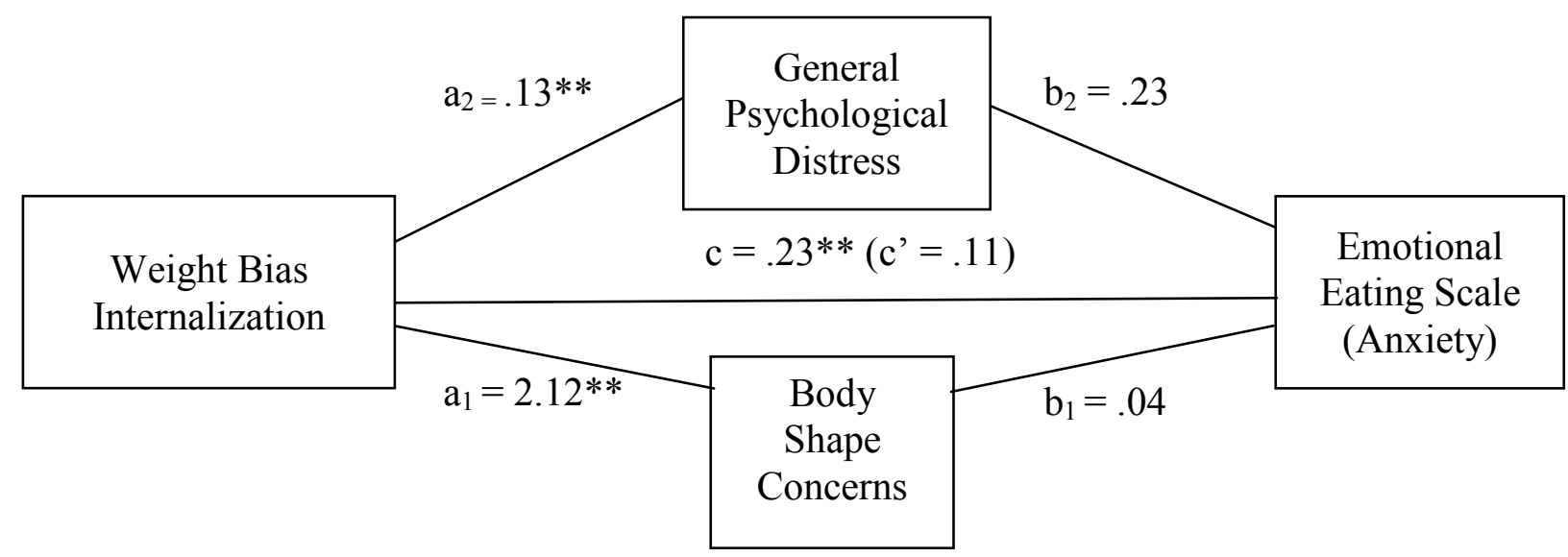

Figure 13. Unstandardized regression coefficients between weight bias internalization, potential mediators, and emotional eating (anxiety subscale) controlling for age and BMI in the bariatric sample. c $=$ total effect; c' $=$ direct effect. $N=94$. ${ }^{*} p<0.05, * * p<0.01$.

The twelfth mediation analysis examined the indirect effects of weight bias internalization on emotional eating-depression subscale through body shape concerns and general psychological distress, controlling for age and BMI (see Figure 14). The total effect of weight bias internalization on emotional eating- depression subscale was significant, $b=.10, S E$ $=.04, t(91)=2.92, p<.05$. There were no significant indirect effects in this model (see Table 5).

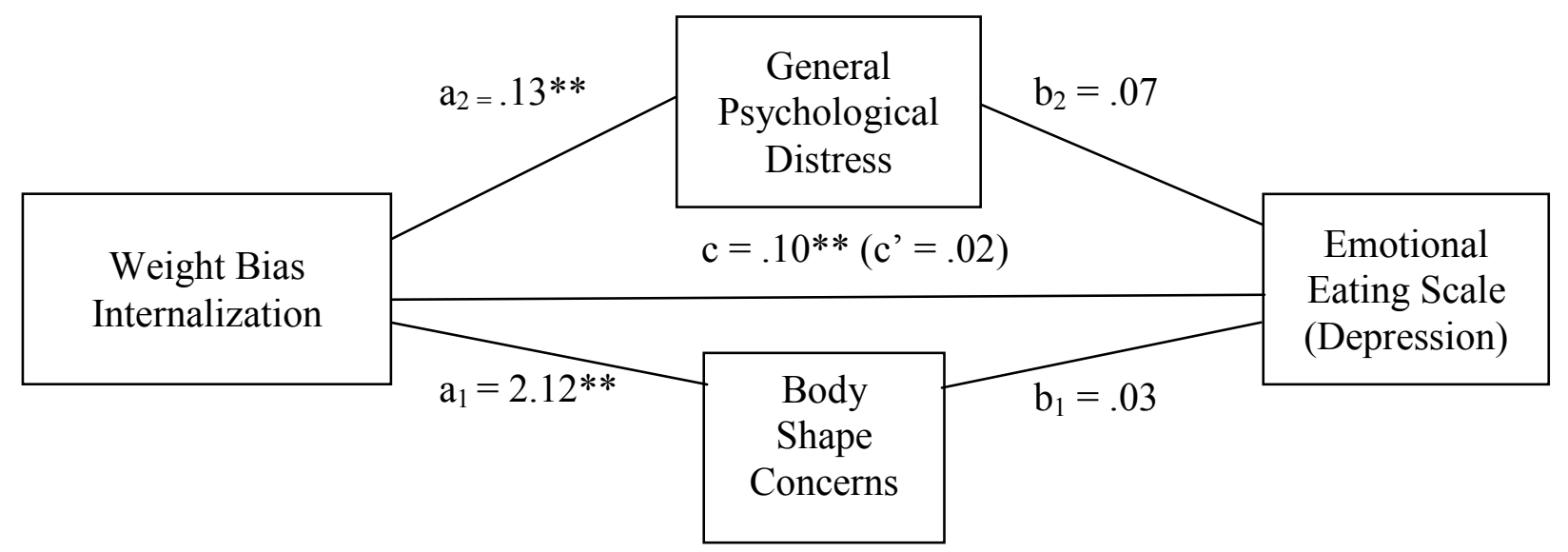

Figure 14. Unstandardized regression coefficients between weight bias internalization, potential mediators, and emotional eating (depression subscale) controlling for age and BMI in the bariatric sample. $\mathrm{c}=$ total effect; c' $=$ direct effect. $N=95$.

$*_{p}<0.05, * * p<0.01$. 


\section{Chapter 3: Undergraduate Sample}

\section{Method}

Participants. Undergraduate female participants $(n=195)$ were recruited to participate in the research study from the Ryerson University psychology subject pool (SONA; See Appendix J). Participants ranged in age from 17 to $30(M=18.86, S D=2.23)$, and ranged in BMI from 15.94 to $32.12 \mathrm{~kg} / \mathrm{m}^{2}(M=21.97, S D=3.07)$. The majority of participants $(73.5 \%)$ had a BMI in the normal-weight range, with an additional $9.0 \%$ and $17.5 \%$ in the underweight and overweight categories, respectively. The majority of participants were Caucasian (42.7\%), single (90.6\%), had attained some university education $(90.9 \%)$ and were employed part-time $(54.2 \%)$. Additional sociodemographic characteristics of the undergraduate sample can be found in Table 6.

Measures. Undergraduate female participants completed the same questionnaire package as Bariatric Surgery participants (See Chapter 2 for a detailed description of these measures), along with a demographic questionnaire.

Demographic questionnaire (Appendix H). Participants completed a demographic questionnaire that included the following items: age, ethnicity, current relationship status, current employment status, highest level of education attained, and BMI.

Procedure. Undergraduate student participants completed the questionnaire packages in a laboratory setting. They first read the letter of information and signed the consent form (Appendix K). Consenting individuals completed the electronic questionnaire package on a computer. The electronic questionnaire was created using Qualtrics Research Suite (http://qualtrics.com/), an online website geared towards survey creation and data collection. Participation took approximately 60 minutes, and upon completion, all participants were 
provided a debriefing form (Appendix L) and were verbally debriefed. Undergraduate student participants were compensated with 1.0 psychology credit.

Table 6 Sociodemographic Characteristics of the Undergraduate Sample

\begin{tabular}{lr}
\hline Characteristic & $n(\%)$ \\
\hline Relationship Status & $164(90.6)$ \\
Single, Never married & $15(8.3)$ \\
Other & $2(1.1)$ \\
Common-law & $0(0.0)$ \\
Married & $0(0.0)$ \\
Separated or divorced & \\
Race/Ethnicity & $79(42.7)$ \\
White (Caucasian) & $25(13.5)$ \\
Southeast Asian & $24(13.0)$ \\
South Asian & $20(10.8)$ \\
East Asian & $17(9.2)$ \\
Other & $10(5.4)$ \\
Black (African American) & $8(4.3)$ \\
Latin/South American & $2(1.1)$ \\
Arab/West Asian & \\
Highest Level of Education & $168(90.9)$ \\
Some university & $11(5.9)$ \\
Bachelor's degree & $3(1.6)$ \\
College diploma & $2(1.1)$ \\
Some college & $1(0.5)$ \\
Graduate degree & $0(0.0)$ \\
High school graduate & $0(0.0)$ \\
Some high school & \\
Employment Status & \\
Part-time & $97(53.6)$ \\
Unemployed & $63(34.8)$ \\
Full-time & $8(4.1)$ \\
Other & $2(1.1)$ \\
Disability insurance & $0(0.0)$ \\
Social Assistance & $0(0.0)$ \\
Retired & $0(0.0)$ \\
Leave of Absence & \\
&
\end{tabular}

Note. Due to missing data, $n$ 's range from 181 to 185 . 


\section{Results}

\section{Preliminary Analyses}

Data were initially assessed for missing values before scoring all of the scales. Scale scores were excluded from analyses if participants were missing more than $10 \%$ of the items on any given scale. Scale scores were pro-rated if participants reported $90 \%$ or more of the data on a given scale (Schlomer et al., 2010).

Data were also examined for outliers and influential cases. Initial examination of the data revealed that four cases demonstrated consistent substantial computational errors (e.g., BMI of 8

$\mathrm{kg} / \mathrm{m}^{2}$ ) and were removed from the sample. Subsequent examination of the standardized residuals of the data indicated that three cases had standardized residuals above 3.29. Examination of the residual statistics (Cook's distance and standardized DFBeta values) indicated that there were no influential cases having an effect on any of the proposed models. All 160 cases (for which data was available) had a Cook's distance less than 1 and standardized DFBetas less than the absolute value of 1 (Cook \& Weisberg, 1982; Field, 2013). Despite meeting the cut-off points for the residual statistics, the three cases represented participants who were significantly older than the sample (age $\geq 32$ years) and demonstrated significantly lower scores on experiences/perceptions of discrimination, such that removal of these cases made the relation between age and experiences/perceptions of discrimination nonsignificant $\left(r_{\mathrm{s}}=-.18, p<\right.$ .05 to $-.14, p=.07)$. Given that experiences/perceptions of discrimination is included as an independent variable in four mediation analyses, the decision was made to remove these three outliers from the sample. 


\section{Descriptive Statistics}

Means and standard deviations of all independent variables, mediators, dependent variables, and potential covariates (age and BMI) can be found in Table 7. All scale medians, except for the Patient Health Questionnaire-4 (a measure of general psychological distress), were significantly higher in the bariatric sample, $p<.01$ with small to moderate effect sizes (Cohen, 1992). The undergraduate sample scored significantly higher scores on the Patient-Health Questionnaire-4 as compared to the bariatric sample, $U=6801.00, z=-3.53 p<.01$. Mean item scores for each scale variable can be found in Appendix I.

\section{Tests of Assumptions and Diagnostics}

Prior to conducting correlational and mediational analyses, assumptions regarding normality, homoscedasticity, and multicollinearity were examined for each mediation model. Skew values indicated that the following variables were significantly positively skewed when applying a $95 \%$ criterion: $\mathrm{BMI}($ skew $=.85$, kurtosis $=.59)$; age $($ skew $=3.06$, kurtosis $=10.46)$; experiences/perceptions of discrimination $($ skew $=.55$, kurtosis $=-.43)$; general psychological distress $($ skew $=.49$, kurtosis $=-.57)$; binge eating $($ skew $=.51$, kurtosis $=-.25)$; emotional eating — anger/frustration subscale $($ skew $=.70$, kurtosis $=-.43)$; and emotional eating — anxiety subscale $($ skew $=.67$, kurtosis $=-.41)$. Homoscedasticity $($ see chapter 2 for a more detailed description) was found to be violated when examining the relations between each of the weight stigma/discrimination variables, the mediators (general psychological distress and body shape concerns), and the emotional eating — anger/frustration and anxiety subscales. Accordingly, a heteroscedasticity- consistent standard error estimator (HC3) was applied in these models (Hayes \& Cai, 2007). 
Table 7

Differences in Scale Means and Medians as a Function of Sample

\begin{tabular}{|c|c|c|c|c|c|c|c|}
\hline & \multicolumn{3}{|c|}{ Bariatric Sample } & \multicolumn{3}{|c|}{ Undergraduate Sample } & \multirow[b]{2}{*}{$r$} \\
\hline Scale & $M$ & $S D$ & Median & $\bar{M}$ & $\overline{S S D}$ & Median & \\
\hline $\begin{array}{l}\text { Weight Stigma } \\
\text { Concerns }\end{array}$ & 24.91 & 8.60 & $25.00 *$ & 17.91 & 7.96 & $18.00 *$ & -0.37 \\
\hline $\begin{array}{l}\text { Experiences/ } \\
\text { Perceptions of } \\
\text { Discrimination }\end{array}$ & 14.73 & 6.71 & $14.00^{*}$ & 10.30 & 4.20 & $10.00 *$ & -0.32 \\
\hline $\begin{array}{l}\text { Weight Bias } \\
\text { Internalization }\end{array}$ & 49.74 & 15.96 & $54.00 *$ & 34.63 & 15.66 & $34.00 *$ & -0.41 \\
\hline $\begin{array}{l}\text { Patient Health } \\
\text { Questionnaire-4 }\end{array}$ & 3.87 & 3.40 & $3.00 *$ & 5.19 & 3.17 & $4.00 *$ & -0.21 \\
\hline $\begin{array}{l}\text { Body Shape } \\
\text { Concerns }\end{array}$ & 117.62 & 40.94 & $119.50^{*}$ & 95.94 & 37.00 & $90.85^{*}$ & -0.25 \\
\hline $\begin{array}{l}\text { Binge Eating } \\
\text { Scale }\end{array}$ & 17.13 & 8.21 & $17.03 *$ & 14.43 & 7.68 & $13.00 *$ & -0.17 \\
\hline $\begin{array}{l}\text { Emotional Eating } \\
\text { Scale } \\
\text { (Anger/ } \\
\text { Frustration) }\end{array}$ & 19.51 & 11.80 & $18.00 *$ & 10.24 & 8.61 & $8.00^{*}$ & -0.38 \\
\hline $\begin{array}{l}\text { Emotional Eating } \\
\text { Scale (Anxiety) }\end{array}$ & 15.39 & 9.12 & $13.50 *$ & 8.94 & 6.96 & $8.00 *$ & -0.34 \\
\hline $\begin{array}{l}\text { Emotional Eating } \\
\text { Scale } \\
\text { (Depression) }\end{array}$ & 11.63 & 5.71 & $12.00 *$ & 8.67 & 4.44 & $8.00^{*}$ & -0.25 \\
\hline BMI & 49.31 & 8.09 & $47.55^{*}$ & 21.97 & 3.09 & $21.26^{*}$ & -0.83 \\
\hline Age & 42.32 & 10.36 & $43.00 *$ & 18.86 & 2.23 & $18.00 *$ & -0.85 \\
\hline
\end{tabular}

Note. Due to non-normal data, the Mann-Whitney U test was employed. Due to missing data, $n$ 's range from 98- 101 in the bariatric sample and from 170- 188 in the undergraduate sample. $r$ is used as a measure of effect size.

$* p<.01$. 
According to guidelines for multicollinearity (See Chapter 2), the high correlation between body shape concerns and weight bias internalization $\left(r_{\mathrm{s}}=.80\right)$ suggested potential for multicollinearity. Despite this strong correlation, tolerance and VIF values were not violated. Tolerance values for the independent variables and the mediators ranged from 0.31 to 0.88 and VIF values from 1.23 to 3.24 , respectively for all models.

\section{Correlations}

Scale intercorrelations between independent variables, dependent variables and proposed mediators can be found in Table 8. Due to violations of normality, Spearman's rho correlations are reported (Field, 2009). The relations of age and BMI to all variables were also calculated to identify potential covariates (see Table 8 ).

In partial support of the first hypothesis, there were significant, positive correlations between weight stigma concerns (independent variable) with the dependent variables, binge eating and two facets of emotional eating (anger/frustration and anxiety). Effect sizes were small to moderate for binge eating and small for both emotional eating subscales (Cohen, 1992). Contrary to the hypothesis, weight stigma concerns was not significantly associated with the depression subscale of emotional eating. Of note, this finding was also observed in the bariatric sample.

In partial support of the second hypothesis, there were significant, positive correlations between experiences/perceptions of discrimination (independent variable) and binge eating (dependent variable) with small effect sizes. However, experiences/perceptions of discrimination did not significantly predict any of the three components of emotional eating (anger/frustration, anxiety, and depression). In support of the third hypothesis, there were significant, positive correlations between weight bias internalization, binge eating, and all three components of 
Table 8

Scale Intercorrelations and Coefficient Alpha Reliabilities for the Undergraduate Sample

\begin{tabular}{|c|c|c|c|c|c|c|c|c|c|c|c|}
\hline Measure & 1 & 2 & 3 & 4 & 5 & 6 & 7 & 8 & 9 & 10 & 11 \\
\hline 1. Weight Stigma Concerns & .93 & $.54 * *$ & $.67 * *$ & $.23 * *$ & $.56 * *$ & $.44 * *$ & $.20 * *$ & $.17^{*}$ & .12 & -.07 & .12 \\
\hline $\begin{array}{l}\text { 2. Experiences/Perceptions } \\
\text { of Discrimination }\end{array}$ & & .87 & $.43 * *$ & $.23 * *$ & $.34 * *$ & $.31 * *$ & .14 & .08 & .10 & -.14 & .03 \\
\hline 3. Weight Bias & & & .93 & $.21 * *$ & $.80 * *$ & $.60 * *$ & $.22 * *$ & $.19 *$ & $.21 * *$ & -.12 & $.35 * *$ \\
\hline Internalization & & & & & & & & & & & \\
\hline 4. Patient Health & & & & .85 & $.32 * *$ & $.36 * *$ & $.26 * *$ & $.22 * *$ & $.25 * *$ & -.03 & $-.22 * *$ \\
\hline Questionnaire-4 & & & & & & & & & & & \\
\hline 5. Body Shape Concerns & & & & & .97 & $.66^{* *}$ & $.27 * *$ & $.21 * *$ & $.31 * *$ & -.05 & $.34 * *$ \\
\hline 6. Binge Eating Scale & & & & & & .89 & $.41 * *$ & $.43 * *$ & $.49 *$ & .01 & $.18^{*}$ \\
\hline $\begin{array}{l}\text { 7. Emotional Eating Scale } \\
\text { (Anger/Frustration) }\end{array}$ & & & & & & & .89 & $.84 * *$ & $.69 * *$ & -.08 & .04 \\
\hline $\begin{array}{l}\text { 8. Emotional Eating Scale } \\
\text { (Anxiety) }\end{array}$ & & & & & & & & .86 & $.67 * *$ & -.11 & .04 \\
\hline $\begin{array}{l}\text { 9. Emotional Eating Scale } \\
\text { (Depression) }\end{array}$ & & & & & & & & & .76 & -.06 & $\begin{array}{l}-.01 \\
.08\end{array}$ \\
\hline 10. Age & & & & & & & & & & & \\
\hline 11. BMI & & & & & & & & & & & \\
\hline
\end{tabular}

Note. Coefficient alpha reliabilities are boldface in the diagonal. Due to missing data (primarily for age), $n$ 's range from 135 to 187. ${ }^{*} p<.05,{ }^{* *} p<.01$. 
emotional eating (anger/frustration, anxiety, and depression). Effects were moderate for binge eating and small for the emotional eating subscales.

\section{Mediation Analyses}

To examine the fourth and final hypothesis that the distress variables will mediate the relation between the stigma- and disordered eating-related variables, multiple mediation analyses were conducted using non-parametric bootstrapping. Twelve mediational analyses were conducted with the undergraduate sample, such that each of the three weight stigma/ discrimination variables were analyzed separately with binge eating and the three emotional eating subscales. Mediation analyses were conducted irrespective of significant total effects in keeping with modern approaches to mediation (e.g., Rucker et al., 2011). See chapter 2 for a more detailed description of mediation.

Ten thousand resamples of the sampling distribution were used to derive bootstrap confidence intervals and determine significance of the indirect effects at the .05 level. Both mediators (general psychological distress and body shape concerns) were examined simultaneously (i.e., in parallel) within each of the twelve models using the SPSS PROCESS Macro (Hayes, 2013). Given that BMI was significantly negatively correlated with general psychological distress, as well as positively correlated with weight bias internalization, body shape concerns, and binge eating, BMI was included as a covariate in each model for consistency. Age was included as a covariate to in order to draw comparisons across both samples. Results were considered significant if a zero value was not present in the $95 \%$ confidence intervals. The completely standardized effect $\left(a b_{c s}\right)$ is reported as a measure of effect size for the indirect (mediated) effects. 
Tables 9 to 11 depict information regarding the indirect (mediated) effects and their confidence intervals. Figures 15 through 26 show a visual representation of the independent, mediator, and dependent variables in each mediation model with the unstandardized regression coefficients. 
Table 9

Specific and Total Indirect Effects of Weight Stigma Concerns on Disordered Eating Variables through Mediators Controlling for Age and BMI, Undergraduate Sample

\begin{tabular}{|c|c|c|c|c|c|c|}
\hline \multirow{2}{*}{$\begin{array}{l}\text { Disordered } \\
\text { Eating } \\
\text { Variable }\end{array}$} & \multirow[t]{2}{*}{$\begin{array}{l}\text { Mediator } \\
\text { Variables }\end{array}$} & \multirow[t]{2}{*}{$\begin{array}{c}\text { Point } \\
\text { Estimate }\end{array}$} & \multirow[t]{2}{*}{$S E$} & \multicolumn{2}{|c|}{$\begin{array}{c}\text { Bootstrapped 95\% } \\
\text { BC Confidence } \\
\text { Intervals }\end{array}$} & \multirow[t]{2}{*}{$a b_{c s}$} \\
\hline & & & & Lower & Upper & \\
\hline \multirow[t]{4}{*}{ BES } & BSQ* & .3068 & .0605 & .2017 & .4426 & .3015 \\
\hline & PHQ-4* & .0303 & .0190 & .0028 & .0798 & .0298 \\
\hline & Total* & .3371 & .0590 & .2341 & .4676 & .3313 \\
\hline & $(\mathrm{C} 1)^{*}$ & .2765 & .0676 & .1575 & .4244 & \\
\hline \multirow[t]{4}{*}{ EES- Ang ${ }^{a}$} & BSQ & .1049 & .0606 & -.0079 & .2351 & .0953 \\
\hline & PHQ-4* & .0440 & .0279 & .0044 & .1187 & .0400 \\
\hline & Total* & .1489 & .0595 & .0389 & .2759 & .1352 \\
\hline & (C1) & .0609 & .0733 & -.0820 & .2110 & \\
\hline \multirow[t]{4}{*}{ EES- An $x^{a}$} & BSQ & .0692 & .0477 & -.0259 & .1628 & .0762 \\
\hline & PHQ-4* & .0364 & .0227 & .0040 & .0999 & .0401 \\
\hline & Total* & .1056 & .0476 & .0176 & .2024 & .1163 \\
\hline & (C1) & .0328 & .0577 & -.0912 & .1396 & \\
\hline \multirow[t]{4}{*}{ EES- Dep } & $\mathrm{BSQ}^{*}$ & .0996 & .0318 & .0440 & .1689 & .1712 \\
\hline & PHQ-4 & .0188 & .0139 & -.0008 & .0575 & .0323 \\
\hline & Total* & .1184 & .0303 & .0640 & .1831 & .2036 \\
\hline & $(\mathrm{C} 1)^{*}$ & .0808 & .0385 & .0073 & .1594 & \\
\hline
\end{tabular}

Note. BES = Binge Eating Scale; EES- Ang = Emotional Eating Scale- Anger /Frustration subscale; EES- Anx = Emotional Eating Scale- Anxiety subscale; EES- Dep = Emotional Eating Scale- Depression subscale; $\mathrm{SE}=$ standard error; $\mathrm{BC}=$ bias corrected; 10,000 bootstrap samples; $\mathrm{ab}_{\mathrm{cs}}=$ completely standardized indirect effect; Total = total combined indirect effects of BSQ and PHQ-4; C1 = Contrast of BSQ vs. PHQ-4. This value is significant if the difference between the two mediators' indirect effects is significant. If the point estimate value for the contrast is positive, this indicates that the indirect effect of BSQ- PHQ-4 is positive, such that BSQ is a significantly greater mediator than PHQ-4 (assuming the point estimates for the indirect effects of both mediators are positive).

${ }^{\mathrm{a}} \mathrm{HC} 3$ correction factor applied. $* p<.05$. 
Table 10

Specific and Total Indirect Effects of Experiences/Perceptions of Discrimination on Disordered Eating Variables through Mediators Controlling for Age and BMI, Undergraduate Sample

\begin{tabular}{|c|c|c|c|c|c|c|}
\hline \multirow{2}{*}{$\begin{array}{l}\text { Disordered } \\
\text { Eating } \\
\text { Variable }\end{array}$} & \multirow[t]{2}{*}{$\begin{array}{l}\text { Mediator } \\
\text { Variables }\end{array}$} & \multirow[t]{2}{*}{$\begin{array}{c}\text { Point } \\
\text { Estimate }\end{array}$} & \multirow[t]{2}{*}{$S E$} & \multicolumn{2}{|c|}{$\begin{array}{c}\text { Bootstrapped } 95 \% \\
\text { BC Confidence } \\
\text { Intervals }\end{array}$} & \multirow[t]{2}{*}{$a b_{c s}$} \\
\hline & & & & Lower & Upper & \\
\hline \multirow[t]{4}{*}{ BES } & $\mathrm{BSQ}^{*}$ & .2942 & .1017 & .1169 & .5166 & .1569 \\
\hline & PHQ4* & .0513 & .0364 & .0023 & .1524 & .0274 \\
\hline & Total* & .3455 & .1108 & . 1445 & .5805 & .1843 \\
\hline & $(\mathrm{C} 1)^{*}$ & .2429 & . 1051 & .0639 & .4782 & \\
\hline \multirow[t]{4}{*}{ EES- Ang ${ }^{\mathrm{a}}$} & $\mathrm{BSQ}^{*}$ & .1157 & .0627 & .0209 & .2721 & .0559 \\
\hline & PHQ4* & .0867 & .0506 & .0153 & .2290 & .0418 \\
\hline & Total* & .2024 & .0734 & .0853 & .3799 & .0977 \\
\hline & (C1) & .0291 & .0871 & -.1451 & .2064 & \\
\hline \multirow[t]{4}{*}{ EES- An $x^{a}$} & $\mathrm{BSQ}^{*}$ & .0864 & .0487 & .0110 & .2066 & .0508 \\
\hline & PHQ4* & .0730 & .0426 & .0123 & .1901 & .0429 \\
\hline & Total* & .1594 & .0619 & .0625 & .3144 & .0937 \\
\hline & (C1) & .0135 & .0675 & -.1300 & .1430 & \\
\hline \multirow[t]{4}{*}{ EES- Dep } & BSQ* & .0967 & .0372 & .0377 & .1885 & .0888 \\
\hline & PHQ4 & .0365 & .0262 & -.0001 & .1094 & .0335 \\
\hline & Total* & . 1332 & .0422 & .0631 & .2337 & 1224 \\
\hline & (C1) & .0602 & .0486 & -.0267 & .1675 & \\
\hline
\end{tabular}

Note. BES = Binge Eating Scale; EES- Ang = Emotional Eating Scale- Anger/Frustration subscale; EES- Anx $=$ Emotional Eating Scale- Anxiety subscale; EES- Dep $=$ Emotional Eating Scale- Depression subscale; $\mathrm{SE}=$ standard error; $\mathrm{BC}=$ bias corrected; 10,000 bootstrap samples; $\mathrm{ab}_{\mathrm{cs}}=$ completely standardized indirect effect; Total = total combined indirect effects of BSQ and PHQ-4; C1 = Contrast of BSQ vs. PHQ-4. This value is significant if the difference between the two mediators' indirect effects is significant. If the point estimate value for the contrast is positive, this indicates that the indirect effect of BSQ- PHQ-4 is positive, such that BSQ is a significantly greater mediator than PHQ-4 (assuming the point estimates for the indirect effects of both mediators are positive).

${ }^{\mathrm{a}} \mathrm{HC} 3$ correction factor applied

$* p<.05$. 
Table 11

Specific and Total Indirect Effects of Weight Bias Internalization on Disordered Eating Variables through Mediators Controlling for Age and BMI, Undergraduate Sample

\begin{tabular}{|c|c|c|c|c|c|c|}
\hline \multirow{2}{*}{$\begin{array}{l}\text { Disordered } \\
\text { Eating } \\
\text { Variable }\end{array}$} & \multirow[t]{2}{*}{$\begin{array}{l}\text { Mediator } \\
\text { Variables }\end{array}$} & \multirow[t]{2}{*}{$\begin{array}{c}\text { Point } \\
\text { Estimate }\end{array}$} & \multirow[t]{2}{*}{$S E$} & \multicolumn{2}{|c|}{$\begin{array}{l}\text { Bootstrapped 95\% } \\
\text { BC Confidence } \\
\text { Intervals }\end{array}$} & \multirow[t]{2}{*}{$a b_{c s}$} \\
\hline & & & & Lower & Upper & \\
\hline \multirow[t]{4}{*}{$\mathrm{BES}$} & $\mathrm{BSQ}^{*}$ & .1786 & .0464 & .0931 & .2760 & .3340 \\
\hline & PHQ-4* & .0219 & .0124 & .0026 & .0531 & .0409 \\
\hline & Total* & .2005 & .0453 & .1170 & .2948 & .3748 \\
\hline & $(\mathrm{C} 1)^{*}$ & .1567 & .0506 & .0624 & .2615 & \\
\hline \multirow[t]{4}{*}{ EES- Ang ${ }^{a}$} & BSQ & .0339 & .0637 & -.0909 & .1578 & .0582 \\
\hline & PHQ-4* & .0324 & .0172 & .0047 & .0740 & .0557 \\
\hline & Total & .0663 & .0623 & -.0537 & .1892 & .1140 \\
\hline & (C1) & .0014 & .0695 & -.1398 & .1353 & \\
\hline \multirow[t]{4}{*}{ EES- Anx ${ }^{a}$} & BSQ & .0044 & .0508 & -.0982 & .1003 & .0092 \\
\hline & PHQ-4* & .0267 & .0146 & .0036 & .0629 & .0559 \\
\hline & Total & .0312 & .0499 & -.0649 & .1299 & .0651 \\
\hline & $(\mathrm{C} 1)$ & -.0223 & .0557 & -.1415 & .0772 & \\
\hline \multirow[t]{4}{*}{ EES- Dep } & $\mathrm{BSQ}^{*}$ & .0686 & .0302 & .0069 & .1249 & .2237 \\
\hline & PHQ-4 & .0136 & .0091 & -.0008 & .0365 & .0445 \\
\hline & Total* & .0822 & .0291 & .0242 & .1385 & .2682 \\
\hline & (C1) & .0549 & .0338 & -.0161 & .1171 & \\
\hline
\end{tabular}

Note. BES = Binge Eating Scale; EES- Ang = Emotional Eating Scale- Anger/Frustration subscale; EES- Anx = Emotional Eating Scale- Anxiety subscale; EES- Dep = Emotional Eating Scale- Depression subscale; $\mathrm{SE}=$ standard error; $\mathrm{BC}=$ bias corrected; 10,000 bootstrap samples; $\mathrm{ab}_{\mathrm{cs}}=$ completely standardized effect; Total= total combined indirect effects of BSQ and PHQ-4; $\mathrm{C} 1=$ Contrast of BSQ vs. PHQ-4. This value is significant if the difference between the two mediators' indirect effects is significant. If the point estimate value for the contrast is positive, this indicates that the indirect effect of BSQ- PHQ-4 is positive, such that BSQ is a significantly greater mediator than PHQ-4 (assuming the point estimates for the indirect effects of both mediators are positive).

${ }^{\mathrm{a}} \mathrm{HC} 3$ correction factor applied. $* p<.05$. 
Weight Stigma Concerns. The first mediation analysis examined the indirect effects of weight stigma concerns on binge eating through body shape concerns and general psychological distress, controlling for age and BMI (see Figure 15). The total effect of weight stigma concerns on binge eating was significant, $b=.39, S E=.08, t(153)=5.17, p<.0001$. Weight stigma concerns had a significant total indirect effect on binge eating through the combined distress variables, as well as significant specific indirect effects on binge eating through body shape concerns and general psychological distress. The indirect effect of weight stigma concerns on binge eating through body shape concerns was significantly greater than the indirect effect of general psychological distress (See Table 9).

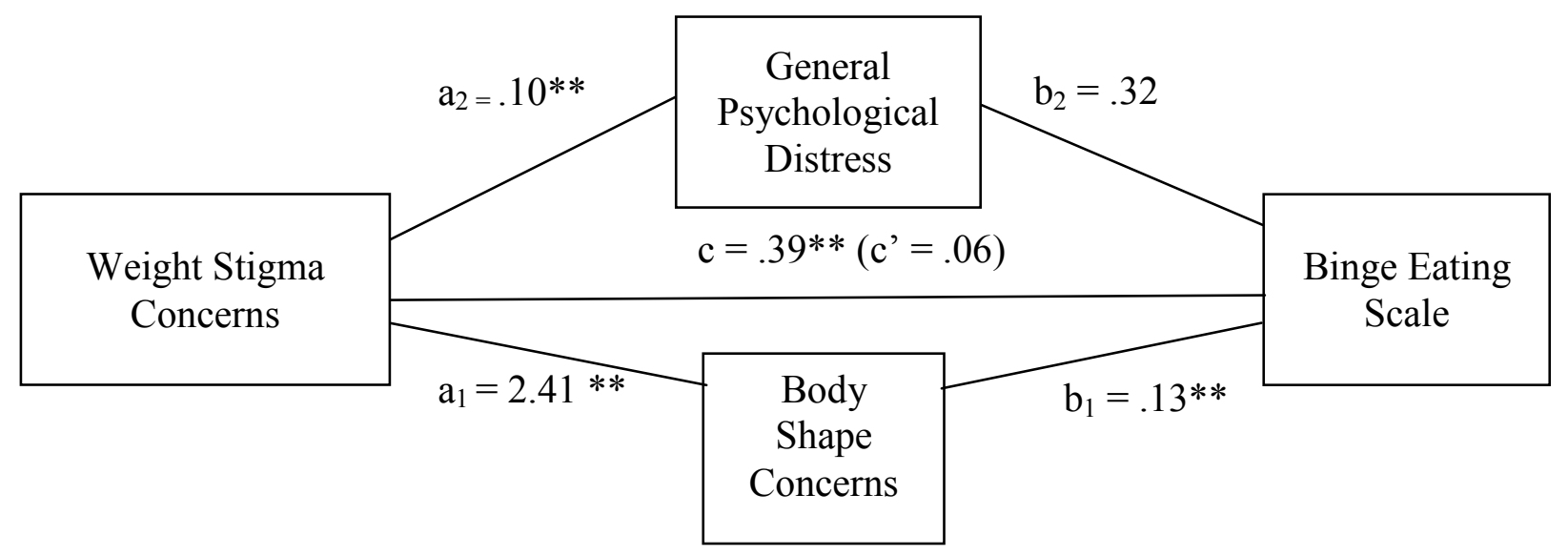

Figure 15. Unstandardized regression coefficients between weight stigma concerns, potential mediators, and binge eating controlling for age and BMI in the undergraduate sample. $\mathrm{c}=$ total effect; c' $=$ direct effect. $N=157$. ${ }^{*} p<0.05,{ }^{* *} p<0.01$.

The second mediation analysis examined the indirect effects of weight stigma concerns on emotional eating — anger/frustration subscale through body shape concerns and general psychological distress, controlling for age and BMI (see Figure 16). The total effect of weight stigma concerns on emotional eating- anger/frustration subscale was significant, $b=.18, S E=$ $.08, t(154)=2.19, p<.05$. Weight stigma concerns had a significant total indirect effect on 
emotional eating- anger/frustration subscale through the combined distress variables and a significant specific indirect effect on emotional eating- anger/frustration subscale through general psychological distress, but not through body shape concerns. The contrast between mediators was nonsignificant (See Table 9).

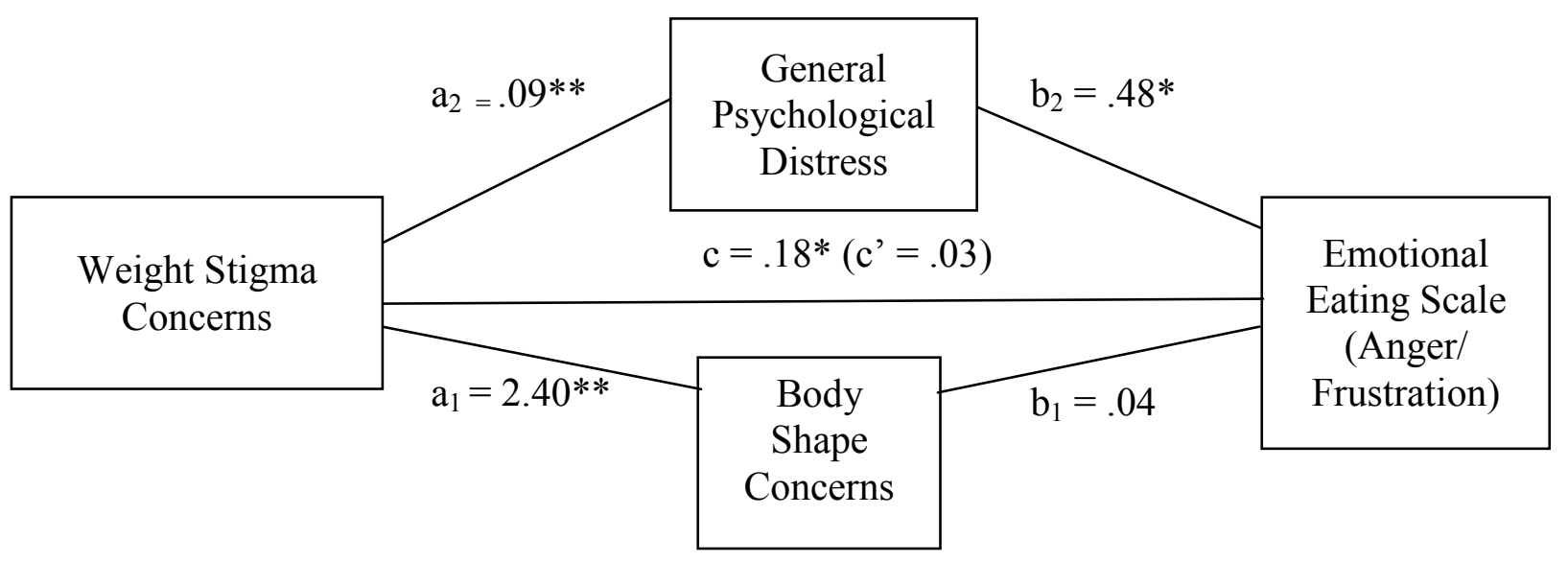

Figure 16. Unstandardized regression coefficients between weight stigma concerns, potential mediators, and emotional eating (anger/frustration subscale) controlling for age and BMI in the undergraduate sample. c $=$ total effect; $\mathrm{c}^{\prime}=$ direct effect. $N=158$. ${ }^{*} p<0.05,{ }^{* *} p<0.01$.

The third mediation analysis examined the indirect effects of weight stigma concerns on emotional eating — anxiety subscale through body shape concerns and general psychological distress, controlling for age and BMI (see Figure 17). The total effect of weight stigma concerns on emotional eating- anxiety subscale was nonsignificant, $b=.13, S E=.07, t(155)=1.79, p>$ .05 . Weight stigma concerns had a significant indirect effect on emotional eating- anxiety subscale through the combined distress variables, and a significant specific indirect effect on emotional eating- anxiety subscale through general psychological distress, but not through body shape concerns. The contrast between mediators was nonsignificant (See Table 9). 


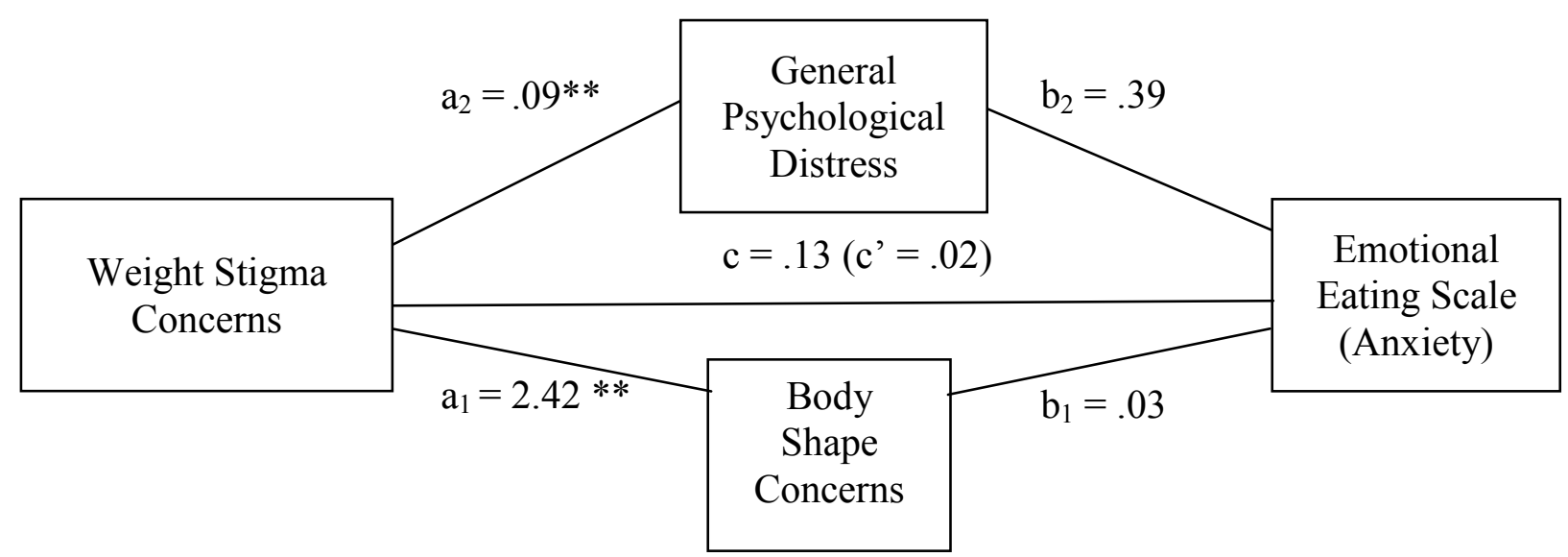

Figure 17. Unstandardized regression coefficients between weight stigma concerns, potential mediators, and emotional eating (anxiety subscale) controlling for age and BMI in the undergraduate sample. $\mathrm{c}=$ total effect; c' $=$ direct effect. $N=159$. ${ }^{*} p<0.05, * * p<0.01$.

The fourth mediation analysis examined the indirect effects of weight stigma concerns on emotional eating - depression subscale through body shape concerns and general psychological distress, controlling for age and BMI (see Figure 18). The total effect of weight stigma concerns on emotional eating- depression subscale was significant, $b=.09, S E=.05, t(155)=1.98, p<$ .05. Weight stigma concerns had a significant total indirect effect on emotional eatingdepression subscale through the combined distress variables, and a significant indirect effect through body shape concerns but not through general psychological distress. The indirect effect of weight stigma concerns on emotional eating- depression subscale through body shape concerns was significantly greater than the indirect effect through general psychological distress (See Table 9). This analysis can best be understood as demonstrating suppression (See Figure $18)$. 


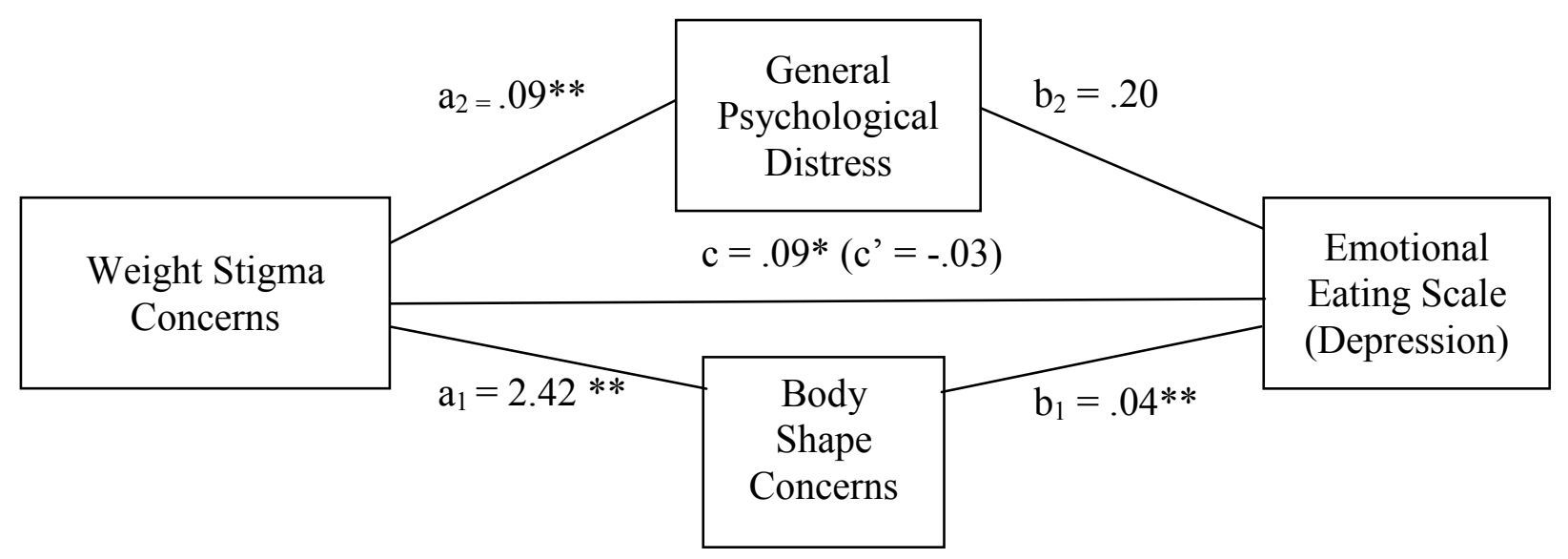

Figure 18. Unstandardized regression coefficients between weight stigma concerns, potential mediators, and emotional eating (depression subscale) controlling for age and BMI in the undergraduate sample. c $=$ total effect; c' $=$ direct effect. $N=159$. $*_{p}<0.05, * * p<0.01$.

Experiences/Perceptions of Discrimination. The fifth mediation analysis examined the indirect effects of experiences/perceptions of discrimination on binge eating through body shape concerns and general psychological distress, controlling for age and BMI (see Figure 19). The total effect was significant, $b=.41, S E=.15, t(152)=2.78, p<.01$. Experiences/perceptions of discrimination had a significant total indirect effect on binge eating through the combined distress variables, and significant specific indirect effects on binge eating through body shape concerns and general psychological distress. The indirect effect of body shape concerns was significantly greater than the indirect effect of general psychological distress (See Table 10). 


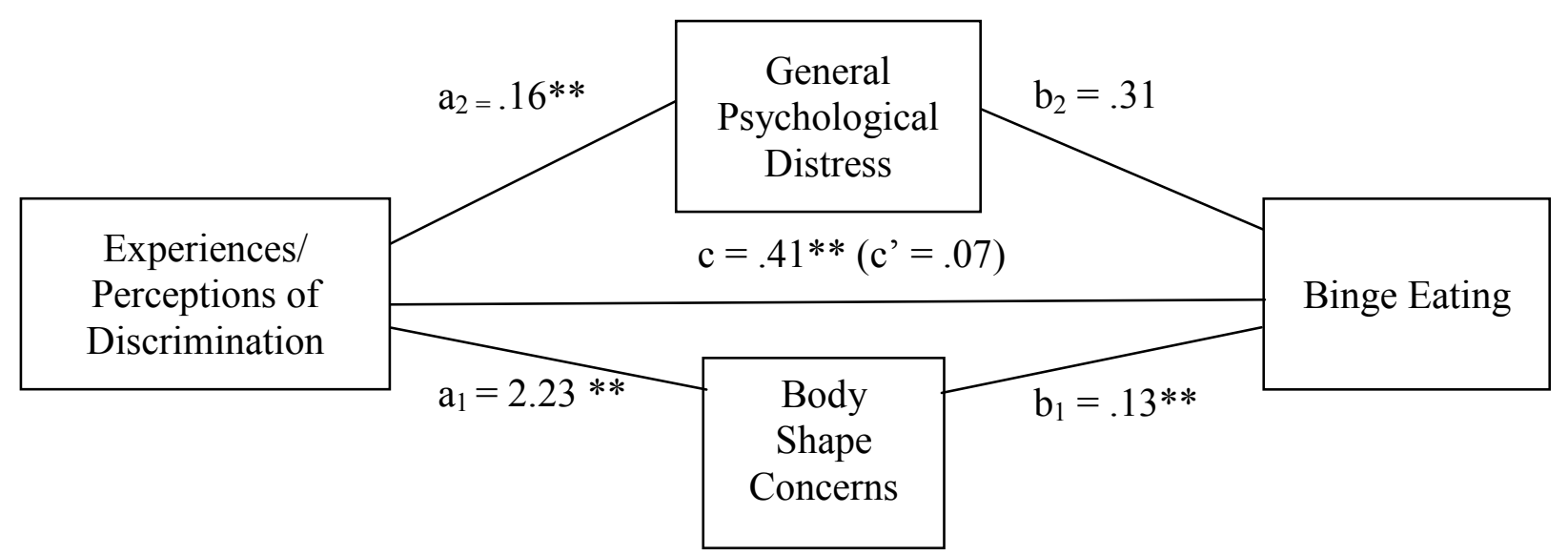

Figure 19. Unstandardized regression coefficients between experiences/perceptions of discrimination, potential mediators, and binge eating controlling for age and BMI in the undergraduate sample. $\mathrm{c}=$ total effect; c' $=$ direct effect. $N=156$. ${ }^{*} p<0.05, * * p<0.01$.

The sixth mediation analysis examined the indirect effects of experiences/perceptions of discrimination on emotional eating — anger/frustration subscale through body shape concerns and general psychological distress, controlling for age and BMI (see Figure 20). The total effect was nonsignificant, $b=.15, S E=.18, t(154)=.83, p>.05$. Experiences/perceptions of discrimination had a significant total indirect effect on emotional eating- anger/frustration subscale through the combined distress variables and significant specific indirect effects on emotional eatinganger/frustration subscale through both body shape concerns and general psychological distress. The contrast between the two mediators was nonsignificant (See Table 10). This analysis can best be understood as demonstrating a suppression effect (See Figure 20). 


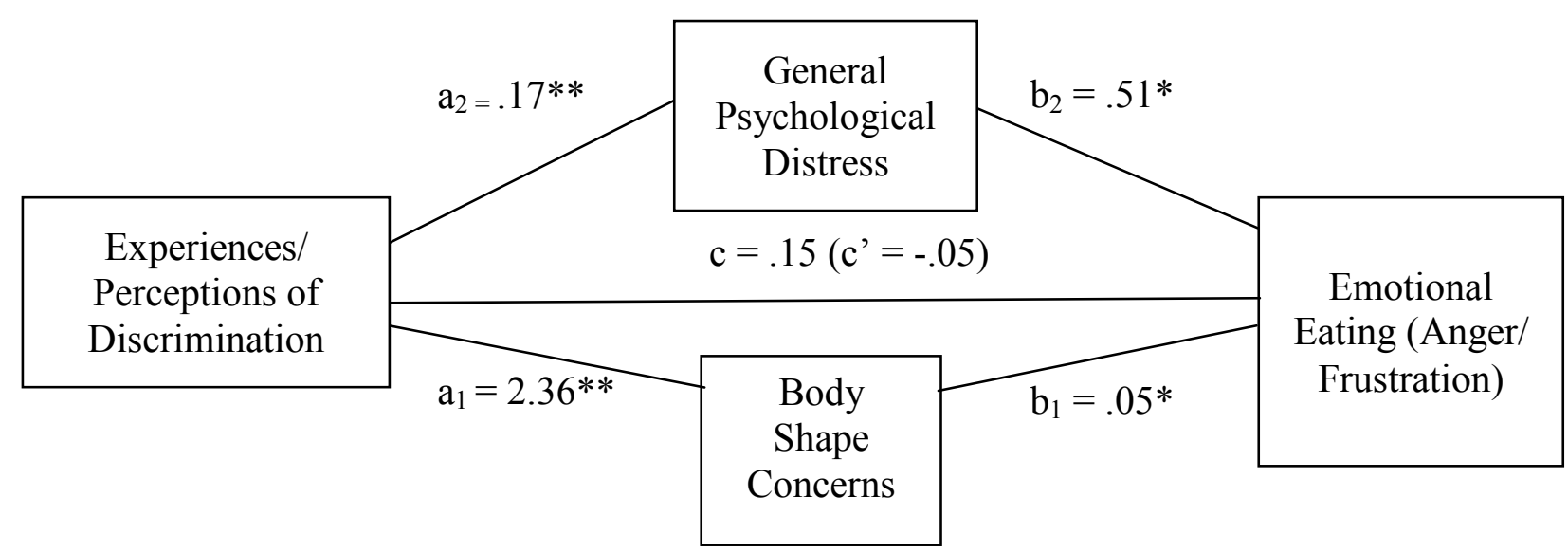

Figure 20. Unstandardized regression coefficients between experiences/perceptions of discrimination, potential mediators, and emotional eating (anger/frustration subscale) controlling age and BMI in the undergraduate sample. $\mathrm{c}=$ total effect; $\mathrm{c}^{\prime}=$ direct effect. $N=157$. $* p<0.05,{ }^{* *} p<0.01$.

The seventh mediation analysis examined the indirect effects of experiences/perceptions of discrimination on emotional eating - anxiety subscale through body shape concerns and general psychological distress, controlling for age and BMI (see Figure 21). The total effect was nonsignificant, $b=-.01, S E=.13, t(154)=-.04, p>.05$. Experiences/perceptions of discrimination had a significant total indirect effect on emotional eating- anxiety subscale through the combined distress variables, and a significant specific indirect effect on emotional eating- anxiety subscale through both body shape concerns and general psychological distress. The contrast between mediators was not significant (See Table 10). This effect can be interpreted as a suppression effect (See Figure 21). 


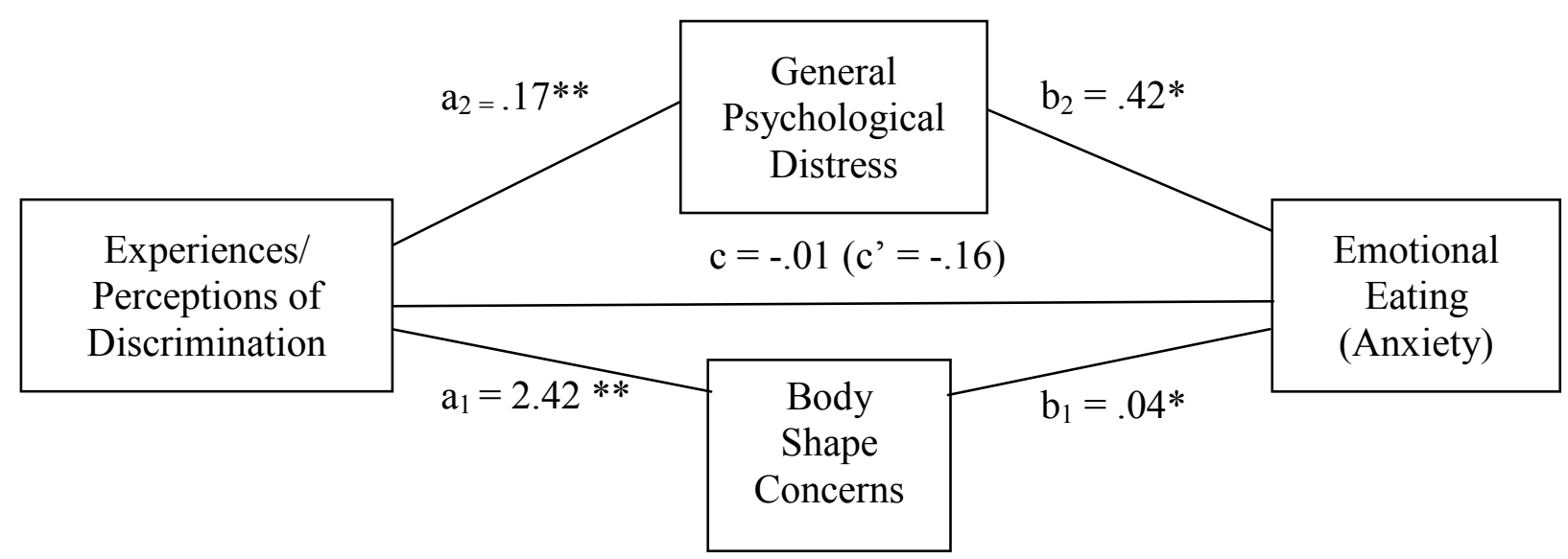

Figure 21. Unstandardized regression coefficients between experiences/perceptions of discrimination, potential mediators, and emotional eating (anxiety subscale) controlling age and BMI in the undergraduate sample. $\mathrm{c}=$ total effect; c' $=$ direct effect. $N=158$. $* p<.05, * * p<.01$.

The eighth mediation analysis examined the indirect effects of experiences/perceptions of discrimination on emotional eating-depression subscale through body shape concerns and general psychological distress, controlling for age and BMI (see Figure 22). The total effect was nonsignificant, $b=.06, S E=.09, t(154)=.69, p>.05$. Experiences/perceptions of discrimination had a significant total indirect effect on emotional eating- depression subscale through the combined distress variables, and a significant specific indirect effect on emotional eatingdepression subscale through body shape concerns, but not through general psychological distress. The contrast between mediators was nonsignificant (See Table 10). This effect can also be interpreted as a suppression effect (See Figure 22). 


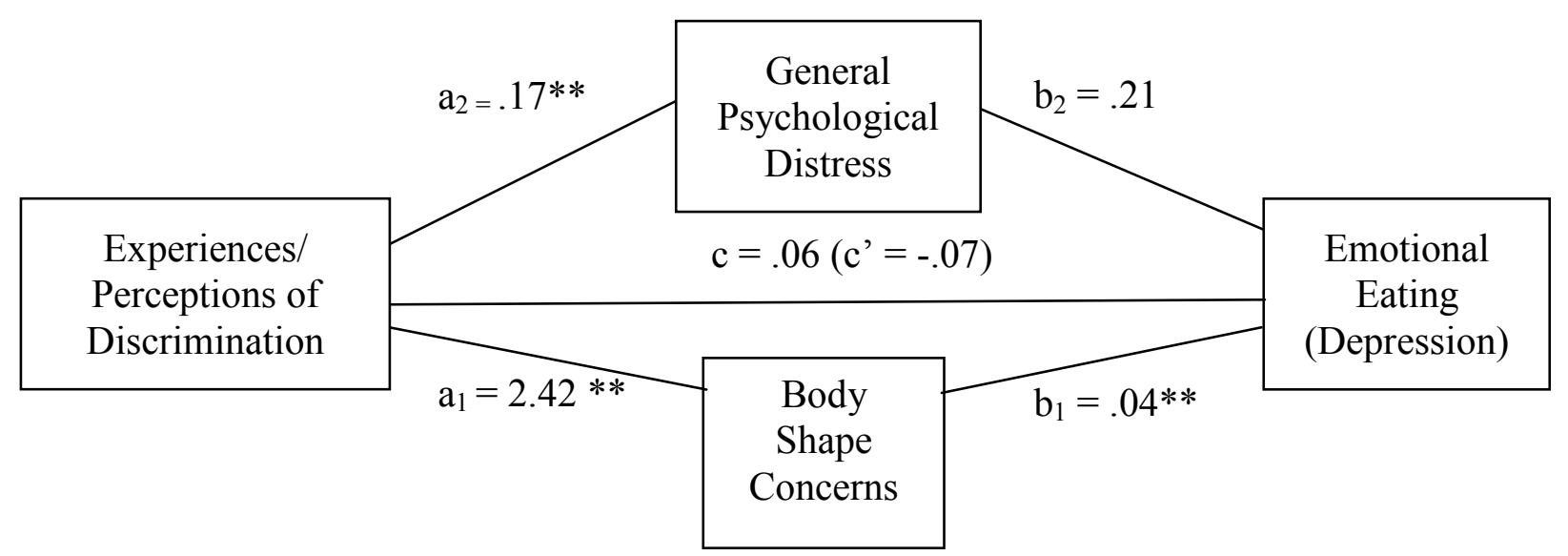

Figure 22. Unstandardized regression coefficients between experiences/perceptions of discrimination, potential mediators, and emotional eating (depression subscale) controlling for age and BMI in the undergraduate sample. $\mathrm{c}=$ total effect; $\mathrm{c}^{\prime}=$ direct effect. $N=158$. $* p<.05, * * p<.01$.

Weight Bias Internalization. The ninth mediation analysis examined the indirect effects of weight bias internalization on binge eating through body shape concerns and general psychological distress, controlling for age and BMI (see Figure 23). The total effect of weight bias internalization on binge eating was significant, $b=.32, S E=.03, t(153)=9.07, p<.0001$. Weight bias internalization had a significant total indirect effect on binge eating through the combined distress variables, as well as through both body shape concerns and general psychological distress. The contrast between mediators was significant, such that body shape concerns had a significantly greater indirect effect as compared to general psychological distress (See Table 11). 


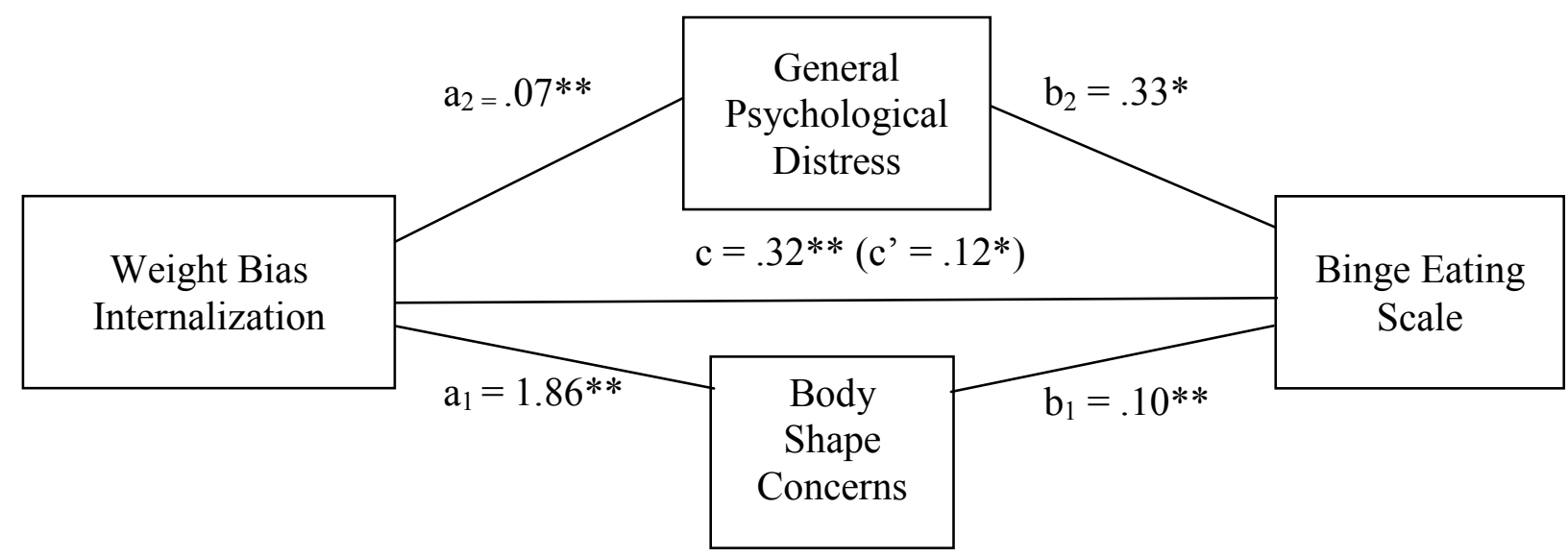

Figure 23. Unstandardized regression coefficients between weight bias internalization, potential mediators, and binge eating controlling for age and BMI in the undergraduate sample. $\mathrm{c}=$ total effect; c' $=$ direct effect. $N=157$.

$* p<.05, * * p<.01$.

The tenth mediation analysis examined the indirect effects of weight bias internalization on emotional eating - anger/frustration subscale through body shape concerns and general psychological distress, controlling for age and BMI (see Figure 24). The total effect of weight bias internalization on emotional eating- anger/frustration subscale was significant, $b=.15, S E=$ $.05, t(154)=3.01, p<.01$. Weight bias internalization had a significant specific indirect effect on emotional eating- anger/frustration subscale through general psychological distress, but not through body shape concerns or their combined total effects. The contrast between mediators was nonsignificant (See Table 11). 


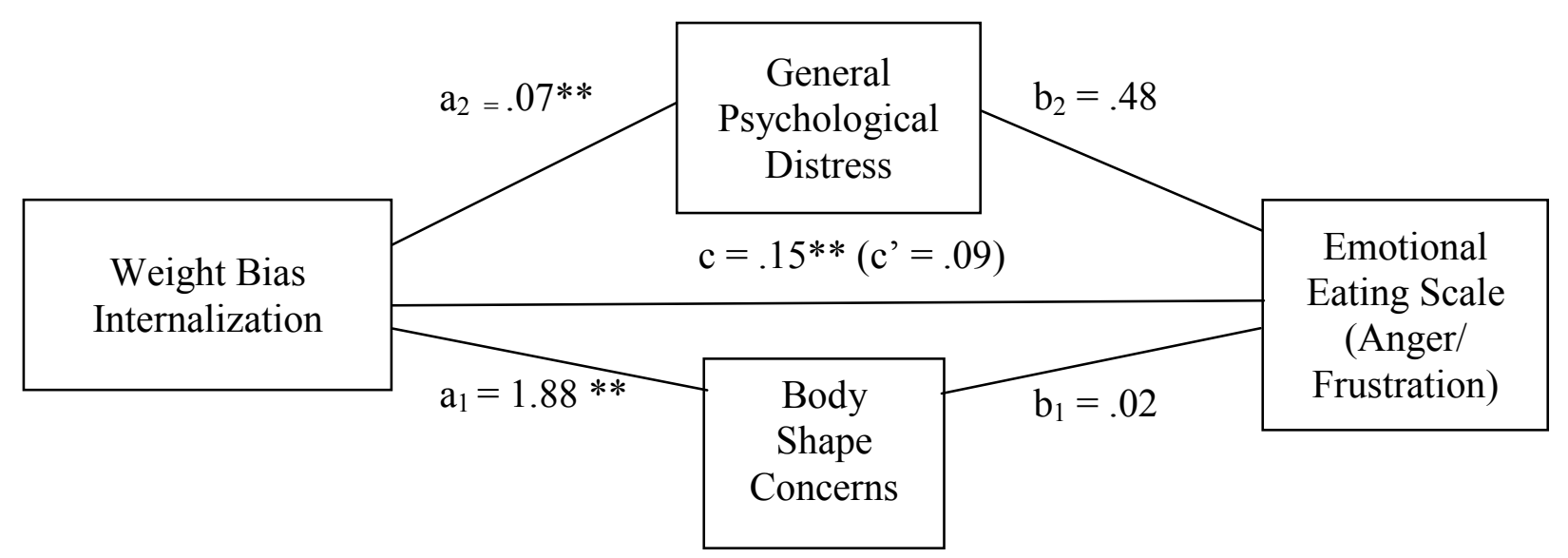

Figure 24. Unstandardized regression coefficients between weight bias internalization, potential mediators, and emotional eating (anger/frustration subscale) controlling for age and BMI in the undergraduate sample. $\mathrm{c}=$ total effect; c' $=$ direct effect. $N=158$. $* p<0.05, * * p<0.01$.

The eleventh mediation analysis examined the indirect effects of weight bias internalization on emotional eating - anxiety subscale through body shape concerns and general psychological distress, controlling for age and BMI (see Figure 25). The total effect of weight bias internalization on emotional eating- anxiety subscale was significant, $b=.12, S E=.04$, $t(155)=2.74, p<.01$. Weight bias internalization had a significant specific indirect effect on emotional eating- anxiety subscale through general psychological distress, but not through body shape concerns or their combined total effects. The contrast between mediators was nonsignificant (See Table 11). 


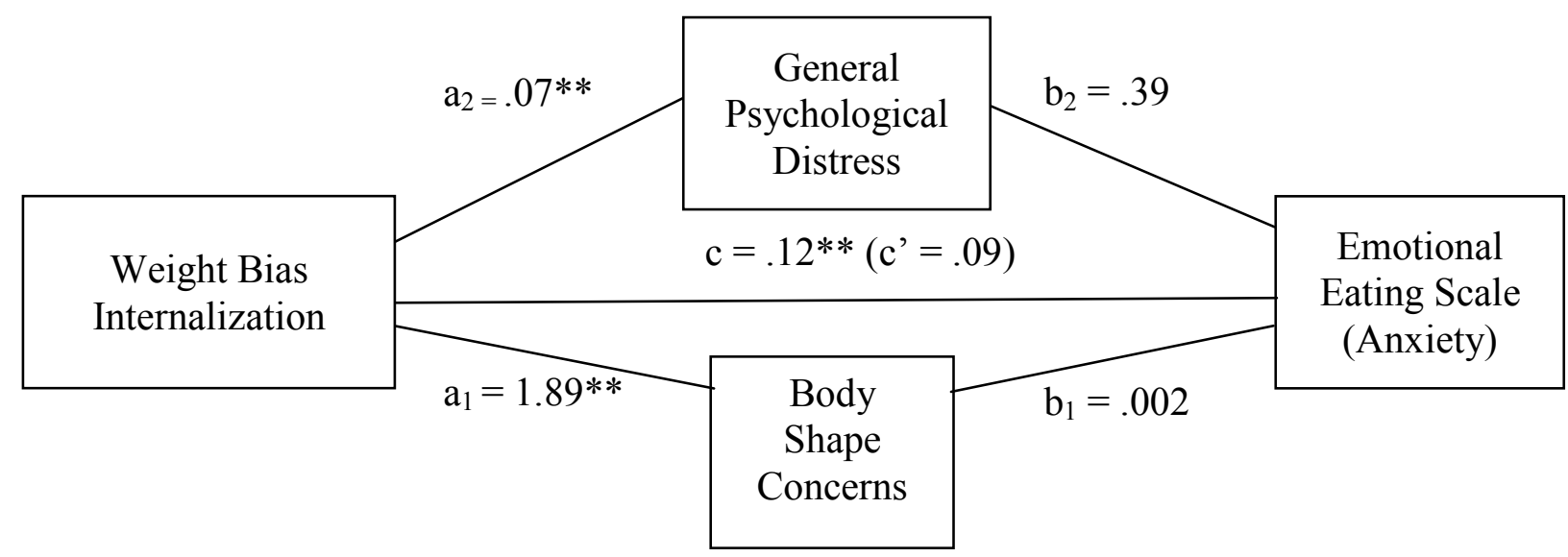

Figure 25. Unstandardized regression coefficients between weight bias internalization, potential mediators, and emotional eating (anxiety subscale) controlling for age and BMI in the undergraduate sample. $\mathrm{c}=$ total effect; c' $=$ direct effect. $N=159$. $*_{p}<0.05, * * p<0.01$.

The twelfth mediation analysis examined the indirect effects of weight bias internalization on emotional eating-depression subscale through body shape concerns and general psychological distress, controlling for age and BMI (see Figure 26). The total effect of weight bias internalization on emotional eating- depression subscale was significant, $b=.09, S E$ $=.02, t(155)=3.67, p<.001$. Weight bias internalization had a significant indirect effect on emotional eating- depression subscale through the combined distress variables as well as through a specific indirect effect of body shape concerns, but not through general psychological distress. The contrast between mediators was nonsignificant (See Table 11). 


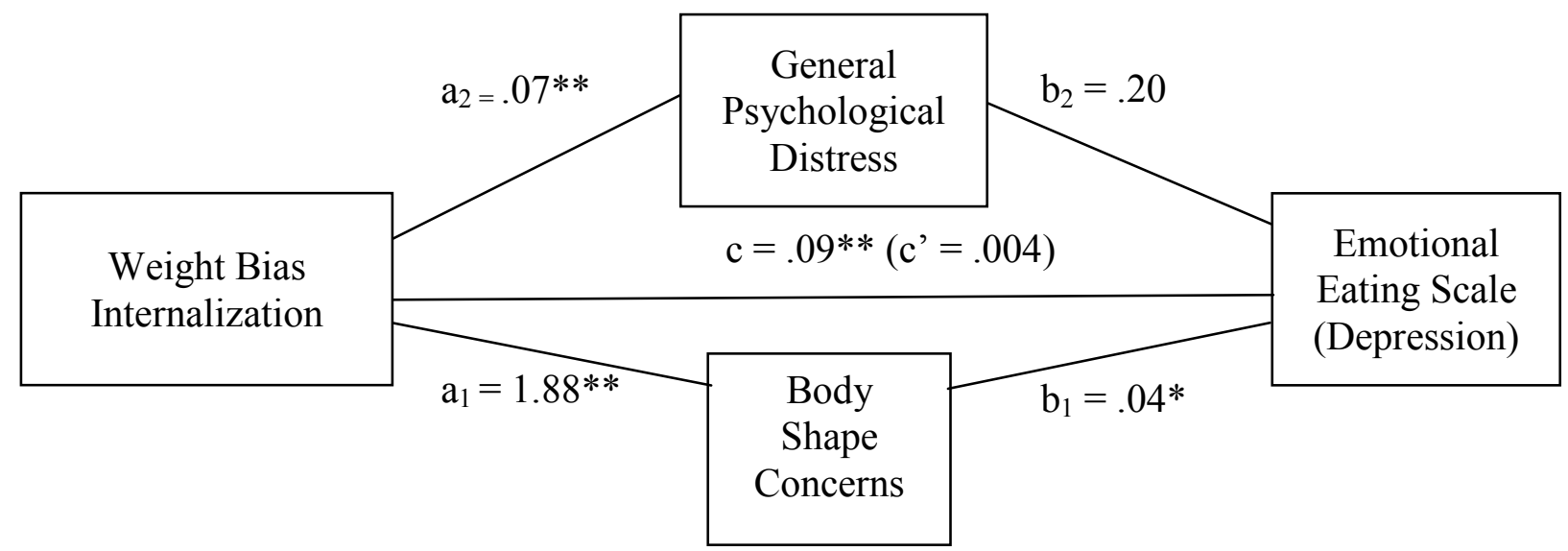

Figure 26. Unstandardized regression coefficients between weight bias internalization, potential mediators, and emotional eating (depression subscale) controlling for age and BMI in the undergraduate sample. $\mathrm{c}=$ total effect; c' $=$ direct effect. $N=159$. $* p<0.05, * * p<0.01$. 


\section{Chapter 4}

\section{Discussion}

The primary purpose of this study was to determine the effects of three facets of weightbased stigma/discrimination (weight stigma concerns, experiences/perceptions of discrimination, and weight bias internalization) on disordered eating in female bariatric surgery patients and undergraduate students, and the secondary purpose was to examine psychological distress variables as potential mediators of these relations across both samples. As such, this study represents a partial test of Tomiyama's (2014) COBWEBS model that posits that weight stigma/discrimination begets distress, which in turn predicts disordered eating.

\section{Summary of Descriptive and Correlational Results}

In partial support of the first hypothesis, there were significant, positive correlations between weight stigma concerns, binge eating and two facets of emotional eating (anger/frustration and anxiety) in both samples. Effect sizes were small to moderate for binge eating and small for emotional eating- anger/frustration and anxiety subscales (Cohen, 1992). Contrary to the hypothesis, weight stigma concerns were not significantly associated with the emotional eating- depression subscale in either sample. These findings suggest that individuals across both samples who report concerns regarding experiencing weight-based stigma appear to be at an elevated risk for both binge eating and emotional eating in response to anger/frustration and anxiety; however, this risk appears to be greater for binge eating.

In partial support of the second hypothesis, there were significant, positive correlations between experiences/perceptions of discrimination, binge eating, and two facets of emotional eating (anger/frustration and anxiety) in the bariatric sample. Effect sizes were moderate for binge eating and small for emotional eating (Cohen, 1992). In the undergraduate sample, 
experiences/perceptions of discrimination were significantly positively correlated with binge eating with a small effect size; however, the relation between experiences/perceptions of discrimination and all emotional eating subscales was nonsignificant. These findings suggest that obese individuals who perceive they have been discriminated against on the basis of their weight appear to be at a greater risk for binge eating in particular, as well as for emotional eating in response to anger/frustration and anxiety. In contrast, predominately normal-weight undergraduate students who report perceived weight-based discrimination appear to be at an elevated risk for binge eating, but not for emotional eating.

In support of the third hypothesis, there were significant, positive correlations between weight bias internalization, binge eating, and all three emotional eating subscales in both samples. Effect sizes were moderate for binge eating in both samples. Effect sizes for the emotional eating subscales were small to moderate in the bariatric sample, and small in the undergraduate sample. These findings demonstrate that across both samples, greater internalization of anti-fat attitudes is linked to higher rates of binge eating and emotional eating, with stronger relations across both samples with binge eating.

Taken together, these findings suggest that, consistent with some previous research (e.g., Pearl et al., in press), there appears to be differential relations between various measures of weight-based stigma/discrimination and disordered eating. There is, however, one key similarity that emerges: across both samples, relations between weight-based stigma/discrimination and binge eating were stronger than the relations between weight-based stigma/discrimination and emotional eating. As well, these results suggest that the strength and nature of the relation between weight-based stigma/discrimination and disordered eating may differ somewhat in clinical and non-clinical samples. In the present study, relations between weight-based 
stigma/discrimination and emotional eating were stronger in the bariatric sample than the undergraduate sample, suggesting that normal-weight and obese individuals who report experiencing weight-based stigma/discrimination may be at a similarly elevated risk for binge eating, but obese individuals may be at greater risk for emotional eating relative to normalweight individuals.

It is important to note that the correlation between weight bias internalization and body shape concerns was very high, $r_{s}{ }^{\prime} \mathrm{s}=.83$ and .80 in the bariatric and undergraduate samples, respectively, suggesting that these two scales may in fact be measuring the same underlying construct. Although an examination of the items on both scales did not uncover clear conceptual overlap with respect to specific items, it is important to note that the vast majority of the items on the Body Shape Questionnaire (Cooper et al., 1987) directly reference "feeling fat" or the desire to be thinner, which would be predicated upon internalizing negative stereotypes about individuals who are overweight or obese. In other words, in order to experience concern about one's body with respect to "feeling fat" or desiring to be thinner, these results suggest that individuals would have to demonstrate a high degree of weight bias internalization. Similarly, thin-ideal internalization, a related construct measuring the degree to which individuals internalize the Western ultra-thin ideal (Thompson, Heinberg, Altabe, \& Tantleff-Dunn, 1999), has been found to be highly correlated with the Body Shape Questionnaire (Cooper et al., 1987) in a Caucasian female undergraduate student sample ( $r=.76$; Warren, Gleaves, Cepeda-Benito, del Carmen Fernandez, Rodriguez-Ruiz, 2005). Future research is needed in order to further elucidate whether these two variables are measuring the same underlying construct.

With respect to mean differences between the two samples, the bariatric sample scored significantly higher on all measures aside from the PHQ-4, which assesses both depression and 
anxiety and was used as a measure of general psychological distress. Post hoc analyses were conducted using the GAD-7 and the PHQ-8 (the PHQ-4 is a derivative of these scales) in order to clarify this unexpected finding. These analyses revealed that the undergraduate population scored significantly higher on the GAD-7, but not on the PHQ-8, as compared to the bariatric sample, $p<.05$. In fact, the mean score on the GAD-7 within the undergraduate sample ( $M=$ 9.52, $S D=5.74$ ) was just below the cut-off score of 10 used to diagnose Generalized Anxiety Disorder using the GAD-7 (Spitzer et al., 2006). The mean score on the GAD-7 in the bariatric sample $(M=6.11, S D=5.83)$ was consistent with the mean GAD-7 score reported in female primary care patients ( $\mathrm{M}=6.10$; Spitzer et al., 2006), as well as with past research conducted with bariatric surgery patients at TWH $(M=5.58, S D=5.34$; Sockalingam et al., 2015).

Although this finding may appear to be paradoxical, there are a number of factors that may contribute to first-year university students' psychological distress, including transitioning to university, academic and socioeconomic pressures, and a lack of social support. Accordingly, previous research has demonstrated that undergraduate students report significant psychological distress, with one study reporting that about one-third of female first-year undergraduate students self-reported psychological distress that exceeded the cut-off score on a validated measure of psychological distress (The Mental Health Inventory-5; MHI-5; Verger et al., 2009). Psychological distress symptoms (e.g., depression, panic disorder, generalized anxiety disorder, and suicidal thoughts) are also significantly related to eating disorder symptoms in university students (e.g., Eisenberg, Nicklett, Roeder, \& Kirz, 2011). It is plausible that this high level of psychological distress may in part explain why the transition to university is considered to be a high-risk period for development of disordered eating (e.g., Delinsky \& Wilson, 2008). 


\section{Summary of Mediation Results}

With respect to the fourth hypothesis, interpretation of the mediation results was limited by the high correlations between mediators in the bariatric sample. The correlation between general psychological distress and body shape concerns in the bariatric sample was moderate to large, $r_{s}=.64$, whereas the correlation in the undergraduate sample was small, $r_{s}=.32$.

Accordingly, results for the bariatric sample were more difficult to interpret and more negatively impacted by multicollinearity. When multiple mediation is conducted, the indirect effect of a given mediator within a model is assessed while statistically controlling for the other mediator(s) within the model. In other words, when body shape concerns, for example, is assessed as a potential mediator, general psychological distress is held constant. When mediators have moderate to high correlations, the standard error estimates and power required to detect specific indirect effects are negatively impacted (Hyun, Trudeau \& Shin, 2014). As multicollinearity increases, so too does sampling variance, which in turn increases the width of the confidence intervals reported for mediation and increases the magnitude of the $p$-values (Hayes, 2013). Multicollinearity can potentially account for a number of the inconsistent findings throughout the study. For example, a combined total effect for mediation emerged as significant in a number of the models without any significant specific indirect effects. When mediators are highly correlated within the model, greater sampling variance impacts the ability to detect a specific indirect effect; however, the combined total of multiple effects (i.e., body shape concerns and general psychological distress) will have a greater effect size and thus increased power to detect a significant effect.

High correlations between the independent variables and the mediators (path $a$ ) are also relevant in the context of mediation. The indirect effect (i.e., mediated effect) is a product of 
paths $a$ and $b$ (i.e., $a b$ ), and as such, the more variance accounted for by the relation between the independent variable and the mediator, the less variance there is in the mediator to predict the dependent variable. In other words, the power to detect an indirect effect decreases as the correlation between the independent variable and the mediator increases (Hoyle \& Kenny, 1999). Hayes (2013) indicates that specific indirect effects are theoretically more meaningful when interpreting mediation, and thus, the following summary of the mediation results will focus primarily on specific indirect effects rather than combined total effects.

Weight Stigma Concerns. Across both samples, body shape concerns emerged as a significant mediator in the relation between weight stigma concerns and binge eating, suggesting that body shape concerns can in part account for this relation. Although general psychological distress also emerged as a significant mediator in the undergraduate sample in the relation between weight stigma concerns and binge eating, the indirect effect of body shape concerns had a significantly larger effect size, suggesting that body shape concerns is a more relevant explanatory mechanism in this model.

These findings suggest that body shape concerns in particular may in part explain the relation between weight stigma concerns and binge eating for women in both samples. Although this study was the first to examine body shape concerns as a mediator between weight-based stigma/discrimination and disordered eating, this finding is in line with some preliminary research evidence. For example, holding BMI constant, Friedman and colleagues (2005) found that weight stigma experiences significantly predicted greater body shape concerns in an obese, treatment-seeking adult sample. Similarly, following exposure to a weight-stigmatizing news article, women who self-perceived themselves as being overweight consumed significantly more calories than women who were exposed to a control news article (Major et al., 2014). 
Furthermore, these findings suggest that similar to research conducted in other domains of stigma (e.g., race, sexual orientation), simply suspecting or anticipating the potential for stigma can lead to detrimental outcomes. For example, in a sample of men and women who identified as either gay, lesbian, or bisexual, greater stigma consciousness (a related construct measuring the degree to which minority group members' expect to be stereotyped on the basis of their minority group status; Pinel, 1999) was associated positively with depressive symptoms (Lewis, Derlega, Griffin, \& Krowinski, 2003), suggesting that the expectation of experiencing stigma can produce negative psychological outcomes.

With respect to the emotional eating subscales in the bariatric sample, body shape concerns emerged as a significant mediator in the relation between weight stigma concerns and the emotional eating- anger/frustration subscale; however, there were no additional specific indirect effects for the emotional eating subscales. In the undergraduate sample, general psychological distress emerged as a significant mediator in the relation between weight stigma concerns and emotional eating- anger/frustration and anxiety subscales. However, upon a closer examination of the results, the effect sizes for general psychological distress are actually smaller than the effects for body shape concerns, despite body shape concerns emerging as nonsignificant (See Table 9). This phenomenon can result from multicollinearity between the independent variable and the mediator. Controlling for age and BMI, the partial correlation between weight stigma concerns and body shape concerns is moderate, $r_{s}=.53$; whereas the partial correlation between weight stigma concerns and general psychological distress is substantially smaller, $r_{s}=.23$. Given that the power to detect an indirect effect decreases as the correlation between the independent variable and the mediator increases (Hoyle \& Kenny, 1999), multicollinearity could potentially account for these paradoxical findings. 
Lastly, there was some evidence of suppression in the relation between body shape concerns and the emotional eating-depression subscale in the undergraduate sample. An effect is considered to be a suppression effect, as compared to a mediation effect, according to the following criteria: (a) the magnitude of the indirect effect $(a b)$ increases after inclusion of the mediator when compared to the total effect $c$, such that the predictive validity of a variable (i.e., emotional eating-depression) increases when a mediator (i.e., body shape concerns) is included in the model, and (b) The direct (c') and indirect effects also have different signs (MacKinnon et al., 2000). Conversely, this finding may also have emerged due to the lack of zero-order correlation between weight stigma concerns and the emotional eating-depression subscale, suggesting that there may not be an actual relation to mediate.

Taken together, these results demonstrate that across both samples, body shape concerns emerged as a significant explanatory mechanism in the relation between weight stigma concerns and binge eating. There was some evidence of mediation in the relation between weight stigma concerns and the emotional eating subscales across both samples; however, multicollinearity strongly impacted interpretation of these results.

Experiences/Perceptions of Discrimination. In the bariatric sample, body shape concerns emerged as a significant suppressor variable in the relation between experiences/perceptions of discrimination and binge eating. In other words, instead of body shape concerns reducing the total effect between experiences/perceptions of discrimination and binge eating, the total effect increased, suggesting that including body shape concerns in the model with experiences/perceived discrimination as an independent variable and binge eating as a dependent variable strengthened the relation between these two variables. In the undergraduate sample, body shape concerns and general psychological distress emerged as significant 
mediators in the relation between experiences/perceptions of discrimination and binge eating, suggesting that both of these variables, in particular body shape concerns, are relevant explanatory mechanisms in this relation. These findings suggest that body shape concerns and psychological distress may in part account for the relation between experiences/perceptions of discrimination and binge eating in undergraduate females.

For the emotional eating subscales, body shape concerns was a significant mediator for all subscales in the bariatric sample, with some evidence of possible suppression in the depression subscale only. Similarly, there was some evidence of possible suppression in the undergraduate sample as well for all emotional eating subscales. However, these effects may also be interpreted as emerging due to the lack of zero-order relation between experiences/perceptions of discrimination and the emotional eating subscales in the undergraduate sample, suggesting that there may not be any relation to mediate.

This is the first research study to examine mediators of the relation between experiences/perceptions of discrimination and binge/emotional eating; however, these findings do reflect some previous research. In a community sample of normal-weight, overweight, and obese adults (about $80 \%$ women), Durso and colleagues (2012) found that participants who had reported at least one major weight-related discriminatory event (either an institutional or interpersonal event, irrespective of weight status) reported significantly greater emotional eating scores as compared to participants who did not report discriminatory treatment. Similarly, across the entire sample, interpersonal discrimination and discrimination impact (items measuring the extent of impact the discrimination had on the participant) were significantly correlated with emotional eating and binge eating frequency at both 3 and 6 months. Institutional discrimination was significantly positively correlated with emotional eating scores and binge frequency at 3 
months, but not at 6 months. Effect sizes for emotional eating and binge eating frequency were highest for interpersonal discrimination, suggesting that this variable may be particularly relevant in the context of disordered eating. Unlike Durso and colleagues' (2012) findings, experiences/perceptions of discrimination in the current study were not significantly correlated with any of the emotional eating subscales in the undergraduate sample. However, it is important to note that the Emotional Eating Scale (Arnow et al., 1995) was examined as a total score, and not by subscale scores, in Durso and colleagues' (2012) study, which could explain the differential outcomes. Also, about $60 \%$ of their sample self-reported as being overweight or obese, which may have impacted the outcomes. Furthermore, the measure used to assess perceived discrimination in the current study (Experiences/Perceptions of Discrimination; Hunger \& Major, 2015), appears to measure interpersonal, rather than institutional discrimination; however, it is plausible that some of the items could be interpreted by participants as relating exclusively to institutional-based settings (i.e., being teased and harassed at the workplace in particular). Separation of institutional and interpersonal discrimination in future research studies may help to further elucidate any differential outcomes.

Taken together, these results demonstrate that body shape concerns appear to be the more relevant explanatory mechanism in the relation between experiences/perceptions of discrimination and emotional eating- anger/frustration and anxiety in the bariatric sample, and binge eating in the undergraduate sample. Additionally, these results highlight a key difference between the bariatric and undergraduate samples; although there are moderate correlations between experiences/perceptions of discrimination and binge eating in both samples, body shape concerns functions as a mediator variable in the undergraduate sample and as a suppressor variable in the bariatric sample. In other words, body shape concerns helps to account for some 
of the relation between experiences/perceptions of discrimination and binge eating in the undergraduate sample, whereas it further increases the relation between these two variables in the bariatric sample.

Weight Bias Internalization. With respect to the bariatric sample, there were no specific indirect effects for any of the outcome variables. These results may suggest that neither body shape concerns nor general psychological distress are relevant explanatory mechanisms in the relation between weight bias internalization and binge/emotional eating; however, this finding may also be accounted for by the high degree of multicollinearity between weight bias internalization and body shape concerns negatively influencing the sampling variance $\left(r_{\mathrm{s}}\right.$ 's $\left.>.80\right)$.

In the undergraduate sample, body shape concerns and general psychological distress emerged as significant mediators in the relation between weight bias internalization and binge eating, with the indirect effect of body shape concerns being significantly larger. For the Emotional Eating Scale (Arnow et al., 1995) in the undergraduate sample, general psychological distress emerged as a significant mediator in the relation between weight bias internalization and the anger/frustration and anxiety subscales. In contrast, body shape concerns emerged as a significant mediator in the relation between weight bias internalization and the emotional eatingdepression subscale. In other words, general psychological distress may in part explain the relation between weight bias internalization and emotional eating in response to anger/frustration and anxiety, whereas body shape concerns may account for this relation with respect to emotional eating in response to depression. These results may be interpreted as suggesting that body shape concerns and general psychological distress appear to be relevant mediators in the relation between weight bias internalization and disordered eating; however, the high degree of multicollinearity between weight bias internalization and body shape concerns may have 
impacted these results.

Research to date regarding the relation between weight bias internalization and disordered eating suggests that both body shape concerns and psychological distress may be relevant explanatory mechanisms in this relation. With respect to concerns about body shape, overevaluation of shape and weight mediated the relation between weight bias internalization and self-esteem in a sample of obese adults with Binge Eating Disorder (Pearl et al., 2014b), highlighting that appearance-related distress may be an important explanatory mechanism in the relation between weight bias internalization and psychological outcomes. Furthermore, some previous research studies with weight bias internalization have in fact identified general psychological distress as a relevant variable in the relation between weight-bias internalization and binge eating. For example, weight bias internalization has been found to be associated positively with psychological distress and increased binge eating episodes in obese adolescents seeking bariatric surgery (Roberto et al., 2012), however, the relation between dietary restraint and binge eating episodes was not significant. This finding suggests that similar to the present study, it is plausible that individuals may be responding to the psychological distress associated with weight stigma by binge eating. To date, one study has found depression to be a significant mediator in the relation between weight-bias internalization and poorer mental health in a group of treatment-seeking adults with BED (Pearl et al., 2014a); however, the reverse relation with weight-bias internalization as a mediator was also significant, suggesting a reciprocal relation between these variables.

In light of these research findings, the nonsignificant mediation results for weight bias internalization within the present study (in particular in the bariatric sample) should be interpreted as being highly impacted by multicollinearity. In other words, consistent with 
Tomiyama's (2014) model, psychological distress variables may in fact still be relevant explanatory mechanisms in the relation between weight bias internalization and disordered eating.

It is also plausible that weight bias internalization may function as a mediator between weight-based stigma/discrimination and disordered eating, as opposed to being considered an independent variable within Tomiyama's (2014) model. In addition to the aforementioned study by Pearl and colleagues (2014) that found a reciprocal relation between depression, weight bias internalization and mental health, Pearl, Puhl and Dovidio (in press) found that weight bias internalization partially mediated the relation between weight stigma experiences and exercise behaviour in a sample of overweight and obese women. Similarly, Durso and colleagues (2012) found that among overweight and obese participants, weight bias internalization partially mediated the relation between perceived interpersonal discrimination and eating disturbance (a latent variable comprising binging and purging behaviours, emotional eating, restrictive eating, and weight-related cognitions), suggesting that individuals who perceive they have been discriminated against on the basis of their weight in interpersonal situations may be protected from the negative eating-related outcomes if do not internalize the negative anti-fat attitudes. With respect to Tomiyama's (2014) model, weight bias internalization may act as a psychological distress variable resulting from experiencing weight-based stigma/discrimination. Accordingly, weight bias internalization and body shape concerns were highly correlated in both samples, suggesting that these variables may in fact represent the same, or very similar, construct.

Taken together, mediation results for the weight bias internalization scale were very difficult to interpret given the high correlation between body shape concerns and weight bias 
internalization. These findings may also suggest that body shape concerns and general

psychological distress are important explanatory mechanisms in the relation between weight bias internalization and disordered eating; however, future research is needed in order to further elucidate this relation given the impact of multicollinearity in both samples.

\section{General Implications}

The present study has a number of implications. Across both samples, individuals who reported weight based stigma concerns, perceived they have been discriminated against on the basis of their weight, and/or internalized anti-fat attitudes appeared to be at an elevated risk for binge eating. Risk for greater emotional eating was dependent upon the specific weight-based stigma/discrimination variable and the sample in which it was examined, suggesting that correlational effects were overall more robust across both samples with binge eating. When comparing the results between binge eating and the emotional eating subscales across both samples, it is important to note the distinctions in content between the two scales. The Binge Eating Scale (Gormally et al., 1982) is a measure of both emotional/cognitive and behavioural symptoms associated with binge eating, whereas the Emotional Eating Scale (EES; Arnow et al., 1995 ) assesses individuals' urges to eat in response to experiencing particular emotions. In other words, the BES measures actual binge eating behaviours (in addition to cognitive/emotional symptoms associated with these behaviours), whereas the EES measures the desire to eat emotionally. Given that individuals may experience urges to eat in response to certain emotions but not necessarily respond to these urges by eating, utilizing a behavioural measure of emotional eating may have yielded different results. For example, three items on the ThreeFactor Eating Questionnaire (Stunkard \& Messick, 1985) have previously been analyzed as a separate subscale measuring a more behavioural manifestation of emotional eating (e.g., "When I 
feel anxious, I find myself eating”; Anglé et al., 2009; de Lauzon et al., 2004; Karlsson, Persson, Sjöström, \& Sullivan, 2000). Future researchers should examine whether distinguishing between desire to eat emotionally, and actual emotional eating produces differential results.

Furthermore, these findings represent the first partial test of Tomiyama's (2014) COBWEBS model that posits that obesity/weight-based stigma produces stress, which in turn predicts increased eating. Within the context of this study, body shape concerns emerged as the most consistent mediator between weight-based stigma/discrimination and disordered eating, in particular when binge eating was included as a dependent variable. Although body shape concerns in particular is not explicitly mentioned in Tomiyama's (2014) model, this finding suggests that appearance-related distress may be an important component within Tomiyama's conceptualization of stress.

Interestingly, BMI was not significantly correlated with any of the study variables in the bariatric sample despite the large range in BMI (35.39 to $\left.73.36 \mathrm{~kg} / \mathrm{m}^{2}\right)$. In the undergraduate sample, BMI was significantly positively correlated with weight bias internalization, body shape concerns, and binge eating, such that individuals with higher BMIs reported higher scores on these measures. Given that participants seeking bariatric surgery can expect to lose approximately $60-70 \%$ of their excess body weight (Buchwald, Avidor, Braunwald, Jensen, Fahrbach, \& Schoelles, 2004), most participants with higher BMIs prior to surgery will continue to be considered obese post-surgery. These findings suggest that once an individual reaches a particular weight threshold (i.e., exceeds the BMI cut-off for extreme obesity), actual BMI becomes less relevant in predicting weight-based stigma/discrimination and psychological distress. Accordingly, in a recent longitudinal study conducted by Mitchell and colleagues (2014) with adults who underwent bariatric surgery, depressive symptoms significantly improved at 1- 
year post-surgery; however, there was a recurrence in depressive symptoms at the 3-year mark (albeit depressive symptoms were still significantly lower than pre-surgery levels). It is plausible that continued weight-based stigma/discrimination experiences could contribute to persistence or recurrence of depressive symptoms post-surgery. Furthermore, BMI was negatively correlated with general psychological distress in the undergraduate sample, such that individuals with lower BMIs were experiencing greater psychological distress. This finding comes in direct opposition with commonly-held beliefs that the ultra-thin ideal body type is associated with positive life success (e.g., Evans, 2003), and instead, suggests that being thinner may actually lead to more deleterious emotional outcomes with respect to psychological distress.

A final implication of this study is that consistent with Tomiyama's (2014) assertion that individuals do not need to be objectively overweight to enter the COBWEBS cycle, mediation results emerged in both the bariatric and undergraduate samples. Body shape concerns in particular emerged as the most relevant explanatory mechanism in the relation between weightbased stigma/discrimination and disordered eating across both the samples, providing preliminary evidence that Tomiyama's (2014) model may hold in clinical and non-clinical populations. Given that body shape concerns was the most relevant explanatory mechanism, this study also provides preliminary data suggesting that body shape concerns may be an appropriate treatment target for both female undergraduate students and obese women, such that by reducing their body shape and weight concerns, it is plausible that the relation between weight-based stigma/discrimination and disordered eating outlined by Tomiyama's (2014) COBWEBS model may be attenuated.

\section{Limitations}

This study has a number of strengths. First, this study included three different measures 
of weight-based stigma/discrimination (weight stigma concerns, experiences/perceptions of discrimination, and weight bias internalization) and two measures of disordered eating (binge eating, emotional eating) within the same research study, which allowed for examination of differential outcomes. Second, this study found evidence for experiences of weight-based stigma/discrimination and disordered eating across both normal-weight and obese samples, thereby contributing to an ongoing body of research suggesting that weight stigma is not exclusive to objectively overweight or obese individuals. Lastly, this study represents the first explicit test of a component of Tomiyama's (2014) model, in which body shape concerns appears to be the most relevant explanatory mechanism underlying the relation between weightbased stigma/discrimination and disordered eating in both samples.

However, the study findings must be interpreted in light of several limitations. First, as mentioned previously, interpretation of the mediation results was limited by a high degree of multicollinearity between measures, resulting in increased sampling variance and decreased power to detect significant indirect effects (Hayes, 2013).

Second, with respect to Tomiyama's (2014) COBWEBS model, the Binge Eating Scale (Gormally et al., 1982) and the Emotional Eating Scale (Arnow et al., 1995) were included as measures of "increased eating". As described earlier, the Emotional Eating Scale measures individuals' desire to eat in response to specific emotions, rather than an actual behavioural manifestation of emotional eating. Thus, it is possible that this measure may not be the most appropriate measure to include when testing the COBWEBS model; however, given the significant positive correlations between the emotional eating subscales and binge eating in both samples, it is likely that many individuals who were experiencing the urge to eat emotionally were responding to this urge by eating to some extent. Similarly, the COBWEBS model does not 
specifically account for suspected or anticipated weight stigma (Hunger et al., in press); however, these findings suggest that similar to research in other non-weight stigma domains (e.g., sexual orientation), concerns regarding experiencing stigma are associated positively with negative psychological- and eating-related outcomes.

Third, within the undergraduate sample, students self-selected to participate in this study based on a study description addressing weight-based stigma, eating behaviours, and psychological distress. Thus, it is plausible that the students who chose to participate may not be an accurate representation of the general female undergraduate sample. Furthermore, given that this undergraduate sample demonstrated GAD-7 scores that far exceeded the mean in the general population (Lowe et al., 2008), the female undergraduate students in this sample may demonstrate a significantly greater level of anxiety-related psychological distress as compared to the greater population of female undergraduate students.

Fourth, only female participants were included in the present study, which does not allow for gender-based comparisons in the relation between weight-based stigma/discrimination and disordered eating. Given that women experience higher rates of disordered eating (StriegelMoore et al., 2009), greater weight-based discrimination (Puhl et al., 2008), and bariatric surgery samples are comprised of approximately $80 \%$ females (Sockalingam et al., 2013), there was a clear rationale for restricting participation in this study to female participants.

Lastly, there are some limitations associated with the specific data analytic method employed within the present study. When using a macro such as PROCESS to test for mediation in SPSS, the researcher is constrained by the specific models available in the program (Hayes, 2013). For example, PROCESS does not allow for simultaneous testing of both parallel and serial mediation. In order to evaluate additional components of Tomiyama's (2014) model; for 
example, that experiencing weight-based stigma/discrimination predicts body shame, which in turn predicts increased cortisol secretion and increased eating, a different data analytic plan that allows the researcher to configure their desired models (e.g., Structural Equation Modelling; SEM) would need to be employed. Additionally, SEM programs also provide measures of model fit to allow for comparisons between specific models, which is particularly relevant with respect to validating a model across two different samples. SEM programs would therefore provide researchers with specific indices of model fit that could be used to validate whether the same mediational model demonstrated good model fit across the weight spectrum (Hayes, 2013).

\section{Future Directions}

The present study highlights a number of important future directions. First, additional research should examine the relation between body shape concerns and weight bias internalization in both clinical and non-clinical samples to determine whether these variables indeed represent the same underlying constructs. Second, various facets of weight-based stigma/discrimination should continue to be examined within the same research studies, as these constructs are often confounded in the literature and may in fact result in differential outcomes as seen in the present study. Similarly, various facets of disordered eating should be explored, in particular a behavioural manifestation of emotional eating. Third, a comprehensive, longitudinal study including both questionnaire-based and physiological measures (i.e., cortisol secretions) should be conducted in order to examine additional components of Tomiyama's (2014) COBWEBS model. For example, a longitudinal design would allow researchers to evaluate the cyclical nature of this theory, in particular whether weight stigma/discrimination predicts actual weight gain through the indirect effects of distress and increased eating/increased cortisol, which in turn heightens the level of weight stigma/discrimination experienced. Lastly, these results 
should be replicated with additional clinical and non-clinical samples and using different measures of the same constructs in order to further examine body shape concerns and general psychological distress as potential mediators in this relation. This research may help to determine whether body shape concerns and/or general psychological distress might be effective treatment targets to reduce disordered eating in clinical and non-clinical populations who endorse weightbased stigma/discrimination.

\section{Conclusions}

The current study examined the relation between various facets of weight-based stigma/discrimination (weight stigma concerns, experiences/perceptions of discrimination, and weight bias internalization) with disordered eating (binge eating, emotional eating) across two samples: a bariatric sample of obese female bariatric surgery-seeking patients, and a group of female undergraduate students. Second, this study also examined potential psychological distress mechanisms (body shape concerns, general psychological distress) underlying this relation as a partial test of Tomiyama's (2014) COBWEBS model. Correlational results revealed that individuals who reported weight-based stigma concerns, perceived that they have been discriminated against on the basis of their weight, and/or internalized anti-fat attitudes were at an elevated risk for binge eating across both samples. In addition, body shape concerns emerged as the most relevant explanatory mechanism in the relation between weight-based stigma/discrimination and disordered eating across both samples. Results in both samples were limited in part by the high correlation between certain variables such weight bias internalization and body shape concerns (i.e., multicollinearity). Overall, the study results provide preliminary support for Tomiyama's COBWEBS model, suggesting that weight stigma/discrimination predicts distress, which in turn predicts disordered eating. Future research is needed in order to 
test additional components of this theoretical model, as well as to determine whether body shape concerns and/or general psychological distress would be appropriate treatment targets to reduce disordered eating in women endorsing weight-based stigma/discrimination. 
Appendix A: Weight Stigma Concerns (Hunger \& Major, 2015)

WSC

Please indicate your agreement or disagreement with the following statements:

1) I am concerned that other people's opinion of me will be based on my weight.

Strongly

Neutral

Strongly

Disagree

1

2

3

4

5

6

Agree

2) I am afraid that other people will reject me because of my weight.

Strongly

Neutral

Strongly

Disagree

1

2

3

4

5

Agree

7

3) I am worried that most people will judge me on the basis of my weight.

Strongly

Neutral

Strongly

Disagree

Agree

1

2

3

4

5

7

4) I am concerned that I will not be treated fairly by others because of my weight.

Strongly

Disagree

1

2

Neutral

Strongly

Agree

7

5) I am concerned that others will not respect me because of my weight.

Strongly

Neutral

Strongly

Disagree

1

2

3

4

5

6

Agree

7 


\section{Appendix B: Experiences/Perceptions of Discrimination (Hunger \& Major, 2015)}

\section{$\underline{(\mathbf{E} / \mathbf{P D})}$}

In the past 12 months, how often have:

1) You been treated differently than others because of your weight?

$\begin{array}{cccccc}\text { Never } & \text { Rarely } & \text { Sometimes } & \text { Often } & \text { Usually } & \text { Always } \\ 1 & 2 & 3 & 4 & 5 & 6\end{array}$

2) You been treated with less respect than other people because of your weight?

$\begin{array}{cccccc}\text { Never } & \text { Rarely } & \text { Sometimes } & \text { Often } & \text { Usually } & \text { Always } \\ 1 & 2 & 3 & 4 & 5 & 6\end{array}$

3) Other people treated you unfairly because of your weight?

$\begin{array}{cccccc}\text { Never } & \text { Rarely } & \text { Sometimes } & \text { Often } & \text { Usually } & \text { Always } \\ 1 & 2 & 3 & 4 & 5 & 6\end{array}$

4) People acted as if they are better than you because of your weight?

$\begin{array}{cccccc}\text { Never } & \text { Rarely } & \text { Sometimes } & \text { Often } & \text { Usually } & \text { Always } \\ 1 & 2 & 3 & 4 & 5 & 6\end{array}$

5) You have been teased or harassed because of your weight?

$\begin{array}{cccccc}\text { Never } & \text { Rarely } & \text { Sometimes } & \text { Often } & \text { Usually } & \text { Always } \\ 1 & 2 & 3 & 4 & 5 & 6\end{array}$


Appendix C: Modified Weight Bias Internalization Scale (WBIS; Durso \& Latner, 2008)

\section{WBIS}

Please rate how much you agree or disagree with each of the following statements:

1) As much as I weigh, I feel that I am just as competent as anyone.

Strongly

Neutral

Strongly

Disagree

Agree

1

2

3

4

5

7

2) I am less attractive than most other people because of my weight.

Strongly

Neutral

Strongly

Disagree

1

2

3

4

5

Agree

7

3) I feel anxious about my weight because of what people might think of me.

Strongly

Neutral

Strongly

Disagree

1

2

3

4

5

6

Agree

4) I wish I could drastically change my weight.

Strongly

Neutral

Strongly

Disagree

1

2

3

4

5

6

Agree

7

5) Whenever I think a lot about my weight, I feel depressed.

Strongly

Disagree

1

2

3

Neutral

Strongly

Agree

4

5

6

7 
6) I hate myself for my weight.

$\begin{array}{cccccc}\begin{array}{c}\text { Strongly } \\ \text { Disagree }\end{array} & & \text { Neutral } & & & \begin{array}{c}\text { Strongly } \\ \text { Agree }\end{array} \\ 1 & 2 & 3 & 4 & 5 & 6\end{array}$

7) My weight is a major way that I judge my value as a person.

Strongly

Neutral

Strongly

Disagree

1

2

3

4

5

Agree

8) I don't feel that I deserve to have a really fulfilling social life, because of my weight.

Strongly

Disagree

1

2

3

Neutral

Strongly

Agree

4

5

6

7

9) I am OK being the weight that I am.

Strongly

Neutral

Strongly

Disagree

Agree

1

2

3

4

5

6

7

10) Because of my weight, I don't feel like my true self.

Strongly

Neutral

Strongly

Disagree

Agree

1

2

3

4

5

6

7

11) Because of my weight, I don't understand how anyone attractive would want to date me.

Strongly

Disagree

1
2
Neutral

4
Strongly

Agree

7 
Appendix D: Patient Health Questionnaire for Anxiety and Depression- 4 (PHQ-4;

Kroenke et al., 2009)

\section{PHQ-4}

Over the last 2 weeks, how often have you been bothered by any of the following problems? Please circle the appropriate number.

\begin{tabular}{lcccc}
\hline & $\begin{array}{c}\text { Not at } \\
\text { all }\end{array}$ & $\begin{array}{c}\text { Several } \\
\text { days }\end{array}$ & $\begin{array}{c}\text { More than } \\
\text { half the days }\end{array}$ & $\begin{array}{c}\text { Nearly } \\
\text { every } \\
\text { day }\end{array}$ \\
\hline 1. Little interest or pleasure in doing things & 0 & 1 & 2 & 3 \\
2. Feeling down, depressed, or hopeless & 0 & 1 & 2 & 3 \\
3. Feeling nervous, anxious or on edge & 0 & 1 & 2 & 3 \\
4. Not being able to stop or control worrying & 0 & 1 & 2 & 3 \\
\hline
\end{tabular}




\section{Appendix E: Body Shape Questionnaire (BSQ; Cooper et al., 1987)}

$\underline{\text { BSQ }}$

We should like to know how you have been feeling about your appearance. Please read each question and circle the appropriate answer.

\section{Over the past FOUR WEEKS $\ldots$}

1. Has feeling bored made you brood about your shape?

Never Rarely $\quad$ Sometimes Often $\quad$ Very Often Always

2. Have you been so worried about your shape that you have been feeling you ought to diet?

Never Rarely Sometimes Often Very Often Always

3. Have you thought that your thighs, hips or bottom are too large for the rest of you?

$\begin{array}{lllll}\text { Never } & \text { Rarely } & \text { Sometimes } & \text { Often } & \text { Very Often }\end{array}$

4. Have you been afraid that you might become fat (or fatter)?

$\begin{array}{lllll}\text { Never } & \text { Rarely } & \text { Sometimes } & \text { Often } & \text { Very Often }\end{array}$

5. Have you worried about your flesh being not firm enough?

Never Rarely Sometimes Often Very Often Always

6. Has feeling full (e.g., after eating a large meal) made you feel fat?

$\begin{array}{lllll}\text { Never } & \text { Rarely } & \text { Sometimes } & \text { Often } & \text { Very Often }\end{array}$

7. Have you felt so bad about your shape that you have cried?

$\begin{array}{lllll}\text { Never } & \text { Rarely } & \text { Sometimes } & \text { Often } & \text { Very Often }\end{array}$

8. Have you avoided running because your flesh might wobble?

Never Rarely Sometimes Often $\quad$ Very Often Always

9. Has being with thin women made you feel self-conscious about your shape?

Never Rarely Sometimes Often Very Often Always

10. Have you worried about your thighs spreading out when sitting down? 
Never Rarely $\quad$ Sometimes Often $\quad$ Very Often Always

11. Has eating even a small amount of food made you feel fat?

Never Rarely Sometimes Often Very Often Always

12. Have you noticed the shape of others and felt that your own shape compared unfavourably?

Never Rarely $\quad$ Sometimes Often $\quad$ Very Often Always

13. Has thinking about your shape interfered with your ability to concentrate (e.g., while watching television, reading, listening to conversations)?

Never Rarely Sometimes Often Very Often Always

14. Has being naked, such as when taking a bath or shower, made you feel fat?

Never Rarely Sometimes Often Very Often Always

15. Have you avoided wearing clothes which make you particularly aware of the shape of your body?

Never Rarely Sometimes Often $\quad$ Very Often Always

16. Have you imagined cutting off fleshy areas of your body?

Never Rarely Sometimes Often Very Often Always

17. Has eating sweets, cakes, or other high calorie food made you feel fat?

Never Rarely Sometimes Often Very Often Always

18. Have you not gone out to social occasions (e.g., parties) because you have felt bad about your shape?

Never Rarely Sometimes Often Very Often Always

19. Have you felt excessively large and rounded?

Never Rarely $\quad$ Sometimes Often Very Often Always

20. Have you felt ashamed of your body?

Never Rarely Sometimes Often Very Often Always 
21. Has worry about your shape made you diet?

$\begin{array}{lllll}\text { Never } & \text { Rarely } & \text { Sometimes } & \text { Often } & \text { Very Often }\end{array}$

22. Have you felt happiest about your shape when your stomach has been empty (e.g., in the morning)?

$\begin{array}{lllll}\text { Never } & \text { Rarely } & \text { Sometimes } & \text { Often } & \text { Very Often }\end{array}$

23. Have you thought that you are in the shape you are because you lack self-control?

$\begin{array}{lllll}\text { Never Rarely } & \text { Sometimes Often Very Often }\end{array}$

24. Have you worried about other people seeing rolls of fat around your waist or stomach?

$\begin{array}{lllll}\text { Never } & \text { Rarely } & \text { Sometimes } & \text { Often } & \text { Very Often }\end{array}$

25. Have you felt that it is not fair that others are thinner than you?

$\begin{array}{lllll}\text { Never } & \text { Rarely } & \text { Sometimes } & \text { Often } & \text { Very Often }\end{array}$

26. Have you vomited in order to feel thinner?

$\begin{array}{lllll}\text { Never } & \text { Rarely } & \text { Sometimes } & \text { Often } & \text { Very Often }\end{array}$

27. When in company have your worried about taking up too much room (e.g., sitting on a sofa, or a bus seat)?

$\begin{array}{lllll}\text { Never } & \text { Rarely } & \text { Sometimes } & \text { Often } & \text { Very Often }\end{array}$

28. Have you worried about your flesh being dimply?

$\begin{array}{lllll}\text { Never } & \text { Rarely } & \text { Sometimes } & \text { Often }\end{array}$

29. Has seeing your reflection (e.g. in a mirror or window) made you feel bad about your shape?

$\begin{array}{lllll}\text { Never } & \text { Rarely } & \text { Sometimes } & \text { Often } & \text { Very Often }\end{array}$

30. Have you pinched areas of your body to see how much fat there is?

$\begin{array}{lllll}\text { Never } & \text { Rarely } & \text { Sometimes } & \text { Often } & \text { Very Often }\end{array}$

31. Have you avoided situations where people could see your body (e.g., communal changing rooms or swimming baths)?

$\begin{array}{lllll}\text { Never } & \text { Rarely } & \text { Sometimes } & \text { Often } & \text { Very Often }\end{array}$


32. Have you taken laxatives in order to feel thinner?

$\begin{array}{lllll}\text { Never } & \text { Rarely } & \text { Sometimes } & \text { Often } & \text { Very Often }\end{array}$

33. Have you been particularly self-conscious about your shape when in the company of other people?

Never Rarely Sometimes Often $\quad$ Very Often Always

34. Has worry about your shape made you feel you ought to exercise?

Never Rarely Sometimes Often $\quad$ Very Often Always 


\section{Appendix F: Binge Eating Scale (BES; Gormally et al., 1982)}

\section{$\underline{\text { BES }}$}

Below are groups of numbered statements. Read all of the statements in each group and circle the one that best describes the way you feel about your eating behavior.

1.

1. I don't feel self-conscious about my weight or body size when I'm with others.

2. I feel concerned about how I look to others, but it normally does not make me feel disappointed with myself.

3. I do get self-conscious about my appearance and weight which makes me feel disappointed in myself.

4. I feel very self-conscious about my weight and frequently, I feel intense shame and disgust for myself. I try to avoid social contacts because of my self-consciousness.

2.

1. I don't have any difficulty eating slowly in the proper manner.

2. Although I seem to "gobble down" foods, I don't end up feeling stuffed because of eating too much.

3. At times, I tend to eat quickly and then, I feel uncomfortably full afterwards.

4. I have the habit of bolting down my food, without really chewing it. When this happens I usually feel uncomfortably stuffed because I've eaten too much.

3.

1. I feel capable to control my eating urges when I want to.

2. I feel like I have failed to control my eating more than the average person.

3. I feel utterly helpless when it comes to feeling in control of my eating urges.

4. Because I feel so helpless about controlling my eating I have become very desperate about trying to get in control.

4.

1. I don't have the habit of eating when I'm bored.

2. I sometimes eat when I'm bored, but often I'm able to "get busy" and get my mind off food.

3. I have a regular habit of eating when I'm bored, but occasionally, I can use some other activity to get my mind off eating.

4. I have a strong habit of eating when I'm bored. Nothing seems to help me break the habit.

5.

1. I'm usually physically hungry when I eat something.

2. Occasionally, I eat something on impulse even though I really am not hungry.

3. I have the regular habit of eating foods, that I might not really enjoy, to satisfy a hungry feeling even though physically, I don't need the food.

4. Even though I'm not physically hungry, 1 get a hungry feeling in my mouth that only seems to be satisfied when I eat a food, like a sandwich, that fills my mouth. Sometimes, 
when I eat the food to satisfy my mouth hunger, I then spit the food out so I won't gain weight.

6.

1. I don't feel any guilt or self-hate after I overeat.

2. After I overeat, occasionally I feel guilt or self-hate.

3. Almost all the time I experience strong guilt or self-hate after I overeat.

7.

1. I don't lose total control of my eating when dieting even after periods when I overeat.

2. Sometimes when I eat a "forbidden food" on a diet, I feel like I "blew it" and eat even more.

3. Frequently, I have the habit of saying to myself, "I've blown it now, why not go all the way" when I overeat on a diet. When that happens I eat even more.

4. I have a regular habit of starting strict diets for myself, but I break the diets by going on an eating binge. My life seems to be either a "feast" or "famine."

8.

1. I rarely eat so much food that I feel uncomfortably stuffed afterwards.

2. Usually about once a month, I eat such a quantity of food, I end up feeling very stuffed.

3. I have regular periods during the month when I eat large amounts of food, either at mealtime or at snacks.

4. I eat so much food that I regularly feel quite uncomfortable after eating and sometimes a bit nauseous.

9.

1. My level of calorie intake does not go up very high or go down very low on a regular basis.

2. Sometimes after I overeat, I will try to reduce my caloric intake to almost nothing to compensate for the excess calories I've eaten.

3. I have a regular habit of overeating during the night. It seems that my routine is not to be hungry in the morning but overeat in the evening.

4. In my adult years, I have had week-long periods where I practically starve myself. This follows periods when I overeat. It seems I live a life of either "feast or famine."

10.

1. I usually am able to stop eating when I want to. I know when "enough is enough."

2. Every so often, I experience a compulsion to eat which I can't seem to control.

3. Frequently, I experience strong urges to eat which I seem unable to control, but at other times I can control my eating urges.

4. I feel incapable of controlling urges to eat. I have a fear of not being able to stop eating voluntarily.

11.

1. I don't have any problem stopping eating when I feel full. 
2. I usually can stop eating when I feel full but occasionally overeat leaving me feeling uncomfortably stuffed.

3. I have a problem stopping eating once I start and usually I feel uncomfortably stuffed after I eat a meal.

4. Because I have a problem not being able to stop eating when I want, I sometimes have to induce vomiting to relieve my stuffed feeling.

12.

1. I seem to eat just as much when I'm with others (family, social gatherings) as when I'm by myself.

2. Sometimes, when I'm with other persons, I don't eat as much as I want to eat because I'm self-conscious about my eating.

3. Frequently, I eat only a small amount of food when others are present, because I'm very embarrassed about my eating.

4. I feel so ashamed about overeating that I pick times to overeat when I know no one will see me. I feel like a "closet eater."

13.

1. I eat three meals a day with only an occasional between meal snack.

2. I eat 3 meals a day, but I also normally snack between meals.

3. When I am snacking heavily, I get in the habit of skipping regular meals.

4. There are regular periods when I seem to be continually eating, with no planned meals.

14.

1. I don't think much about trying to control unwanted eating urges.

2. At least some of the time, I feel my thoughts are pre-occupied with trying to control my eating urges.

3. I feel that frequently I spend much time thinking about how much I ate or about trying not to eat anymore.

4. It seems to me that most of my waking hours are pre-occupied by thoughts about eating or not eating. I feel like I'm constantly struggling not to eat.

15.

1. I don't think about food a great deal.

2. I have strong cravings for food but they last only for brief periods of time.

3. I have days when I can't seem to think about anything else but food.

4. Most of my days seem to be pre-occupied with thoughts about food. I feel like I live to eat.

16.

1. I usually know whether or not I'm physically hungry. I take the right portion of food to satisfy me.

2. Occasionally, I feel uncertain about knowing whether or not I'm physically hungry. At these times it's hard to know how much food I should take to satisfy me.

3. Even though I might know how many calories I should eat, I don't have any idea what is a "normal" amount of food for me. 
Appendix G: Emotional Eating Scale (EES; Arnow et al., 1995)

$\underline{\text { EES }}$

We all respond to different emotions in different ways. Some types of feelings lead people to experience an urge to eat. Please indicate the extent to which the following feelings lead you to feel an urge to eat by checking the appropriate box.

\begin{tabular}{|c|c|c|c|c|c|c|}
\hline & & $\begin{array}{l}\text { No } \\
\text { Desire } \\
\text { to Eat }\end{array}$ & $\begin{array}{c}\text { A Small } \\
\text { Desire to } \\
\text { Eat }\end{array}$ & $\begin{array}{l}\text { A Moderate } \\
\text { Desire to } \\
\text { Eat }\end{array}$ & $\begin{array}{l}\text { A Strong } \\
\text { Urge to } \\
\text { Eat }\end{array}$ & $\begin{array}{c}\text { An } \\
\text { Overwhelming } \\
\text { Urge to Eat }\end{array}$ \\
\hline 1. & Resentful & 1 & 2 & 3 & 4 & 5 \\
\hline 2. & Discouraged & 1 & 2 & 3 & 4 & 5 \\
\hline 3. & Shaky & 1 & 2 & 3 & 4 & 5 \\
\hline 4. & Worn Out & 1 & 2 & 3 & 4 & 5 \\
\hline 5. & Inadequate & 1 & 2 & 3 & 4 & 5 \\
\hline 6. & Excited & 1 & 2 & 3 & 4 & 5 \\
\hline 7. & Rebellious & 1 & 2 & 3 & 4 & 5 \\
\hline 8. & Blue & 1 & 2 & 3 & 4 & 5 \\
\hline 9. & Jittery & 1 & 2 & 3 & 4 & 5 \\
\hline 10. & Sad & 1 & 2 & 3 & 4 & 5 \\
\hline 11. & Uneasy & 1 & 2 & 3 & 4 & 5 \\
\hline 12. & Irritated & 1 & 2 & 3 & 4 & 5 \\
\hline 13. & \begin{tabular}{|l} 
Jealous \\
\end{tabular} & 1 & 2 & 3 & 4 & 5 \\
\hline 14. & Worried & 1 & 2 & 3 & 4 & 5 \\
\hline 15. & Frustrated & 1 & 2 & 3 & 4 & 5 \\
\hline 16. & Lonely & 1 & 2 & 3 & 4 & 5 \\
\hline 17. & Furious & 1 & 2 & 3 & 4 & 5 \\
\hline 18. & On edge & 1 & 2 & 3 & 4 & 5 \\
\hline 19. & Confused & 1 & 2 & 3 & 4 & 5 \\
\hline 20. & \begin{tabular}{|l} 
Nervous \\
\end{tabular} & 1 & 2 & 3 & 4 & 5 \\
\hline 21. & Angry & 1 & 2 & 3 & 4 & 5 \\
\hline
\end{tabular}




\begin{tabular}{|c|l|c|c|c|c|c|}
\hline 22. & Guilty & 1 & 2 & 3 & 4 & 5 \\
\hline 23. & Bored & 1 & 2 & 3 & 4 & 5 \\
\hline 24. & Helpless & 1 & 2 & 3 & 4 & 5 \\
\hline 25. & Upset & 1 & 2 & 3 & 4 & 5 \\
\hline
\end{tabular}




\section{Appendix H: Demographic Questionnaire}

\section{Demographic Questionnaire}

1. Age:

2. Ethnicity (please select one option):
a) Aboriginal
b) Arab/West Asian
c) Black (African American)
d) East Asian
e) Latin/South American
f) South Asian
g) Southeast Asian
h) White (Caucasian)
i) Other

3. Relationship Status (please select one option):
a) Married
b) Common-law
c) Divorced
d) Separated
e) Single/never married
f) Widowed

4. Employment Status (please select one option):
a) Full-time
b) Part-time
c) Unemployed
d) Retired
e) Social Assistance
f) Disability

\section{Highest Level of Education (please select one option):}
a) Some school
b) High school graduate
c) Some college
d) Some university
e) College diploma
f) Bachelor's degree
g) Graduate degree 


\section{Appendix I: Mean Item Scores on Scale Variables in the Bariatric and Undergraduate Samples}

Table 12

Mean Item Scores on Scale Variables in the Bariatric and Undergraduate Samples

\begin{tabular}{|c|c|c|c|c|}
\hline & \multicolumn{2}{|c|}{$\begin{array}{r}\text { Bariatric } \\
\text { Sample } \\
\end{array}$} & \multicolumn{2}{|c|}{$\frac{\text { Undergraduate }}{\text { Sample }}$} \\
\hline Scale & $M$ & $S D$ & $M$ & $S D$ \\
\hline Weight Stigma Concerns ${ }^{\mathrm{a}}$ & 4.98 & 1.72 & 3.58 & 1.59 \\
\hline $\begin{array}{l}\text { Experiences/ Perceptions of } \\
\text { Discrimination }^{\mathrm{b}}\end{array}$ & 2.95 & 1.34 & 2.06 & 0.84 \\
\hline Weight Bias Internalization $^{a}$ & 4.52 & 1.45 & 3.15 & 1.42 \\
\hline Patient Health Questionnaire- $4^{\mathrm{c}}$ & 0.97 & 0.85 & 1.30 & 0.79 \\
\hline Body Shape Concerns ${ }^{b}$ & 3.46 & 1.20 & 2.82 & 1.09 \\
\hline Binge Eating Scale $^{\mathrm{d}}$ & 1.07 & 0.51 & 0.90 & 0.48 \\
\hline $\begin{array}{l}\text { Emotional Eating Scale } \\
\text { (Anger/ Frustration) }^{\mathrm{e}}\end{array}$ & 1.77 & 1.07 & 0.93 & 0.78 \\
\hline $\begin{array}{l}\text { Emotional Eating Scale } \\
\text { (Anxiety) }^{\mathrm{e}}\end{array}$ & 1.71 & 1.01 & 0.99 & 0.77 \\
\hline $\begin{array}{l}\text { Emotional Eating Scale } \\
\text { (Depression) }^{\mathrm{e}}\end{array}$ & 2.33 & 1.14 & 1.73 & 0.89 \\
\hline
\end{tabular}

Note. Due to missing data, $n$ 's range from 98- 101 in the bariatric sample and from 170- 188 in the undergraduate sample. Means and standard deviations were calculated by dividing the total mean score for each scale by the number of items in the scale.

${ }^{\mathrm{a}}$ Possible scores range from 1 (strongly disagree) to 7 (strongly agree), ${ }^{\mathrm{b}}$ Possible scores range

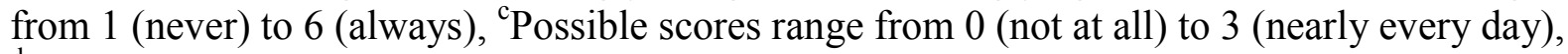
${ }^{\mathrm{d}}$ Possible scores range from 0 (no binge eating problem) to 3 (severe binge eating problem), ${ }^{\mathrm{e}}$ Possible scores range from 0 (no overwhelming urge to eat) to 4 (an overwhelming urge to eat). 
Appendix J: SONA Advertisement

\section{Study Weight-Based Stigma and Eating Behaviours in Female Name Undergraduates}

Brief This study asks female undergraduates to make one 30-minute visit to the lab, during which they will complete a series of questionnaires that will address topics related to weight stigma, eating behaviours, and psychological distress.

Description The purpose of this study is to examine the effects of weight-based stigma on eating behaviours in female university undergraduate students.

All participants $(n=200)$ will be female undergraduate students enrolled in the Introductory Psychology course PSY102 or PSY202. Study participation will involve completion of an electronic questionnaire package that addresses topics related to weight-based stigma, psychological distress, and eating behaviours. Participants will be granted 0.5 psychology credit for compensation.

Participants may benefit from gaining knowledge on the topics of weight-based stigma and eating behaviours, as well as by developing a better understanding of research methodology.

Risk should be no more than that experienced in everyday life.

Completion of these questionnaires may cause emotional discomfort for some individuals; however, it is expected that the discomfort will be temporary if experienced. Should participants feel uncomfortable, they can choose not to answer questions and/or to discontinue participation at any time and still receive their credit.

The study will take place in the South Bond Building, $1^{\text {st }}$ floor. Upon arrival at 105 Bond Street, please take a seat in the waiting area on the $1^{\text {st }}$ floor where the researcher will come to meet you. In case of difficulties, the lab extension is 3232 . Please call $416-979-5000 \times 3232$ to be let into the building after 6 p.m. weekdays, or on weekends. 
Eligibility
Requiremen Enrolled in Introductory Psychology PSY102 or PSY202, Female ts

Duration 30 Minutes

Credits $\quad 0.5$ credits

Preparation NONE

Researcher Aliza Friedman

Laura Pilla (Research Assistant)

\begin{tabular}{c}
$\begin{array}{l}\text { Principal } \\
\text { Investigator } \\
\text { REB } \\
\text { Approval } \\
\text { Code }\end{array}$ \\
or. Stephanie Cassin \\
\hline
\end{tabular}

REB Approval

Expiration

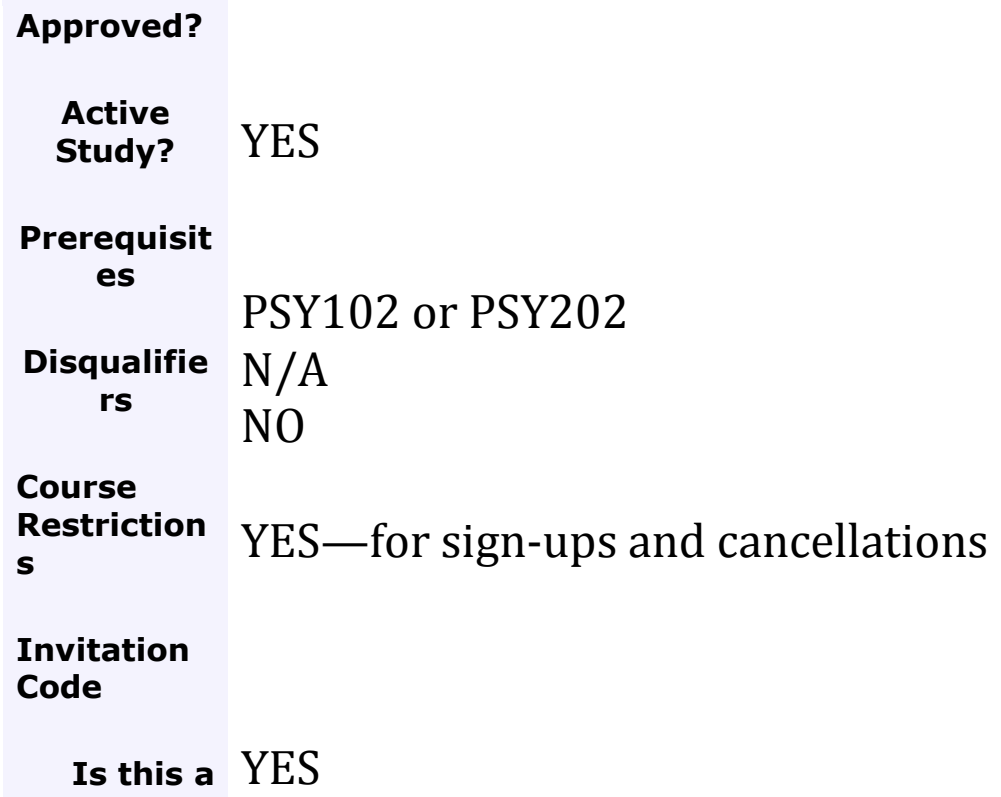


web-based study?

NO

Study URL

Should the researcher receive an email notificatio n when a participant signs up or cancels?

Researcher s at

TimeslotLevel

Automatic Credit

Granting

Private

Comments

Study

Status 


\section{Appendix K: Informed Consent Agreement}

\section{RYERSON UNIVERSITY \\ Informed Consent Agreement \\ Weight-Based Stigma and Eating Behaviours in Female Undergraduates}

You are being asked to participate in a research study. Before signing this consent form, it is important that you read the following information. You may ask as many questions as necessary to be sure that you understand what the study entails.

Investigators: This study is being conducted by Aliza Friedman, BSc. (Hons), Graduate Student, Department of Psychology, Ryerson University (Principal Investigator) under the direct supervision of Drs. Stephanie Cassin, C. Psych and Becky Choma, Assistant Professors, Department of Psychology, Ryerson University.

Purpose of the Study: The purpose of this social psychological study is to examine the effects of weight-based stigma on eating behaviours in female university undergraduate students. Two hundred students enrolled in PSY 102/202 will be invited to participate in this research.

Description of the Study: If you decide to participate in the research, you will be asked to visit the Healthy Eating and Lifestyle (HEAL) laboratory at Ryerson University, located at 105 Bond Street on the first floor. Your visit will last approximately 30 minutes, and will be scheduled at your convenience. During your visit, you will be asked to do the following: read and sign a consent form ( 5 minutes), complete an electronic questionnaire package (20 minutes), and read a debriefing form ( 5 minutes). The electronic questionnaire package addresses topics related to weight-based stigma (e.g. "In the past 12 months, how often have you been treated differently than others because of your weight?"), psychological distress (e.g., "Over the last 2 weeks, how often have you been bothered by feeling nervous, anxious, or on edge?"), and eating behaviours (e.g., "On how many of the past 28 days have you had a definite desire to have a totally flat stomach?").

What is Experimental in this Study: None of the procedures or questionnaires used in this study is experimental in nature, in the sense that they have all been used by other researchers and found to be useful procedures and questionnaires. From a technical or procedural point of view, part of this study is considered "experimental", because by following the procedure described above, the study examines the impact of one variable (called the "independent variable") on another variable (called the "dependent variable"). More information about the independent and dependent variables will be provided at the end of the session.

Risks or Discomforts: This is a minimal risk study. However, you may experience some emotional discomfort due to the potentially sensitive nature of the questionnaires. Any discomfort is expected to be temporary and not greater than you might experience in a typical day. Participants may choose to refuse to participate in any aspect of the research (e.g., responding to questionnaire items). If any aspect of this study makes you feel uncomfortable, you may temporarily or permanently discontinue your participation without penalty or loss of your course participation credit. 
Benefits of the Study: There is no direct benefit to participants in this study although the information gained from the overall study may help inform the scientific community and psychological health professionals about the nature of weight-based stigma and eating behaviours. You may also gain knowledge on the topic of weight-based stigma and eating behaviours, as well as develop a better understanding of research methodology. I cannot guarantee, however, that you will receive any benefits from participating in this study. When the session is over, we will describe the purpose and hypotheses of the study to you in more detail.

Confidentiality: You will not put your name or student number on the questionnaires. You will be asked to sign only this consent form (if you decide to participate), and it will be filed separately from your questionnaires. Your responses in this research will be anonymous and so there will be no way of linking your responses with your identity. This informed consent agreement will be stored in a locked file cabinet in the HEAL laboratory at Ryerson University for a seven-year period, to which only investigators and associated personnel will have access. An ID number, as opposed to your name, will be used on all computer files that contain the data you provide during the study. The data you generate while participating in this study will be stored in a password-protected file on a password-protected computer, separate from this consent agreement and any data that may identify you. Only authorized researchers have access to the file. Confidentiality will be maintained at all times. The data being collected today may be presented in scientific journals or at conferences, but any such presentations will be general findings and will never breach individual confidentiality. Should you be interested, you are entitled to a copy of the findings. All of the data will be destroyed 7 years after publication of the results.

Only your SONA ID will be included with your questionnaire responses so that we can identify your data should you wish to withdraw your data from the study. The online questionnaires are hosted by Qualtrics, a web survey company located in the USA and as such, is subject to U.S. laws; in particular, the US Patriot Act, which allows authorities access to the records of internet service providers. This survey or questionnaire does not ask for personal identifiers or any information that may be used to identify you. However, if you choose to participate in the survey, you understand that your responses to the survey questions will be stored, and can be accessed, in the USA. The security and privacy policy for the websurvey company can be found at the following link: http://www.qualtrics.com/security-statement/

Incentives to Participate: You will receive 0.5 participation credit to use towards your PSY $102 / 202$ course at Ryerson. If you would prefer to 'walk through' the study (that is, if you would like to observe the research process but not provide any personal data), you will still be given the 0.5 credit assuming you have not already received the maximum allotted for research participation (currently 4\%).

Voluntary Nature of Participation: Participation in this study is voluntary. Your choice of whether or not to participate will not affect your grades or academic status. If you decide to participate, you are free to withdraw your consent and to stop your participation at any time without penalty or loss of benefits to which you are allowed, and without any explanation to the researcher. Should you withdraw from the study, you will still be given your 0.5 credit. The right to withdraw consent also applies to use of your data. If you withdraw from the study before you have completed it, any data that you have provided us up to that point will be destroyed. If you 
decide that you do not want us to keep or analyze data that you have provided during the study, please feel free to notify us within one week of the study. Data will be aggregated after one week of study participation, after which data will not be able to be withdrawn because it will not be possible to identify an individual's contributions. If you would like to participate but do not wish to contribute data to this study, you have the option to complete a 'walk-through' of the study and still receive the full compensation amount $(0.5$ credit).

Questions about the Study: If you have any questions about the research now, please ask. If you have questions about the research later, you may contact Aliza Friedman, B.Sc. (Hons.), Graduate Student, Department of Psychology, Ryerson University, 416-979-5000 ext. 3232, aliza.friedman@psych.ryerson.ca or Dr. Stephanie Cassin, C. Psych., Assistant Professor, Department of Psychology, Ryerson University, 416-979-5000 ext. 3007, stephanie.cassin@psych.ryerson.ca.

If you have questions regarding your rights as a human participant in this study, you may contact Toni Fletcher, Research Ethics Coordinator at the Ryerson University Research Ethics Board for information:

Research Ethics Board

c/o Office of the Vice President, Research and Innovation

Ryerson University

350 Victoria Street

Toronto, ON M5B 2K3

416-979-5042

rebchair@ryerson.ca

\section{If you have any questions about receiving your Psychology 102/202 credit for participation} please contact: thepool@psych.ryerson.ca

Agreement: Your signature below means that you have read the information in this agreement and have had a chance to ask any questions you have about the study. Your signature also means that you agree to be in the study and have been told that you can change your mind at any time during the study and withdraw from it. You have been given a copy of this agreement.

You have been told that by signing this consent agreement you are not giving up any of your legal rights.

Name of Participant (please print)

Signature of Participant

Date

Signature of Investigator

Date 


\section{Appendix L: Debriefing Form}

\section{RYERSON UNIVERSITY}

Debriefing Form

Title of study: Weight-Based Stigma and Eating Behaviours in Female Undergraduates

Weight-based stigma, defined as negative attitudes towards individuals on the basis of their weight and shape, is often considered to be the last socially acceptable form of bias (Latner et al., 2008; Puhl \& Brownell, 2001). Although some researchers have proposed that stigma may be an effective strategy for targeting public health concerns like obesity, weight-based stigma among overweight and obese individuals is instead associated with numerous detrimental psychological and physical health outcomes, including increased rates of psychological distress, suicide ideation, avoidance of exercise, and disordered eating (Ashmore et al., 2008; Chen et al., 2012; Varatanian \& Novak, 2011). Weight-based stigma has been traditionally studied exclusively among overweight and obese populations; however, recent research findings suggest that weightbased stigma may actually affect individuals across the weight spectrum. The primary goal of the present study is to explore the relationship between weight-based stigma and eating behaviours in an undergraduate female population. The results of this study will help inform the scientific community about the nature of weight-based stigma/discrimination in normal-weight populations. The present study may also help to identify the explanatory mechanisms between weight-based stigma/discrimination and eating behaviours, which is the first step towards identifying targets for prevention and treatment of disordered eating.

If you would like further information on this area of research, these are some related references that might be of interest to you:

Durso, L.E., \& Latner, J.D. (2008). Understanding self-directed stigma: Development of the weight bias internalization scale. Obesity, 16(Suppl. 2), S80- S86.

Major, B., \& O'Brien, L.T. (2005). The social psychology of stigma. Annual Review of Psychology, 56, 393- 421.

Pearl, R.L., \& Puhl, R.M. (2014). Measuring internalized weight attitudes across body weight categories: Validation of the modified weight bias internalization scale. Body Image, 11(1), 89- 92.

Puhl, R.M., \& Heuer, C.A. (2009). The stigma of obesity: A review and update. Obesity, 17(5), 941- 964.

Puhl, R.M., Moss-Racusin, C.A., \& Schwartz, M.B. (2007). Internalization of weight bias: Implications for binge eating and emotional eating. Obesity, 15(1), 19-23.

Varatanian, L.R., \& Novak, S.A. (2011). Internalized societal attitudes moderate the impact of weight stigma on avoidance of exercise. Obesity, 19(4), 757- 762.

If you are currently experiencing psychological distress and would like to discuss your concerns in a safe and confidential environment, please be aware that the Ryerson Centre for Student Development and Counselling (CSDC) is a free resource for students located on campus. Staff at the Counselling Centre provides support and guidance for a range of concerns including anxiety, low mood, and academic difficulties. The contact information for the CSDC is as follows: 


\section{Centre for Student Development and Counselling}

Website: http://www.ryerson.ca/counselling/index.html

Email: csdc@ryerson.ca

Phone: 416-979-5195

Location: JOR-07C (Lower level of Jorgensen Hall, 380 Victoria Street)

If you are interested in community-based counselling resources specific to disordered eating or eating disorders, please be aware of the following resources:

\section{Toronto General Hospital (TGH)- Eating Disorder Program}

Website: http://www.eatingdisorderuhn.com/index.html

Contact: Penn Charest, Intake Coordinator

Phone: 416-340-3041

Location: Toronto General Hospital

Sheena's Place

Website: http://sheenasplace.org/

Phone: 416-927-8900

Email: info@sheenasplace.org

Location: 87 Spadina Road

If you are interested in self-help websites or telephone helplines, please be aware of the following resources:

\section{National Eating Disorder Information Centre (NEDIC)}

Website: http://www.nedic.ca/

Information/Support Helpline: 1-866-633-4220 or 416-340-4156 (9 am-9 pm Monday-Friday EST)

\section{Canadian Mental Health Association Toronto}

Website: http://toronto.cmha.ca/

\section{Mind Your Mind}

Website: http://www.mindyourmind.ca/

We will be running this study for some time and would appreciate it if you would not talk to anyone about the study. Sometimes if people know what the study is about, that knowledge can affect their responses.

Any questions about study participation may be directed to Aliza Friedman, BSc. (Hons.), Graduate Student, Ryerson University at aliza.friedman@psych.ryerson.ca or 416-979-5000 ext. 3232 or Dr. Stephanie Cassin, C. Psych., Assistant Professor, Ryerson University at stephanie.cassin@psych.ryerson.ca or 416-979-5000 ext. 3007.

Again, thank you. Your interest in participating in this research study is greatly appreciated.
Aliza Friedman
Dr. Stephanie E. Cassin
Dr. Becky Choma
Graduate Student
Assistant Professor
Assistant Professor 


\section{References}

American Psychiatric Association. (2013). Diagnostic and statistical manual of mental health disorders: DSM-5 (5th ed.). Washington, DC: American Psychiatric Publishing.

Arnow, B., Kenardy, J., \& Agras, W.S. (1995). The emotional eating scale: The development of a measure to assess coping with negative affect by eating. International Journal of Eating Disorders, 18(1), 79- 90. doi: 10.1002/1098-108X(199507)18:1<79::AIDEAT2260180109>3.0.CO;2-V

Andreyeva, T., Puhl, R.M., \& Brownell, K. D. (2008). Changes in perceived weight discrimination among Americans, 1995-1996 through 2004-2006. Obesity, 16(5), 11291134. doi: 10.1038/oby.2008.35

Anglé, S., Engblom, J., Eriksson, T., Kautiainen, S., Saha, M-T., Lindfors, P.,...Rimpela, A. (2009). Three factor eating questionnaire-R18 as a measure of cognitive restraint, uncontrolled eating and emotional eating in a sample of young Finnish females. International Journal of Behavioural Nutrition and Physical Activity, 6(41). doi:10.1186/1479-5868-6-41

Ashmore, J.A., Friedman, K.E., Reichmann, S.K., \& Musante, G.J. (2008). Weight-based stigmatization, psychological distress, and binge-eating among obese treatment-seeking adults. Eating Behaviors, 9(2), 203- 209. doi: 10.1016/j.eatbeh.2007.09.006

Bayer, R. (2008). Stigma and the ethics of public health: Not can we but should we. Social Science \& Medicine, 67(3), 463- 472. doi: 10.1016/j.socscimed.2008.03.017 Ben-Zeev, T., Fein, S., Inzlicht, M. (2005). Arousal and stereotype threat. Journal of Experimental Social Psychology, 41, 174- 181. doi:10.1016/j.jesp.2003.11.007 
Berryman, D.E., Dubale, G.M., Manchester, D.S., \& Mittelstaedt, R. (2006). Dietetics students possess negative attitudes towards obesity similar to nondietetics students. Journal of the American Dietetic Association, 106(10), 1678- 1682. doi: 10.1016/j.jada.2006.07.016

Bjorntorp, P., \& Rosmond, R. (2000). Obesity and cortisol. Nutrition, 16(10), 924- 936. http://dx.doi.org/10.1016/S0899-9007(00)00422-6

Buchwald, H., Avidor, Y., Braunwald, E., Jensen, M.D., Fahrbach, K., \& Schoelles, K. (2004). Bariatric surgery: A systematic review and meta-analysis, Journal of the American Medical Association, 292(14), 1724- 1737. doi: 10.1001/jama.292.14.1724

Carels, R.A., Wott, C.B., Young, K.M., Gumble, A., Koball, A. \& Oehlhof, M.W. (2010). Implicit, explicit, and internalized weight bias and psychosocial maladjustment among treatment-seeking adults. Eating Behaviors, 11(3), 180- 185. doi:

10.1016/j.eatbeh.2010.03.002

Carr, D., \& Friedman, M.A. (2005). Is obesity stigmatizing? Body weight, perceived discrimination, and psychological well-being in the United States. Journal of Health and Social Behavior, 46(3), 244- 259. doi: 10.1177/002214650504600303

Chen, E.Y., Fettich, K.C., \& McCloskey, M.S. (2012). Correlates of suicidal ideation and/or behavior in bariatric-surgery-seeking individuals with severe obesity. The Journal of Crisis Intervention and Suicide Prevention, 33(3) 137- 143. doi: 10.1027/0227-5910/a000115

Cohen, J. (1992). A power primer. Psychological Bulletin, 112(1), 155- 159. http://dx.doi.org/10.1037/0033-2909.112.1.155

Cook, R.D., \& Weisberg, S. (1982). Residuals and influence in regression. New York, NY: Chapman \& Hall. 
Cooper, P.J., Taylor, M.J., Cooper, Z., Fairburn, C.G. (1987). The development and validation of the body shape questionnaire. International Journal of Eating Disorders, 6(4), 485- 494. doi: 10.1002/1098-108X(198707)6:4<485::AID-EAT2260060405>3.0.CO;2-O

Corson, K., Gerrity, M.S., \& Dobscha, S.K. (2004). Screening for depression and suicidality in a VA primary care setting: 2 items are better than 1 item. The American Journal of Managed Care, 10(11), 839- 845. Retrieved from http://www.ajmc.com/

Crandall, C.S. (1994). Prejudice against fat people: Ideology and self-interest. Journal of Personality and Social Psychology, 66(5), 882- 894. doi: 10.1037/0022-3514.66.5.882

Crawford, D., \& Campbell, K. Lay definitions of ideal weight and overweight. International Journal of Obesity, 23(7), 738- 745. doi: 10.1038/sj.ijo.0800922

Crocker, J., \& Major, B. (1989). Social stigma and self-esteem: The self-protective properties of stigma. Psychological Review, 96(4), 608-630. doi: 10.1037//0033-295X.96.4.608

Davis-Coelho, K., Waltz, J., Davis-Coelho, B. (2000). Awareness of prevention of bias against fat clients in psychotherapy. Professional Psychology: Research and Practice, 31(6), 682684. doi: 10.1037/0735-7028.31.6.682

Davison, K.K., \& Birch, L.L. (2004). Predictors of fat stereotypes among 9-year-old girls and their parents. Obesity Research, 12(1), 86- 94. doi: 10.1038/oby.2004.12

DeJong, W. (1980). The stigma of obesity: The consequences of native assumptions concerning the cause of physical deviance. Journal of Health and Social Behavior, 21(1), 75- 87. Retrieved from http://hsb.sagepub.com/ de Lauzon, B., Romon, M., Deschamps, V., Lafay, L., Borys, J.M., Karlsson, J.,...Fleurbaix Laventie Ville Sante Study Group. (2004). The three-factor eating questionnaire-R18 is able 
to distinguish among different eating patterns in a general population. Journal of Nutrition, 134(9), 2372- 2380. Retrieved from http://jn.nutrition.org/

Delgadillo, J., Payne, S., Gilbody, S., Godfrey, C., Gore, S., Jessop, D., \& Dale, V. (2012). Brief case finding tools for anxiety disorders: Validation of GAD-7 and GAD-2 in addictions treatment. Drug and Alcohol Dependence, 125(1-2), 37- 42. doi:

10.1016/j.drugalcdep.2012.03.011

Delinsky, S.S., \& Wilson, G.T. (2008). Weight gain, dietary restraint, and disordered eating in the freshman year of college. Eating Behaviours, 9(1), 82- 90. doi:

10.1016/j.eatbeh.2007.06.001

Dickerson, S.S., \& Kemeny, M.E. (2004). Acute stressors and cortisol responses: A theoretical integration and synthesis of laboratory research. Psychological Bulletin, 130(3), 355- 391. doi: http://dx.doi.org/10.1037/0033-2909.130.3.355

Dovidio, J. F., Hewstone, M., Glick, P., \& Esses, V. M. (2010). Prejudice, stereotyping, and discrimination: Theoretical and empirical overview. In J. F. Dovidio, M. Hewstone, P. Glick, \& V. M. Esses (Eds.), The SAGE handbook of prejudice, stereotyping, and discrimination (pp. 3-28). London, England: Sage Publications Ltd.

Durso, L.E., \& Latner, J.D. (2008). Understanding self-directed stigma: Development of the weight bias internalization scale. Obesity, 16(Suppl. 2), S80- S86. doi: 10.1038/oby.2008.448

Durso, L.E., Latner, J.D., \& Hayashi, K. (2012). Perceived discrimination is associated with binge eating in a community sample of non-overweight, overweight, and obese adults. Obesity Facts, 5, 869- 880. doi: 10.1159/000345931 
Eisenberg, D., Nicklett, E.J., Roeder, K., \& Kirz, N.E. (2011). Eating disorder symptoms among college students: Prevalence, persistence, correlates, and treatment-seeking. Journal of American College Health, 59(8), 700- 707. doi: 10.1080/07448481.2010.546461

Epel, E., Lapidus, R., McEwen, B., \& Brownell, K. (2001). Stress may add bite to appetite in women: A laboratory study of stress-induced cortisol and eating behaviour. Psychoneuroendocrinology, 26(1), 37- 49. http://dx.doi.org/10.1016/S0306-4530(00)00035-4

Evans, C. (2003). "If only I were thin like her, maybe I could be happy like her": The selfimplications of associating a thin female ideal with life success. Psychology of Women Quarterly, 7(3), 209- 214. doi: 10.1111/1471-6402.00100

Evans, C., \& Dolan, B. (1993). Body shape questionnaire: Derivation of shortened "alternate forms". International Journal of Eating Disorders, 13(3), 315- 321. doi: 10.1002/1098108X(199304)13:3<315::AID-EAT2260130310>3.0.CO;2-3

Farrow, C.V., \& Tarrant, M. (2009). Weight-based discrimination, body dissatisfaction and emotional eating: the role of perceived social consensus. Psychology \& Health, 24(9), 10211034.

Fayet, F., Petocz, P., \& Samman, S. (2012). Prevalence and correlates of dieting in college women: A cross sectional study. International Journal of Women's Health, 4, 405- 411. doi: 10.2147/IJWH.S33920

Field, A. P. (2009). Discovering statistics using IBM SPSS statistics: and sex and drugs and rock ' $n$ ' roll ( $3^{\text {rd }}$ ed.) London, England: SAGE Publications Ltd.

Field, A. P. (2013). Discovering statistics using IBM SPSS statistics: and sex and drugs and rock ' $n$ ' roll ( $4^{\text {th }}$ ed.) London, England: SAGE Publications Ltd. 
Fischer, S., Chen, E., Katterman, S., Roerhig, M., Bochierri-Ricciardi, L., Munoz, D.,...le Grange, D. (2007). Emotional eating in a morbidly obese bariatric surgery-seeking population. Obesity Surgery, 17(6), 778- 784. doi: 10.1007/s11695-007-9143-x

Friedman, K.E., Reichmann, S.K., Costanzo, P.R., Zelli, A., Ashmore, J.A., \& Musante, G.J. (2005). Weight stigmatization and ideological beliefs: Relation to psychological functioning in obese adults. Obesity Research, 13(5), 907- 916. doi: 10.1038/oby.2005.105

Fritz, M., \& MacKinnon, D. (2007). Required sample size to detect the mediated effect. Psychological Science, 18(3), 233- 239. doi: 10.1111/j.1467-9280.2007.01882.x

Geliebter, A., \& Aversa, A. (2003). Emotional eating in overweight, normal weight, and underweight individuals. Eating Behaviors, 3(4), 341- 347. doi: 10.1016/S14710153(02)00100-9

Ghaderi, A., \& Scott, B. (2004). The reliability and validity of the Swedish version of the Body Shape Questionnaire. Scandinavian Journal of Psychology, 45(4), 319- 324. doi:

10.1111/j.1467-9450.2004.00411.x

Goffman, Erving. (1963). Stigma: Notes on the management of spoiled identity. New York, NY: Simon \& Schuster, Inc.

Gormally, J., Black, S., Daston, S., \& Rardin, D. (1982). The assessment of binge eating severity among obese persons. Addictive Behaviors, 7(1), 47- 55. doi: 10.1016/0306-4603(82)90024-7

Greenwald, A.G., McGhee, D.E., \& Schwarz, J.L.K. (1998). Measuring individual differences in implicit cognition: The implicit association test. Journal of Personality and Social Psychology, 74(6), 1464- 1480. http://dx.doi.org/10.1037/0022-3514.74.6.1464 
Grupski, A.E., Hood, M.M., Hall, B.J., Azarbad, L., Fitzpatrick, S.L., \& Corsica, J.A. (2013). Examining the binge eating scale in screening for binge eating disorder in bariatric surgery candidates. Obesity Surgery, 23(1), 1- 6. doi: 10.1007/s11695-011-0537-4

Harris, M.B., Harris, R.J., \& Bochner, S. (1982). Fat, four-eyed and female: Stereotypes of obesity, glasses, and gender. Journal of Applied Social Psychology, 12(6), 503- 516. doi: 10.1111/j.1559-1816.1982.tb00882.x

Heatherton, T.F., \& Baumeister, R.F. (1991). Binge eating as escape from self-awareness. Psychological Bulletin, 110(1), 86- 108. doi: 10.1037/0033-2909.110.1.86

Henderson, N.J., \& Huon, G.F. (2002). Negative affect and binge eating in overweight women. British Journal of Health Psychology, 7(1), 77- 87. doi: 10.1348/135910702169376

Hayes, A. F. (2013). Introduction to mediation, moderation, and conditional process analysis: A regression-based approach. New York, NY: The Guilford Press.

Hayes, A. (2015). Supplementary PROCESS documentation. Retrieved from http://www.afhayes.com/public/docaddendum.pdf

Hayes, A.F., \& Cai, L. (2007). Using heteroskedasticity-consistent standard error estimators in OLS regression: An introduction and software implementation. Behaviour Research Methods, 39(4), 709- 722. doi: 10.3758/BF03192961

Health Canada. (2003). Canadian guidelines for body weight classification in adults. Ottawa, ON: Minister of Public Works and Government Services Canada. Retrieved from: http://www.hc-sc.gc.ca/fn-an/nutrition/weights-poids/guide-ld-adult/bmi_chart-graph_imceng.php. 
Hebl, M.R., \& Xu, J. (2001). Weighing the care: Physicians' reactions to the size of a patient. International Journal of Obesity, 25, 1246- 1252. Retrieved from http://www.nature.com/ijo/index.html

Henderson, N.J., \& Huon, G.F. (2002). Negative affect and binge eating in overweight women. British Journal of Health Psychology, 7(1), 77- 87. doi: 10.1348/135910702169376

Hilbert, A., Braehler, E., Haeuser, W., \& Zenger, M. (2014). Weight bias internalization, core self-evaluation, and health in overweight and obese persons. Obesity, 22(1), 79- 85. doi: 10.1002/oby.20561

Hilbert, A., Rief, W., \& Braehler, E. (2008). Stigmatizing attitudes toward obesity in a representative population- based sample. Obesity, 16(7), 1529- 1534. doi:

10.1038/oby.2008.263

Hoyle, R.H., \& Kenny, D.A. (1999). Sample size, reliability, and tests of statistical mediation. In R.H. Hoyle (Ed.), Statistical strategies for small sample research (pp. 195- 222). Thousand Oaks, CA: SAGE.

Hunger, J.M., \& Major, B. (2015). Weight stigma mediates the association between BMI and self-reported health. Health Psychology, 34(2), 172- 175. doi: 10.1037/hea0000106

Hunger, J.M., Major, B., Blodorn, A., \& Miller, C. (In press). Weighed down by sigma: How weight-based social identity threat contributes to weight gain and poor health. Social and Personality Psychology Compass.

Hyun, G., Trudeau, L., \& Shin, C. (2014, May). A simulation study on the correlated mediators in multiple mediation models. Poster presented at the Society for Prevention Research, Washington, D.C. 
Karlsson, J.,, Persson, L.O., Sjöström, L., \& Sullivan, M. (2000). Psychometric properties and factor structure of the three-factor eating questionnaire (TFEQ) in obese men and women. Results from the Swedish obese subjects (SOS) study. International Journal of Obesity, 23(12), 1715- 1725. doi: 10.1038/sj.ijo.0801442

Kroenke, K., \& Spitzer, R.L. (2002). The PHQ-9: A new depression diagnostic and severity measure. Psychiatric Annals, 32(9), 1- 7. doi: 10.3928/0048-5713-20020901-06

Kroenke, K., Spitzer, R.L., Williams, J.B., \& Lowe, B. (2009). An ultra-brief screening scale for anxiety and depression: The PHQ-4. Psychosomatics, 50(6), 613- 621. doi:

10.1176/appi.psy.50.6.613

Latner, J.D., Durso, L.E., \& Mond, J.M. (2013). Health and health-related quality of life among treatment-seeking overweight and obese adults: Associations with internalized weight bias. Journal of Eating Disorders, 1(3). doi: 10.1186/2050-2974-1-3

Latner, J.D., O’Brien, K.S., Durso, L.E., Brinkman, L.A., \& MacDonald, T. (2008). Weighing obesity stigma: The relative strength of different forms of bias. International Journal of Obesity, 32(7), 1145- 1152. doi: 10.1038/ijo.2008.53

Lent, M.R., Napolitano, M.A., Wood, G.C., Argyropoulos, G., Gerhard, G.S., Hayes, S.,...Still, C.D. (2014). Internalized weight bias in weight-loss surgery patients: Psychological correlates and weight loss outcomes. Obesity Surgery, 24, 2195- 2199. doi: 10.1007/s11695014-1455-Z

Lewis, R.J., Derlega, V.J., Griffin, J.L., \& Krowinski, A.C. (2003). Stressors for gay men and lesbians: Life stress, gay-related stress, stigma consciousness, and depressive symptoms. Journal of Social and Clinical Psychology, 22(6), 716- 729. doi:

10.1521/jscp.22.6.716.22932 
Lowe, B., Decker, O., Muller, S., Brahler, E., Schellberg, D., Herzog, W., Herzberg, P.Y. (2008). Validation and standardization of the generalized anxiety disorder screener (GAD-7) in the general population. Medical Care, 46(3), 266- 274. doi: 10.1097/MLR.0b013e318160d093

MacKinnon, D.P, Krull, J.L., \& Lockwood, C.M. (2000). Equivalence of the mediation, confounding and suppression effect. Prevention Science, 1(4), 173- 181. doi:

$$
\text { 10.1023/A:1026595011371 }
$$

Major, B., Eliezer, D., \& Rieck, H. (2012). The psychological weight of weight stigma. Social Psychological and Personality Science, 3(6), 651- 658. doi: 10.1177/1948550611434400

Major, B., Hunger, J.M., Bunyan, D.P, \& Miller, C.T. (2014). The ironic effects of weight stigma. Journal of Experimental Social Psychology, 51, 74- 80. doi:10.1016/j.jesp.2013.11.009

Major, B., \& O’Brien, L.T. (2005). The social psychology of stigma. Annual Review of Psychology, 56, 393- 421. doi: 10.1146/annurev.psych.56.091103.070137

Mann, T., Tomiyama, A.J., Westling, E., Lew, A.M., Samuels, B., \& Chatman, J. (2007). Medicare's search for effective obesity treatments: Diets are not the answer. American Psychologist, 62(3), 220- 233. http://dx.doi.org/10.1037/0003-066X.62.3.220

Menard, S. (1995). Applied logistic regression analysis. Sage university paper series on quantitative applications in the social sciences, 07- 106. Thousand Oaks, CA: SAGE.

Mitchell, J.E., King, W.C., Chen, J-Y., Devlin, M.J., Flum, D., Garcia, L.,...Yanovski, S. (2014). Course of depressive symptoms and treatment in the longitudinal assessment of bariatric surgery (LABS-2) study. Obesity, 22(8), 1799-1806. doi: 10.1002/oby.20738

Myers, R. (1990). Classical and modern regression with applications $\left(2^{\text {nd }}\right.$ ed.). Boston, MA: Duxbury. 
Myers, A., \& Rosen, J.C. (1999). Obesity stigmatization and coping: Relation to mental health symptoms, body image, and self-esteem. International Journal of Obesity, 23, 221- 230. doi: $10.1038 /$ sj.ijo.0800765

Napolitano, M.A., \& Himes, S. (2011). Race, weight, and correlates of binge eating in female college students. Eating Behaviors, 12(1), 29- 36. doi: 10.1016/j.eatbeh.2010.09.003

Neumark-Sztainer, D., Story, M., \& Harris, T. (1999). Beliefs and attitudes about obesity among teachers and school health care providers working with adolescents. Journal of Nutrition Education, 31(1), 3-9. doi:10.1016/S0022-3182(99)70378-X

Paradies, Y.C. (2006). Defining, conceptualizing and characterizing racism in health research. Critical Public Health, 16(2), 143- 157. doi: 10.1080/09581590600828881

Pascoe, E.A., \& Smart Richman, L. (2009). Perceived discrimination and health: A meta-analytic review. Psychological Bulletin, 135(4), 531- 554. doi: 10.1037/a0016059.

Pearl, R.L., \& Puhl, R.M. (2014). Measuring internalized weight attitudes across body weight categories: Validation of the modified weight bias internalization scale. Body Image, 11(1), 89- 92. doi: 10.1016/j.bodyim.2013.09.005

Pearl, R.L., Puhl, R.M., \& Dovidio, J.F. (in press). Differential effects of weight bias internalization on exercise among women with overweight and obesity. Journal of Health Psychology.

Pearl, R.L., White, M.A., \& Grilo, C.M. (2014a). Weight bias internalization, depression, and self-reported health among overweight binge eating disorder patients. Obesity, 22(5), E142E148. doi: 10.1002/oby.20617 
Pearl, R.L., White, M.A., \& Grilo, C.M. (2014b). Overvaluation of shape and weight as a mediator between self-esteem and weight bias internalization among patients with binge eating disorder. Eating Behaviors, 15(2), 259- 261. doi: 10.1016/j.eatbeh.2014.03.005

Pinel, E.C. (1999). Stigma consciousness: The psychological legacy of social stereotypes. Journal of Personality and Social Psychology, 76(1), 114- 128. http://dx.doi.org/10.1037/0022-3514.76.1.114

Pook, M., Tuschen- Caffier, B., \& Brahler, E. (2008). Evaluation and comparison of different versions of the body shape questionnaire. Psychiatry Research, 158(1), 67- 73. doi:10.1016/j.psychres.2006.08.002

Poon, M-Y., \& Tarrant, M. (2009). Obesity: Attitudes of undergraduate student nurses and registered nurses. Journal of Clinical Nursing, 18(16), 2355- 2365. doi: 10.1111/j.13652702.2008.02709.x

Preacher, K. J., \& Hayes, A. F. (2008). Asymptotic and resampling strategies for assessing and comparing indirect effects in multiple mediator models. Behavior Research Methods, 40(3), 879- 891. doi: 10.3758/BRM.40.3.879

Puhl, R.M., Andreyeva, T., \& Brownell, K.D. (2008). Perceptions of weight discrimination: Prevalence and comparison to race and gender discrimination in America. International Journal of Obesity, 32(6), 992- 1000. doi: 10.1038/ijo.2008.22

Puhl, R., \& Brownell, (2001). K.D. Bias, discrimination, and obesity. Obesity Research, 9(12), 788- 805. doi: 10.1038/oby.2001.108

Puhl, R.M., \& Brownell, K.D. (2003). Psychosocial origins of obesity stigma: Toward changing a powerful and pervasive bias. Obesity Reviews, 4(4), 213- 227. doi: 10.1046/j.1467789X.2003.00122.X 
Puhl, R.M., \& Heuer, C.A. (2009). The stigma of obesity: A review and update. Obesity, 17(5), 941- 964. doi: 10.1038/oby.2008.636

Puhl, R.M., \& Heuer, C.A. (2010). Obesity stigma: Important considerations for public health. American Journal of Public Health, 100(6), 1019- 1028. doi: 10.2105/AJPH.2009.159491

Puhl, R.M., Moss-Racusin, C.A., \& Schwartz, M.B. (2007). Internalization of weight bias: Implications for binge eating and emotional eating. Obesity, 15(1), 19- 23. doi: 10.1038/oby.2007.521

Regan, P.C. (1996). Sexual outcasts: The perceived impact of body weight and gender on sexuality. Journal of Applied Social Psychology, 26(20), 1803- 1815. doi: 10.1111/j.15591816.1996.tb00099.x

Roberto, C.A., Sysko, R., Bush, J., Pearl, R., Puhl, R.M., Schvey, N.A., \& Dovidio, J.F. (2012). Clinical correlates of the weight bias internalization scale in a sample of obese adolescents seeking bariatric surgery. Obesity, 20(3), 533- 539. doi: 10.1038/oby.2011.123

Rosen, J.C., Jones, A., Ramirez, E., \& Waxman, S. (1996). Body shape questionnaire: Studies of validity and reliability. International Journal of Eating Disorders, 20(3), 315- 319. doi: 10.1002/(SICI)1098-108X(199611)20:3<315::AID-EAT11>3.0.CO;2-Z

Rucker, D. D., Preacher, K. J., Tormala, Z. L., \& Petty, R.E. (2011). Mediation analysis in social psychology: Current practices and new recommendations. Social and Personality Psychology Compass, 5/6, 359- 371. doi: 10.1111/j.1751-9004.2011.00355.x

Rudman, L. A., Feinberg, J. M., \& Fairchild, K. (2002). Minority members' implicit attitudes: Ingroup bias as a function of group status. Social Cognition, 20(4), 294- 320. doi: 10.1521/soco.20.4.294.19908 
Rusch, N., Corrigan, P.W., Wassel, A., Michaels, P., Olschewski, M., \& Wilkniss, S., \& Batia, K. (2009). A stress-coping model of mental illness stigma: I. Predictors of cognitive stress appraisal. Schizophrenia Research, 110(1-3), 59- 64. doi: 10.1016/j.schres.2009.01.006

Schlomer, G.L., Bauman, S., \& Card, N.A. (2010). Practices for missing data management in counselling psychology. Journal of Counselling Psychology, 57(1), 1- 10. doi:

\section{$10.1037 / \mathrm{a} 0018082$}

Schmitt, M. T., \& Branscombe, N. R. (2002). The internal and external causal loci of attributions to prejudice. Personality and Social Psychology Bulletin, 28(5), 620-628. doi:

\section{$10.1177 / 0146167202288006$}

Schneider, K.L., Panza, E., Appelhans, B.M., Whited, M.C., Oleski, J.L., \& Pagoto, S.L. (2012). The emotional eating scale: Can a self-report measure predict observed emotional eating? Appetite, 58(2), 563- 566. doi: 10.1016/j.appet.2012.01.012

Schwartz, M.B., Chambliss, H.O., Brownell, K.D., Blair, S.N., \& Billington, C. (2003). Weight bias among health professionals specializing in obesity. Obesity Research, 11(9), 10331039. doi: $10.1038 /$ oby.2003.142

Sockalingam, S., Cassin, S., Crawford, S.A., Pitzul, K., Khan, A., Hawa, R., \& Okrainec, A. (2013). Psychiatric predictors of surgery non-completion following suitability assessment for bariatric surgery. Obesity Surgery, 23(2), 205- 211. doi: 10.1007/s11695-012-0762-5

Sockalingam, S., Wnuk, S., Kantarovich, K., Meaney, C., Okrainec, A., Hawa, R., \& Cassin, S. (2015). Employment outcomes one year after bariatric surgery: The role of patient and psychosocial factors. Obesity Surgery, 25, 514- 522. doi: 10.1007/s11695-014-1443-3 
Spitzer, R.L., Kroenke, K., Williams, J.B., \& Lowe, B. (2006). A brief measure for assessing generalized anxiety disorder: The GAD-7. Archives of Internal Medicine, 1, 166(10), 10921097. doi: 10.1001/archinte.166.10.1092

Striegel-Moore, R.H., Rosselli, F., Perrin, N., DeBar, L., Wilson, G.T., May, A., \& Kraemer, H.C. (2009). Gender difference in the prevalence of eating disorder symptoms. International Journal of Eating Disorders, 42(5), 471- 474. doi: 10.1002/eat.20625

Stuber, J., Meyer, I. and Link, B. (2008). Stigma, prejudice, discrimination and health. Social Science \& Medicine, 67(3), 351-357. doi: 10.1016/j.socscimed.2008.03.023

Stunkard, A.J., \& Messick, S. (1985). The three-factor eating questionnaire to measure dietary restraint, disinhibition, and hunger. Journal of Psychosomatic Research, 29(1), 71- 83. Retrieved from http://www.journals.elsevier.com/journal-of-psychosomatic-research/ Sufahani, S.F., \& Ahmad, A. (2012). A comparison between normal and non-normal data in bootstrap. Applied Mathematical Sciences, 6(92), 4547-4560. Retrieved from http://www.m-hikari.com/ams/

Thompson, J.K., Heinberg, L.J., Altabe, M.N., \& Tantleff-Dunn, S. (1999). Exacting beauty: Theory, assessment and treatment of body image disturbance. Washington, DC: American Psychological Association.

Timmerman, G. M. (1999). Binge eating scale: Further assessment of validity and reliability. Journal of Applied Biobehavioral Research, 4(1), 1- 12. doi: 10.1111/j.17519861.1999.tb00051.x

Tomiyama, A.J. (2014). Weight stigma is stressful. A review of evidence for the cyclic obesity/weight-based stigma model. Appetite, 82, 8- 15. doi:10.1016/j.appet.2014.06.108 
University Health Network. (2015). Bariatric clinic: How to get referred. Retrieved from http://www.uhn.ca/Surgery/PatientsFamilies/Clinics_Tests/Bariatric_Clinic

Varatanian, L.R., \& Novak, S.A. (2011). Internalized societal attitudes moderate the impact of weight stigma on avoidance of exercise. Obesity, 19(4), 757- 762. doi:

10.1038/oby.2010.234

Verger, P., Combes, J-B., Kovess-Masfety, V., Choquet, M., Guagliardo, V., Rouillon, F., \& Peretti-Wattel, P. (2009). Psychological distress in first year university students:

Socioeconomic and academic stressors, mastery and social support in young men and women. Social Psychiatry and Psychiatric Epidemiology, 44, 643- 650. doi:

$10.1007 / \mathrm{s} 00127-008-0486-\mathrm{y}$

Waller, G., \& Osman, S. (1998). Emotional eating and eating psychopathology among noneating-disordered women. International Journal of Eating Disorders, 23(4), 419- 424. doi: 10.1002/(SICI)1098-108X(199805)23:4<419::AID-EAT9>3.0.CO;2-L

Wang, S.S., Brownell, K.D., \& Wadden, T.A. (2004). The influence of the stigma of obesity on overweight individuals. International Journal of Obesity, 28(10), 1333- 1337. doi: 10.1038/sj.ijo.0802730

Warren, C.S., Gleaves, D.H., Cepeda-Benito, A., del Carmen Fernandez, M., \& Rodriguez-Ruiz, S. (2005). Ethnicity as a protective factor against internalization of a thin ideal and body dissatisfaction. International Journal of Eating Disorders, 37(3), 241- 249. doi: 10.1002/eat.20102

Weiner, B., Perry, R.P., \& Magnusson, J. (1988). An attributional analysis of reactions to stigmas. Journal of Personality and Social Psychology, 55(2), 738- 748. doi: http://dx.doi.org/10.1037/0022-3514.55.5.738 
West S.G., Finch J.F., \& Curran P.J. (1995). Structural equation models with nonnormal variables: problems and remedies. In: Hoyle RH, editor. Structural equation modeling: Concepts, issues and applications (pp. 56- 75). Newbery Park, CA: Sage.

Wigton, R.S., \& McGaghie, W.C. (2001). The effect of obesity on medical students' approach to patients with abdominal pain. Journal of General Internal Medicine, 16(4), 262- 265. doi: 10.1046/j.1525-1497.2001.016004262.x

Williams, D.R., Yan, Y., \& Jackson, J.S. (1997). Racial differences in physical and mental health: Socio-economic status, stress, and discrimination. Journal of Health Psychology, 2(3), 335- 351. doi: $10.1177 / 135910539700200305$

Wott, C.B., \& Carels, R.A. (2009). Overt weight stigma, psychological distress and weight loss treatment outcomes. Journal of Health Psychology, 15(4), 608- 614. doi:

$10.1177 / 1359105309355339$ 